\title{
RYERSONUNIVERSITY
}

\section{A Probabilistic Approach for Optimal \\ Capacitor Planning in Distribution Systems with Wind Generators}

\author{
by \\ Maryam Dadkhah \\ Bachelor of Electronics Engineering, IAU Central Tehran Branch, Iran, \\ 2008
}

A thesis

Presented to Ryerson University

in partial fulfillment of the

requirements for the degree of

Master of Applied Science

in the program

Electrical and Computer Engineering

Toronto, Ontario, Canada, 2011

CMaryam Dadkhah 2011 
I hereby declare that I am the sole author of this thesis or dissertation.

I authorize Ryerson University to lend this thesis or dissertation to other institutions or individuals for the purpose of scholarly research.

Maryam Dadkhah

I further authorize Ryerson University to reproduce this thesis or dissertation by photocopying or by other means, in total or in part, at the request of other institutions or individuals for the purpose of scholarly research.

Maryam Dadkhah 
A Probabilistic Approach for Optimal

Capacitor Planning in DS with WG

Master of Applied Science 2011

Maryam Dadkhah

Electrical and Computer Engineering

Ryerson University

\begin{abstract}
This thesis proposes a probabilistic approach based on the Cumulant method for optimal capacitor planning in distribution systems with high penetration of wind generators. To account for the problem uncertainties, the probabilistic behaviour of load forecasts and wind generators are modeled using Probability Density Functions. Once the probabilistic framework is defined, an optimization problem can be formulated to minimize the total costs of the capacitors and of the annual energy losses. The optimization problem is then solved by using the Logarithm Barrier Interior Point Method, which provides a linear relationship between the cumulants of load and wind variables and the cumulants of the system parameters and solution cost.

The Cumulant method offers a generous advantage in speed, while maintaining acceptable accuracy, as compared to the traditional Monte Carlo Simulation method. The proposed method is tested on a 7-bus and on a 33-bus systems, and the results are reported and discussed.
\end{abstract}




\section{ACKNOWLEDGMENTS}

I would like to express my sincere appreciation to my supervisor, Prof. Bala Venkatesh for his continuous guidance, inspiring instruction, encouragement and huge support throughout this research.

The financial support represented by the NSERC Discovery grant, Canada awarded to Prof. Bala Venkatesh is gratefully acknowledged.

My deepest gratitude and love goes to my beloved family; for their support and endless love, through the duration of my studies.

Lastly, my regards to Dr. Alexandre Nassif for his guidance during the completion of this thesis and to all of those who supported me in any respect. 


\section{TABLE OF CONTENTS}

Chapter Title

Page

Abstract iii

Acknowledgements $\quad$ iv

Table of Contents $\quad$ v

List of Tables $\quad$ vii

List of Figures $\quad$ viii

List of Symbols $\quad$ ix

List of Abbreviations $\quad$ x

1. CHAPTER1: Introduction 1

1.1 Integration of Wind Energy into the Power Systems .....................................2

1.2 Capacitor Planning in Distribution Systems ................................................4

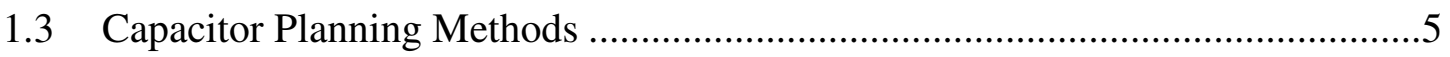

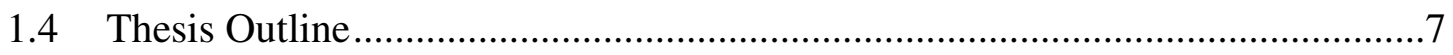

2. CHAPTER 2: Probabilistic Modeling of Load and Wind Generators 9

2.1 Random Variables and Probability Distribution Functions ..............................

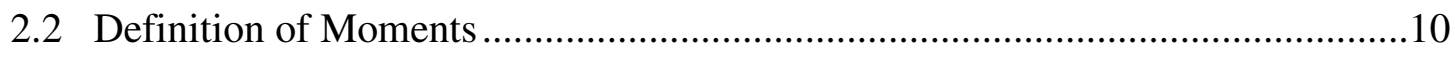

2.2.1 Moment Generating Function............................................................ 11

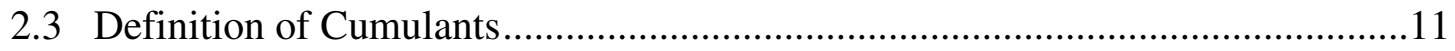

2.3.1 Cumulant Generating Function ........................................................... 13

2.4 Probabilistic Characteristics of Annual Load Demand .....................................14

2.5 Probabilistic Characteristics of Wind Energy Systems ....................................15 
3. CHAPTER 3: Problem Formulation 18

3.1 The Load Flow Solution Method Adapted for RDS .....................................18

3.2 Capacitor Planning Problem Definition using Proposed Probabilistic Approach

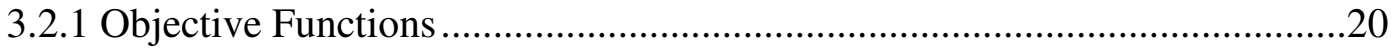

3.2.2 The Complete Nonlinear Optimization Formulation...............................22

3.3 The Cumulant Method for Optimizing Power Systems ..................................23

3.3.1 Sensitivity Analysis to Determine the Candidate Buses (Step 1)...............24

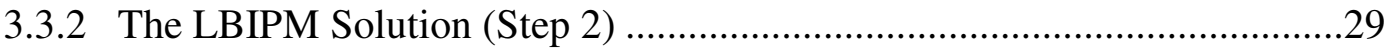

3.3.2.1 Gradient, Hessian and Newton Step ............................................31

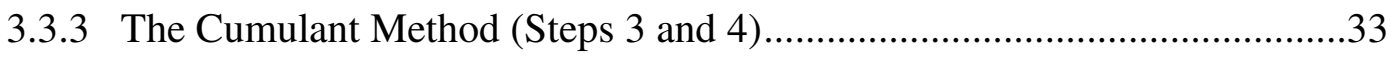

3.3.4 Gram-Charlier Expansion Theory (Step 5).........................................

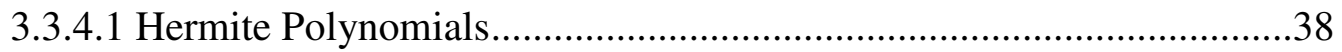

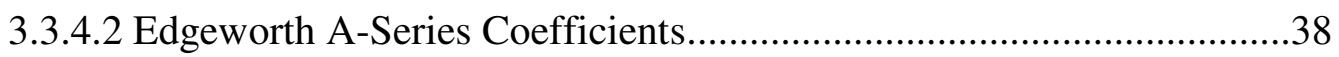

4. CHAPTER 4: Results and Discussions 42

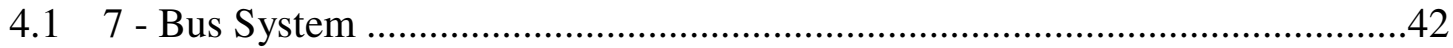

4.1.1 Comparison of the results of the Cumulant method with those of MCS.....43

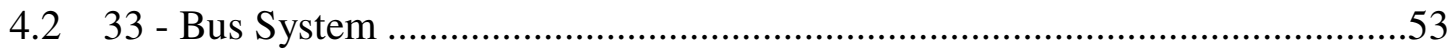

4.2.1 Comparison of the results of the Cumulant method with those of MCS......53

5. CHAPTER 5: Conclusions 65

$\begin{array}{lr}\text { APPENDICES } & 67\end{array}$

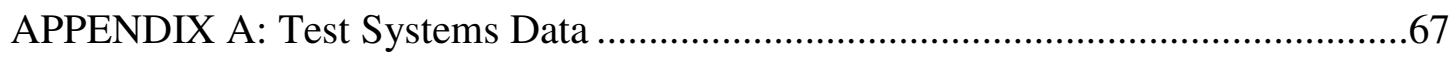

APPENDIX B: Comparison Results of 33-Bus System .......................................67

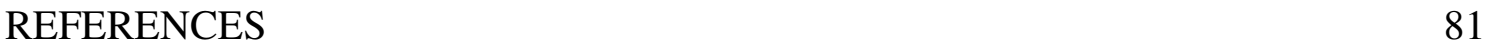




\section{LIST OF TABLES}

Table 1: Edgeworth Coefficients

Table 2: Parameters of the Weibull PDF for the wind generator - 7 Bus

Table 3: Load Duration Data

Table 4: Optimal solutions and comparison of the two methods - 7 Bus

Table 5: Total Cost Values - 7 Bus

Table 6: Mean values of the system variables -7 Bus

Table 7: Standard deviation values of the system variables - 7 Bus

Table 8: Parameters of the Weibull PDF for the wind generator - 33 Bus

Table 9: Optimal solutions and comparison of the two methods - 33 Bus

Table 10: Total Cost Values - 33 Bus

Table 11: maximum error of mean values of the system variables - 33 Bus

Table 12: maximum error of standard deviation values of the system variables-33Bus 61

Table 13: Voltage data: 7-bus RDS

Table 14: Feeder data: 7-bus RDS

Table 15: Shunt capacitor limits: 7-bus RDS

Table 16: Mean values and standard deviation of the loads: 7-bus RDS

Table 17: Line data 7-bus RDS

Table 18: Voltage data: 33-bus RDS

Table 19: Feeder data: 33-bus RDS

Table 20: Shunt capacitor limits: 33-bus RDS

Table 21: Mean values and standard deviation of the loads: 33-bus RDS 


\section{LIST OF FIGURES}

Figure 1: World Total Installed Capacity (MW) 3

Figure 2: Probability Density Function of Load Modeling 15

Figure 3: Weibull distribution function of the wind speed 16

Figure 4: A tree-like generic distribution system 19

Figure 5: A branch model representation in distribution systems 25

Figure 6: Single line diagram of the 7-bus distribution test system 42

Figure 7: Sensitivity Index Solutions - 7 Bus 45

Figure 8: Voltage improvement before and after capacitor installation - 7 Bus $\quad 48$

Figure 9: Single line diagram of the 33-bus distribution test system 53

Figure 10: Sensitivity Index Solutions - 33 Bus 54

Figure 11: Voltage improvement before and after capacitor installation - 33 Bus 58

Figure 12: Reconstructed PDF of Total Cost - 33 Bus 59

Figure 13: Reconstructed CDF of Total Cost - 33 Bus

Figure 14: PDF of Voltage at Bus 8 reconstructed by Gram-Charlier/Edgeworth 62

Figure 15: PDF of real Power at Bus 8 reconstructed by Gram-Charlier/Edgeworth 63

Figure 16: PDF of capacitor size at Bus 8 reconstructed by Gram-Charlier/Edgeworth 63 


\section{LIST OF SYMBOLS}

$f_{x}(x)$

$F_{x}(x)$

$\mathrm{m}_{\mathrm{n}}$

$\mathrm{k}_{\mathrm{n}}$

$\Phi_{\mathrm{x}}(\mathrm{s})$

$\Psi_{\mathrm{X}}(\mathrm{s})$

$\sigma^{2}$

$\hat{\mathrm{f}}_{\mathrm{x}}(\mathrm{t})$

$\mu$

$\gamma$

$\beta$

$\mathrm{Z}_{1}$

$\mathrm{T}_{1}$

$\mathrm{V}_{\mathrm{i}}$

$\mathrm{SD}_{\mathrm{i}}$

$\mathrm{SB}_{\mathrm{i}}$

$\mathrm{P}_{\mathrm{i}}, \mathrm{Q}_{\mathrm{i}}$

$S_{\mathrm{i}}$

$\mathrm{PW}_{\mathrm{i}}$

$\mathrm{QS}_{\mathrm{i}}$

nb, NB

$\mathrm{PL}_{\mathrm{l}}$

TPL

TC

KL

KC

QC

ELC

$\mathrm{T}_{\mathrm{D}}$

$\mathrm{LF}_{\mathrm{D}}$

$\mathrm{H}$

NQS

$\mathrm{He}_{\mathrm{i}}$

$\mathrm{L}(\mathrm{u})$

$\lambda$

$s_{i}$

$\mu_{\mathrm{j}}$

$\mathrm{FV}(\mathrm{X})$

$\mathrm{FS}(\mathrm{X})$

$\mathrm{Jg}_{\mathrm{g}}$

$\nabla \mathrm{L}(\mathrm{u})$

$\nabla_{\mathrm{x}}^{2} \mathrm{~L}_{\mathrm{u}}$
PDF of random variable $x$

$\mathrm{CDF}$ of random variable $\mathrm{x}$

$\mathrm{n}^{\text {th }}$-order moment of random variable $\mathrm{x}$

$\mathrm{n}^{\text {th }}$-order cumulant of random variable $\mathrm{x}$

Moment Generating Function

Cumulant Generating Function

Variance of random variable $\mathrm{x}$

Characteristic function of random variable $\mathrm{x}$

mean of random variable $\mathrm{x}$ Shape Factor of Weibull Distribution

Shape Factor of Weibull Distribution

Scale Factor of Weibull Distribution

impedance of Line 1

The Tap Setting of Transformer

voltage magnitude at $\mathrm{i}^{\text {th }}$ bus

Complex Power of Loads at $\mathrm{i}^{\text {th }}$ bus

The difference between generation and load at bus i

Real and Reactive Power Receiving at $\mathrm{i}^{\text {th }}$ bus

Complex Power Receiving at $\mathrm{i}^{\text {th }}$ bus

Real Power Output of $\mathrm{i}^{\text {th }}$ WG

Reactive Power Injected into the $\mathrm{i}^{\text {th }}$ bus

Number of Buses in the RDS

Real Power Loss on Line 1

Total Real Power Loss of RDS

Total cost

Cost of Energy

Annual Cost of per unit Capacitor Bank Installed in a RDS

Total Cost of Capacitor Banks Installed in a RDS

Total Cost of Annual Energy Loss

Loading Time Interval

Load Factor at $\mathrm{D}^{\text {th }}$ time interval

Hessian of the Lagrangian

Number of capacitors

$\mathrm{i}^{\text {th }}$ Hermite polynomial

Lagrangian function

Lagrangian multiplier

Slack variable

Barrier parameter

Voltage drop equation

power balance equation

Jacobian of the equality constraints, $g(x)$,

Gradient of the Lagrangian

Second derivative of the Lagrangian with respect to $\mathrm{x}$ 


\section{LIST OF ABBREVIATIONS}

PDF

CDF

RDS

WG

SOE

MCS

LBIPM

KKT

ND

NW
Probability Density Function

Cumulative distribution function

Radial Distribution Systems

Wind Generator

Set of Equation

Monte Carlo Simulations

Logarithmic-Barrier Interior Point Method

Karush-Kuhn-Tucker Conditions

Number of the load samples

Number of the wind generation samples 


\section{CHAPTER 1}

\section{INTRODUCTION}

Large scale integration of wind generators has been promoted across the globe in a drive to harness renewable energy. Most of these generators are sources connected to distribution systems. Due to the intermittent nature of wind, these generators introduce uncertainties on power system planning, which is in addition to difficulties associated with the steady state solution of distribution systems. Furthermore, loads are probabilistic in nature as well.

Probabilistic and stochastic programming introduces random variables and uncertainty into conventional linear and nonlinear programming [1]. The randomness and uncertainty are generally represented by using probability density functions (PDFs) [2]. Many of the power system components are often modeled as a known constant parameter, such as a wind generator or a customer load. However, these components do not have a constant behaviour, which can be treated as a random variable. As a consequence, the power system model becomes a probabilistic framework and as such, requires a probabilistic approach to deal with the load and generator uncertainties. Due to the probabilistic nature of loads and availability of wind, to achieve a precise and optimum planning, it is necessary to propose an efficient solution method that includes the load and generator probabilistic models. The ultimate goal is to determine the probabilistic density function of typical variables. 
Distribution system optimization is a multidimensional optimization problem [3]. Finding the optimum capacitor size, conductor size, location of substations and the best network configuration are some of such objectives. Capacitor planning in a distribution system must account for forecasted load and planned Wind Generators [4]. In distribution systems with large penetration of wind generators, these sources supply a significant part of the total load on an average.

With forecasts of loads and generations being probabilistic in nature with differing PDFs, their proper representation in a capacitor planning exercise is imperative. The objective is to minimize the total cost of the capacitors and the annual energy loss in the system.

\subsection{Integration of Wind Energy into the Power Systems}

Wind energy is beginning to play an important role in the energy supply in many regions around the world by growing at the rate of 30\% annually, with a world total installed capacity of 196 Gigawatts (GW) in 2010 as shown in Figure 1 [5]. 


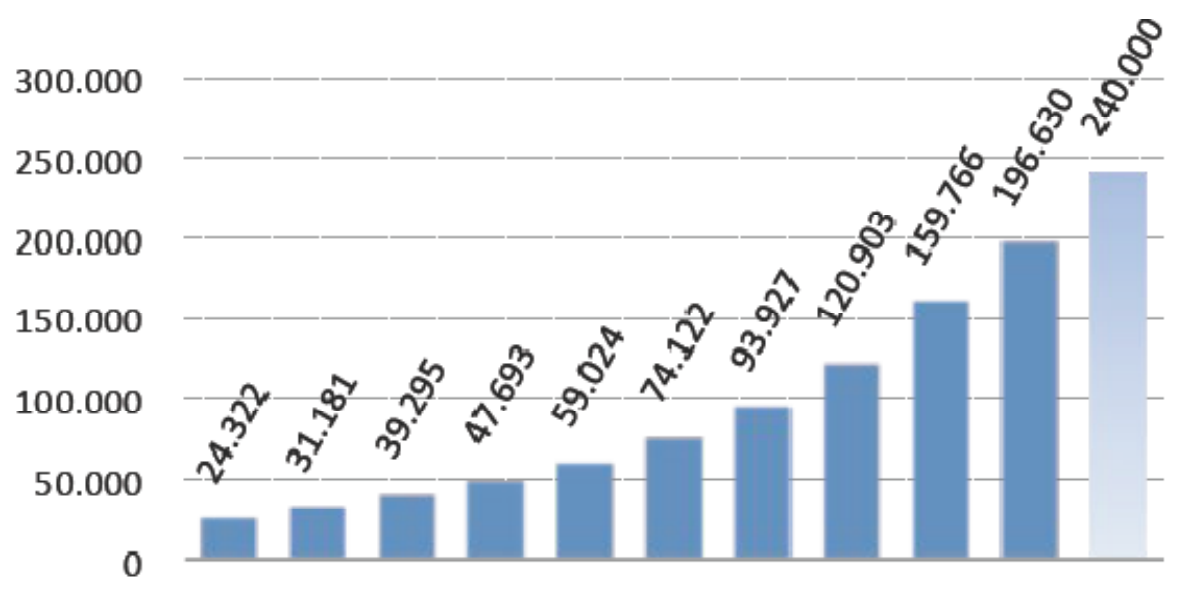

20012002200320042005200620072008200920102011

Figure 1 World Total Installed Capacity (MW)

The integration of wind energy into the electricity grids raises challenges due to its availability and geographical distribution. Wind Energy Generators (WEGs) can be integrated in either the transmission or distribution systems. However, in their traditional configuration, WEGs are mostly connecting to transmission lines and appear much less commonly as embedded distributed generation connecting to distribution feeders. Due to some challenges, such distribution scenarios are not well researched yet. One of the major challenges in using wind energy is the uncertainty in wind speed. Commonly, the probability of wind speed is presented by its PDF. Currently, there are other tools to forecast wind speed but wind speed forecasts errors are inevitable. This thesis deals with these limitations by using a probabilistic approach, as it will be shown in the later chapters. 


\section{Chapter 1 Introduction}

Next section introduces the problem of distribution system capacitor planning and provides a review of existing capacitor planning methods.

\subsection{Capacitor Planning in Distribution Systems}

In power systems, keeping the voltage, frequency, and the amount of power supplied to the loads and their power factor in line with expectations are some of the challenges of distribution system planning. Loads with low power factor draw more current than loads with high power factor for the same amount of active power consumed, increasing the losses in the distribution system. In addition to increased power consumption, the increased current drawn by low power factor loads can reach the limit of the conductors, deteriorating their performances and reducing their useful life.

To avoid problems related to the low power factor of loads, utilities typically install reactive power compensators at several locations of a distribution feeder. For example, reactive power can be compensated by using synchronous condensers or capacitor banks. Synchronous condensers have the advantage of being dynamic devices, but they are more complex and require greater amount of electrical components. A more cost-effective and prevalent way to compensate for reactive power is through the use of capacitors banks. In addition to compensating for reactive power and correcting power factor, shunt capacitor banks are also used in distribution systems to improve stability margin, manage voltage profile, and reduce losses. 


\subsection{Capacitor Planning Methods}

Substantial research has been carried out on the solution of optimal capacitor planning in the distribution systems for the tasks of power factor correction, voltage profile improvement and loss reduction. In some of the pioneer research works (first category of solutions) the algorithms were formulated using a voltage-independent reactive current model. Using these models, the problem was solved by analytical methods [6-8].

Researchers later proposed a general formulation for the cost function comprising the cost of energy losses with respect to constraints such as the number of fixed or switchable capacitors and the limits on system variables such as the voltage. This set of algorithms can be classified as the second category of planning. In [9-12], iterative methods were applied to select a sequence of candidate nodes among which the optimal node can be determined such that by compensating the bus results in the highest loss reduction. Once the sequence of candidate buses are evaluated, the size of the installed capacitors and the corresponding loss saving are determined by solving the related equations.

There is a third category of distribution system capacitor planning that refers to the use of evolutionary and swarm optimization techniques [13-17]. In [13], the author formulated the optimization problem as a mixed-integer nonlinear programming problem. The problem was decomposed into two phases and an evolution search technique was developed for the first phase called master problem. Firstly the location of capacitors was 


\section{Chapter 1 Introduction}

determined and secondly the type and size of capacitor was found. The system formulation is solved using a mixed integer nonlinear programming method. Souza et al. [16] applied a microgenetic algorithm combined with a fuzzy logic technique in two steps:

a) By using fuzzy logic the optimal locations for the capacitor banks installation was determined, and b) the formulated optimal placement of capacitor banks was minimised using a microgenetic algorithm. In addition to the other conventional algorithms described earlier, Venkatesh et al. [17] proposed a single dynamic data structure for an evolutionary programming (EP) algorithm that handles the problems of siting and sizing of new shunt capacitors simultaneously. This proposed method is very efficient since it considers other system control parameters such as transformer taps, reconfiguration options and existing reactive power sources.

However, one may note that these three categories of algorithms discussed above do not consider the integration of wind generators into distribution systems. Furthermore, the probabilistic behaviour of the annual load is not regarded into the modeling. In conclusion, previous problem formulations as well as the obtained solutions are deterministic in nature and therefore unable to represent the true behaviour of the system in the presence of stochastic wind generators and loads.

It can be said that [4] is the pioneer of the fourth and last category of algorithms to take probabilistic behaviour of the wind generation and load into the account. In that work, a Fuzzy stochastic capacitor planning method was formulated to minimize the total costs of newly sited and sized capacitors, as well as the annual energy loss in a distribution 
system by using probabilistic models of load and wind generation as Normal and Weibull PDFs, respectively. The load and wind generation PDFs are divided into load and wind generation segments (ND and NW), respectively, to provide ND random load and NW random generation variables. Then the proposed fuzzy stochastic programming method is linearized to be successively solved using a robust mixed integer linear programming solver while updating the solution.

The probabilistic capacitor planning method proposed in this thesis can be classified under the fourth category as it presents a completely probabilistic formulation. It is intended for distribution systems with high penetration of wind generators and uses probabilistic density functions for both wind speed and load consumption.

\subsection{Thesis Outline}

This thesis is structured in following manner:

Chapter two presents a detailed explanation provided to identify the probabilistic distributions adapted in this thesis for the load consumption and wind speed. These are the Normal and the Weibull distribution, respectively. In addition, it defines moments and cumulants, as well as their generating functions, which are used to develop the probabilistic models of load a generation variables used in this thesis.

Chapter three formulates the capacitor planning problem to be solved in this thesis. In the first part of the chapter, the distribution system model is presented. In the second part of 


\section{Chapter 1 Introduction}

the chapter, the probabilistic formulation of the capacitor planning in distribution systems is given.

Chapter four presents the results of the proposed probabilistic approach tested on a 7-bus and on a 33-bus distribution system with some wind generators connected to the buses. The results are compared with those from Monte Carlo Simulations (MCS). Errors are evaluated and the probabilistic distributions of the variables are re-generated.

Chapter 5 presents the conclusion of this research. 


\section{CHAPTER 2}

\section{PROBABILISTIC MODELING OF LOAD AND WIND GENERATORS}

This chapter presents the probabilistic background used in this thesis to handle

the load behaviour and wind generator speeds. Firstly, the concept of moments and cumulants are introduced. Secondly, the random characteristics of load and wind generators are embodied in terms of Probabilistic Density Functions.

\subsection{Random Variables and Probability Density Functions}

In probability and statistics, a random variable or stochastic variable is a variable which is obtained from some type of random process and can be defined as a function which maps events or outcomes.

The probability of the value of random variable is determined by the probability density function. There are various probability distributions that are used in different applications. Two of the most important ones related to this work are the Normal distribution and the Weibull distribution. The Normal and Weibull distributions have been commonly used to describe the load consumption and wind speed behaviours, 
respectively. While it is widely known that the Normal distribution can be described by its mean and variance (first and second moments), the Weibull distribution can be described by higher order of moments or cumulants. Next sections define moments and cumulants and their relationships with probabilistic distributions.

\subsection{Definition of Moments}

In probability and statistic theory, moments and cumulants are two sets quantities of a random variable $\mathrm{x}$ which are mathematically equivalent. The definition of the moments is explained in this section and the definition of cumulants is presented in the next one.

Let $f_{x}(x)$ be a probability density function of a random variable $x$, then the expected value of $\mathrm{x}$ is defined as [2]

$E[x]=\int_{-\infty}^{\infty} x f_{x}(x) d x$

Accordingly the $\mathrm{n}^{\text {th }}$-order moment $\mathrm{m}_{\mathrm{n}}$ is calculated using the following definition:

$m_{n}=E\left[x^{n}\right]=\int_{-\infty}^{\infty} x^{n} f_{x}(x) d x$

Alternatively, the moments of random variable $\mathrm{x}$ can be determined directly by the use of the moment generating function, which is explained in the next subsection. 


\subsubsection{Moment Generating Function}

Mathematically, the moment generating function $\Phi_{\mathrm{x}}(\mathrm{s})$ of a random variable $\mathrm{x}$ is

$\Phi_{\mathrm{x}}(\mathrm{s})=\mathrm{E}\left[\mathrm{e}^{\mathrm{sx}}\right]$

The $\mathrm{n}^{\text {th }}$ order moment of random variable $\mathrm{x}$ can be computed by taking the $\mathrm{n}^{\text {th }}$ derivative of moment generating function with respect to $s$ and setting $s=0$.

For example the second moment is computed as follows [2]:

$\mathrm{m}_{2}=\left.\frac{\mathrm{d}^{2} \Phi_{\mathrm{x}}(\mathrm{s})}{\mathrm{ds}^{2}}\right|_{\mathrm{s}=0}=\left.\frac{\mathrm{d}^{2} \mathrm{E}\left[\mathrm{e}^{\mathrm{sx}}\right]}{\mathrm{ds}^{2}}\right|_{\mathrm{s}=0}=\mathrm{E}\left[\left.\frac{\mathrm{d}^{2} \mathrm{e}^{\mathrm{sx}}}{\mathrm{ds}^{2}}\right|_{\mathrm{s}=0}\right]=\mathrm{E}\left[\left.\mathrm{x}^{2} \mathrm{e}^{\mathrm{sx}}\right|_{\mathrm{s}=0}\right]=\mathrm{E}\left[\mathrm{x}^{2}\right]$

which is the second order moment of random variable $\mathrm{x}$.

\subsection{Definition of Cumulants}

Moments are widely used to describe the distribution of random variables. However, in some cases it is preferable to use cumulants due to their simplicity over using moments. Furthermore, the several orders of cumulants of a random variable $\mathrm{x}$ can be calculated by using its several orders of moments. The definition of the cumulant $\mathrm{k}_{\mathrm{n}}$ is explained as follows:

Given a scalar random variable $x$, its characteristic function $\hat{f}_{x}(t)$ is defined as:

$\hat{f}_{x}(t)=E\left[e^{i t x}\right]$

The Cumulants $\mathrm{k}_{\mathrm{n}}$ are defined by: 
$\ln \left(\hat{\mathrm{f}}_{\mathrm{x}}(\mathrm{t})\right)=\sum_{\mathrm{n}=1}^{\infty} \mathrm{k}_{\mathrm{n}} \frac{(\mathrm{it})^{\mathrm{n}}}{\mathrm{n} !}$

where $\mathrm{k}_{\mathrm{n}}$ is the cumulant of $\mathrm{x}$. In particular, the cumulants can be related to the moments by the following formula:

$\mathrm{k}_{\mathrm{n}}=\mathrm{m}_{\mathrm{n}}-\sum_{\mathrm{i}=1}^{\mathrm{n}-1}\left(\begin{array}{c}\mathrm{n}-1 \\ \mathrm{i}-1\end{array}\right) \mathrm{k}_{\mathrm{i}} \mathrm{m}_{\mathrm{n}-\mathrm{i}}$

where $m_{n}$ is the $n^{\text {th }}$-order moment. In this work, we use the above formula to calculate the first six cumulants of the known random variable from its moments as follows:

$\mathrm{k}_{1}=\mathrm{m}_{1}$,

$\mathrm{k}_{2}=\mathrm{m}_{2}-\mathrm{m}_{1}^{2}$

$\mathrm{k}_{3}=\mathrm{m}_{3}-3 \times \mathrm{m}_{2} \times \mathrm{m}_{1}+2 \times \mathrm{m}_{1}^{3}$,

$\mathrm{k}_{4}=\mathrm{m}_{4}-4 \times \mathrm{m}_{3} \times \mathrm{m}_{1}-3 \times \mathrm{m}_{2}^{2}+12 \times \mathrm{m}_{2} \times \mathrm{m}_{1}^{2}-6 \times \mathrm{m}_{1}^{4}$

$\mathrm{k}_{5}=\mathrm{m}_{5}-5 \times \mathrm{m}_{4} \times \mathrm{m}_{1}-10 \times \mathrm{m}_{3} \times \mathrm{m}_{2}+20 \times \mathrm{m}_{3} \times \mathrm{m}_{1}{ }^{2}+30 \times \mathrm{m}_{2}{ }^{2} \times \mathrm{m}_{1}-60$ $\times \mathrm{m}_{2} \times \mathrm{m}_{1}{ }^{3}+24 \times \mathrm{m}_{1}{ }^{5}$

$\mathrm{k}_{6}=\mathrm{m}_{6}-6 \times \mathrm{m}_{5} \times \mathrm{m}_{1}-15 \times \mathrm{m}_{4} \times \mathrm{m}_{2}+30 \times \mathrm{m}_{4} \times \mathrm{m}_{1}^{2}-10 \times \mathrm{m}_{3}^{2}+120 \times \mathrm{m}_{3}$ $\times \mathrm{m}_{2} \times \mathrm{m}_{1}-120 \times \mathrm{m}_{3} \times \mathrm{m}_{1}^{3}+30 \times \mathrm{m}_{2}{ }^{3}-270 \times \mathrm{m}_{2}{ }^{2} \times \mathrm{m}_{1}{ }^{2}+360$ $\times \mathrm{m}_{2} \times \mathrm{m}_{1}^{4}-120 \times \mathrm{m}_{1}{ }^{6}$

Alternatively, the cumulants of random variable $\mathrm{x}$ can be determined directly by the use of the cumulant generating function, which is explained in the next subsection. 


\subsubsection{Cumulant Generating Function}

The cumulant generating function can be written in terms of the moment generating function $\Phi_{\mathrm{x}}(\mathrm{s})$ in the following manner:

$\Psi_{\mathrm{X}}(\mathrm{s})=\ln \left(\Phi_{\mathrm{X}}(\mathrm{s})\right)$

In a similar manner as done for the moment generating function, by taking the successive derivatives from the cumulant generating function with respect to $s$ and evaluating $s=0$, the different order of cumulant of random variable $\mathrm{x}$ can be obtained. The $\mathrm{n}^{\text {th }}$ order cumulant is usually denoted as $\mathrm{k}_{\mathrm{n}}$. [2].

The advantage of the cumulants over moments are evident when the aim is to find different orders of cumulant of the random variable $\mathrm{x}$ comprised by a linear combination of some other independent random variables with known cumulants. From the above explanation, it can be shown that the cumulants of the random variable $\mathrm{x}$ can be computed easily by using the given cumulants of the other random variables in the linear combination.

In the next chapter it will be shown that the proposed solution method takes advantage of this concept to provide a linear combination of the system variables to obtain the cumulants of the unknown variables from the cumulants of the known variables. 


\subsection{Probabilistic Characteristics of Annual Load Demand}

The behaviours of the load buses uncertainties including active and reactive loads have been modeled in different research works. In [18], the authors formulated a probabilistic load flow for power system expansion while the loads were modeled using normal probability distribution. However, in [19] the proposed method was examined while the loads were modeled as the gamma distribution in addition to the normal distribution model for the loads. Furthermore, Billinton et al. [20, 21] pointed out that it is difficult to obtain sufficient historical data to determine the distribution type and therefore, it is appropriate to represent uncertainties in the load forecasts with a normal distribution and a given value of standard deviation. [4]

Following the aforementioned ideas, the annual load demand will be modeled in this thesis as a normal distribution. The graph of the associated PDF is depicted in Figure 2. 


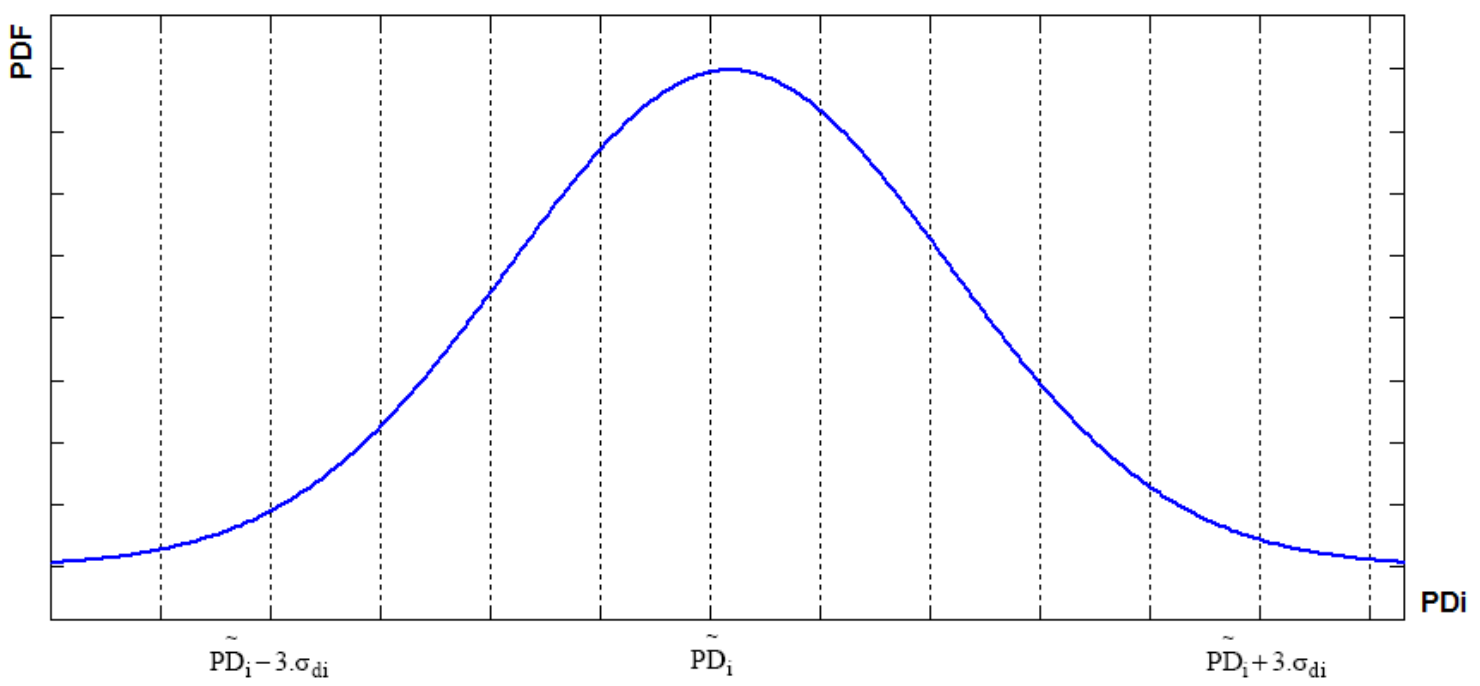

Figure 2 Probability Density Function of Load Modeling

The Gaussian function of the system loading is defined as follow:

$f(x)=\frac{1}{\sqrt{2 \pi \sigma^{2}}} e^{-\frac{(P D-\widetilde{P D})^{2}}{2 \sigma^{2}}}$

where $\widetilde{\mathrm{PD}}$ is the mean of the load and $\sigma^{2}$ is the variance of the load. The distribution with $\widetilde{\mathrm{PD}}=0$ and $\sigma^{2}=1$ is called the standard normal of the system loading.

\subsection{Probabilistic Characteristics of Wind Energy Systems}

As explained earlier in this thesis, a useful way to describe the wind characteristics is by using a probabilistic distribution. Extensive research has been published in the last two decades to describe wind speed distribution. However, the proposed methods should be able to analyze the wind speed statistically since the speed 
of wind is continuously changing. The annual wind speed forecasts can be modeled using Weibull distributions as shown in Figure 3 [22]. The probability density function of the wind forecast for a generator at the $i^{\text {th }}$ bus is given as [4]

$\rho w_{i}=\left(\gamma / \beta_{i}^{\gamma}\right) w_{i}^{\gamma-1} \cdot e^{-\left(w_{i} / \beta_{i}\right)^{\gamma}}$,

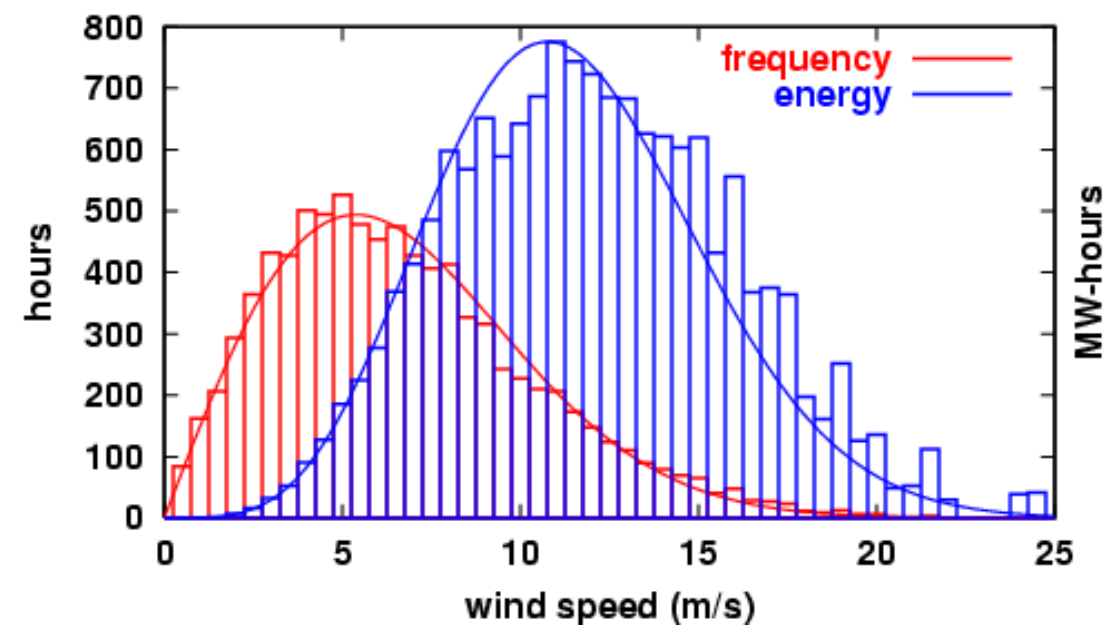

Figure 3 Weibull distribution function of the wind speed

where $W_{i}$ is the wind speed in $\mathrm{m} / \mathrm{s}, \gamma$ and $\beta_{\mathrm{i}}$ are the shape and scale parameters respectively. Due to the fact it is reasonable to assume that all WGs installed in a distribution feeder are in the same geographical area, this thesis also assumes that $\gamma$ is the same for all WGs. The scale parameter $\beta_{\mathrm{i}}$ can be determined for the $W G_{i}$, given the mean forecast $\widetilde{W}_{i}$ and the shape parameter $\gamma$. 
This concludes the load and wind generator probabilistic behaviours as applicable to the capacitor sizing and allocation problem. Chapter 3 presents the distribution system model and the probabilistic approach to deal with the capacitor placement problem. 


\section{CHAPTER 3 PROBLEM FORMULATION}

The probabilistic model for the capacitor planning problem formulation in distribution systems is presented in this chapter. The distribution system model used in this thesis is provided in the first part of the chapter, and the complete nonlinear problem, along with the proposed solution, is formulated thereafter.

\subsection{The Load Flow Solution Method Adapted for RDS [23]}

The accurate voltage solution method for radial distribution systems is developed by formulating a set of equations (SOE) to describe a radial distribution system with high $\mathrm{R} / \mathrm{X}$ ratio. This $\mathrm{SOE}$ comprises $3(\mathrm{~N}-1)$ nonlinear equations for an $\mathrm{N}$-bus distribution system. Then the SOE is solved by using the first-order Newton-Raphson technique. These equations are devoid of bus phase angles and can be subsequently solved using the Newton-Raphson method [23].

The SOE is formed by a voltage equation and real and reactive power balance equations at every bus, and is described as follows. A single-line representation of a treelike distribution systems structure is shown in Figure 4. 


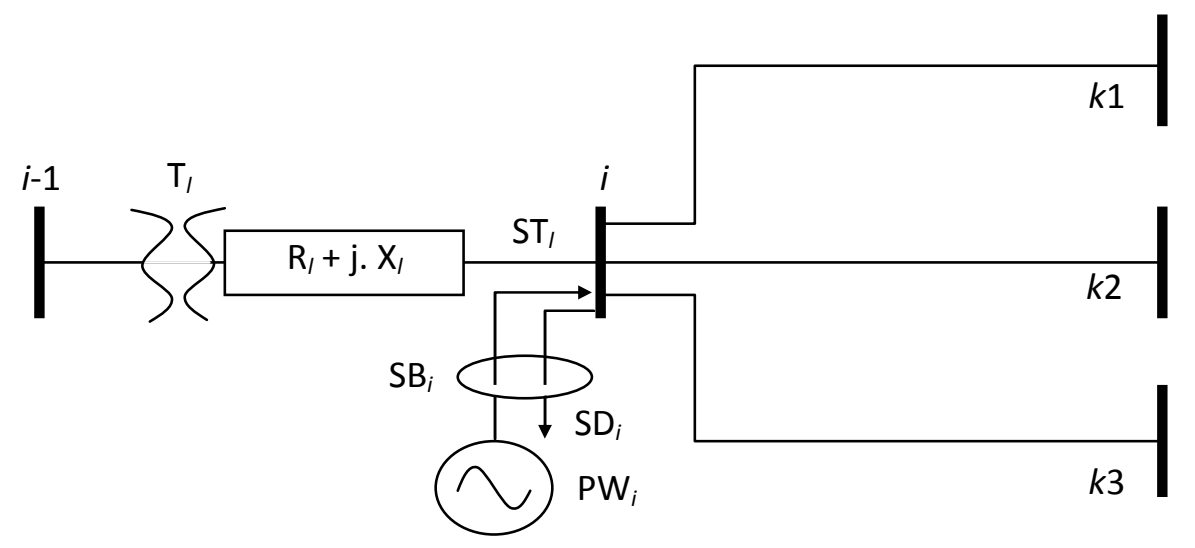

Figure 4 A tree-like generic distribution system

Consider the $i^{\text {th }}$ bus in Figure 4. It has a wind turbine connected to it that injects only real power equal to $P W_{i}$. Its bus load is represented by $\mathrm{SD}_{\mathrm{i}}=\mathrm{PD}_{\mathrm{i}}+\mathrm{jQD}_{\mathrm{i}}$. The total power injected into this bus is $\mathrm{SB}_{\mathrm{i}}=\mathrm{PB}_{\mathrm{i}}+\mathrm{jQB}_{\mathrm{i}}$, and it is the difference between generation and load at that bus. Consider the $\mathrm{l}^{\text {th }}$ line/transformer between buses $\mathrm{i}-1$ and $\mathrm{i}$. The tap setting of this transformer/line is represented by $\mathrm{T}_{1}$ and it has an impedance $Z_{l}=R_{l}+j \cdot X_{1}$. The total apparent power reaching the downstream end of this line equals $\mathrm{ST}_{1}$. The real power loss on this line equals

$\mathrm{PL}_{\mathrm{l}}=\mathrm{R}_{\mathrm{l}} \cdot\left|\mathrm{ST}_{\mathrm{l}}\right|^{2} \cdot \mathrm{V}_{\mathrm{i}}^{-2}$.

The total real power loss in all feeders of the system equals

$\mathrm{TPL}=\sum_{\mathrm{l}=1}^{\mathrm{nl}} \mathrm{R}_{\mathrm{l}} \cdot\left|\mathrm{ST}_{\mathrm{l}}\right|^{2} \cdot \mathrm{V}_{\mathrm{i}}^{-2}$,

where $\mathrm{Vi}$ is the bus voltage magnitude, $\mathrm{nb}$ is the number of buses in the system and $\mathrm{nl}$ is the number of lines/transformers. 
In Figure 4, the power balance at the $i^{\text {th }}$ bus can be expressed as

$\mathrm{P}_{\mathrm{i}}=\mathrm{PD}_{\mathrm{i}}+\sum_{\mathrm{l}=\mathrm{kl} 1, \mathrm{k}=\mathrm{k} 1}^{\mathrm{kl} 3 \mathrm{k} 3} \mathrm{R}_{\mathrm{l}} \cdot\left(\mathrm{P}_{\mathrm{k}}^{2}+\mathrm{Q}_{\mathrm{k}}^{2}\right) \cdot \mathrm{V}_{\mathrm{k}}^{-2}+\sum_{\mathrm{k}=\mathrm{k} 1}^{\mathrm{k} 3} \mathrm{PT}_{\mathrm{k}}-\mathrm{PW}_{\mathrm{i}}$

$\mathrm{Q}_{\mathrm{i}}=\mathrm{QD}_{\mathrm{i}}+\sum_{\mathrm{l}=\mathrm{kl} 1, \mathrm{k}=\mathrm{k} 1}^{\mathrm{kl} 3 \mathrm{~K} 3} \mathrm{X}_{\mathrm{l}} \cdot\left(\mathrm{P}_{\mathrm{k}}^{2}+\mathrm{Q}_{\mathrm{k}}^{2}\right) \cdot \mathrm{V}_{\mathrm{k}}^{-2}+\sum_{\mathrm{k}=\mathrm{k} 1}^{\mathrm{k} 3} \mathrm{QT}_{\mathrm{k}}-\mathrm{QS}_{\mathrm{i}}$

where $\mathrm{QS}_{\mathrm{i}}$ is the reactive power injected into the $\mathrm{i}^{\text {th }}$ bus. Writing the voltage drop equation across line/transformer l gives

2. $\mathrm{V}_{\mathrm{i}}^{2} \cdot\left[\mathrm{PT}_{\mathrm{l}} \cdot \mathrm{R}_{\mathrm{l}}+\mathrm{QT} \cdot \mathrm{X}_{\mathrm{l}}-\frac{1}{2} \cdot \mathrm{V}_{\mathrm{i}-1}^{2} \cdot \mathrm{T}_{\mathrm{l}}^{-2}\right]+\mathrm{V}_{\mathrm{i}}^{4}=-\left|\mathrm{Z}_{\mathrm{l}}\right|^{2} \cdot\left|\mathrm{ST}_{\mathrm{l}}\right|^{2}$,

$\mathrm{i}=2: \mathrm{nb}-1$.

For a system with N-buses, the nonlinear SOE will have $3(\mathrm{~N}-1)$ equations and $3(\mathrm{~N}-1)$ unknowns. Once the SOE is formulated for each bus, a first-order Newton-Raphson Method can be applied to obtain a solution.

\subsection{Capacitor Planning Problem Definition using the Proposed Probabilistic}

\section{Approach}

In this section the probabilistic formulation of the capacitor planning problem for distribution systems is presented.

\subsubsection{Objective Functions}

The goal of a capacitor planning study is to select the optimal size and location for a capacitor banks in a distribution system in such a way that the sum of the total cost of the newly sited and sized capacitor, as well as the annual energy losses, are minimized 
while the voltage profile remains within a prescribed limit. By siting a capacitor unit at a bus along the feeder, the nodal power and voltages are changed, leading to a reduction in real power loss in the system.

This reduction in real power losses is economical and can be obtained by multiplying the annual energy loss by the average cost of energy (KL). However, purchasing new unit of capacitor sustains a cost which is in conflict with the financial benefits accrued by the reduction of real power loss. Consequently, the problem comprises multi-objective functions which conflict with each other.

The objective functions are:

a) minimize the total cost of capacitors $(\$)$

$\mathrm{QC}=\mathrm{KC} \cdot \sum_{\mathrm{i}=1}^{\mathrm{NB}} \mathrm{QS}_{\mathrm{i}}$,

where KC is the annual cost of per unit capacitor bank installed in a RDS (\$/kVAR) and $\mathrm{QS}_{\mathrm{i}}$ is the size of capacitor located at the bus $\mathrm{i}^{\text {th }}$.

b) minimize the total cost of annual energy losses (\$).

$\mathrm{ELC}=\mathrm{KL} \cdot \sum_{\mathrm{D}=1}^{\mathrm{nt}} \sum_{\mathrm{i}=1}^{\mathrm{NB}} \mathrm{T}_{\mathrm{D}} \cdot \mathrm{PL}_{\mathrm{i}, \mathrm{D}}$

where $\mathrm{KL}$ is the annual cost of per unit energy loss $(\$ / \mathrm{kWh}), \mathrm{T}_{\mathrm{D}}$ is loading time interval and $\mathrm{PL}_{\mathrm{i}, \mathrm{D}}$ is the real power loss at the bus $\mathrm{i}^{\text {th }}$ and on load level $\mathrm{D}$. 


\subsubsection{The Complete Nonlinear Optimization Formulation}

The aim is to minimize sum of the total capacitor cost and the cost of the annual energy losses in the system. Since the unit of both objective functions is the dollar value (\$), the multi-objective problem can be reduced to a single objective function by summing up two functions. Hence, the complete model including the constraints can be written as a nonlinear programming problem as below:

Minimize $\mathrm{TC}=\mathrm{QC}+\mathrm{ELC}=\mathrm{KC} \cdot \sum_{\mathrm{i}=1}^{\mathrm{NB}} \mathrm{QS}_{\mathrm{i}}+\mathrm{KL} \cdot \sum_{\mathrm{D}=1}^{\mathrm{nt}} \sum_{\mathrm{i}=1}^{\mathrm{NB}} \mathrm{T}_{\mathrm{D}} \cdot \mathrm{PL}_{\mathrm{i}, \mathrm{D}}$

Subject to

$\mathrm{P}_{\mathrm{i}}=\mathrm{PD}_{\mathrm{i}}+\sum_{\mathrm{l}=\mathrm{kl} 1, \mathrm{k}=\mathrm{k} 1}^{\mathrm{k} 1, \mathrm{R} 3} \cdot\left(\mathrm{P}_{\mathrm{k}}{ }^{2}+\mathrm{Q}_{\mathrm{k}}{ }^{2}\right) \cdot \mathrm{V}_{\mathrm{k}}{ }^{-2}+\sum_{\mathrm{k}=\mathrm{k} 1}^{\mathrm{k} 3} \mathrm{PT}_{\mathrm{k}}-\mathrm{PW}_{\mathrm{i}}$

$\mathrm{Q}_{\mathrm{i}}=\mathrm{QD}_{\mathrm{i}}+\sum_{\mathrm{l}=\mathrm{k} 11, \mathrm{k}=\mathrm{k} 1}^{\mathrm{k} 3 \mathrm{k} 3} \mathrm{X}_{\mathrm{l}} \cdot\left(\mathrm{P}_{\mathrm{k}}{ }^{2}+\mathrm{Q}_{\mathrm{k}}{ }^{2}\right) \cdot \mathrm{V}_{\mathrm{k}}{ }^{-2}+\sum_{\mathrm{k}=\mathrm{k} 1}^{\mathrm{k} 3} \mathrm{QT}_{\mathrm{k}}-\mathrm{QS}_{\mathrm{i}}$

2. $\mathrm{V}_{\mathrm{i}}^{2} \cdot\left[\mathrm{PT}_{1} \cdot \mathrm{R}_{1}+\mathrm{QT}_{1} \cdot \mathrm{X}_{1}-\frac{1}{2} \cdot \mathrm{V}_{\mathrm{i}-1}^{2} \cdot \mathrm{T}_{1}^{-2}\right]+\mathrm{V}_{\mathrm{i}}^{4}=-\left|\mathrm{Z}_{\mathrm{l}}\right|^{2} \cdot\left|\mathrm{ST}_{1}\right|^{2}$

$\mathrm{i}=2: \mathrm{nb}-1$

$\mathrm{V}_{\text {min }} \leq \mathrm{V}_{\mathrm{D}} \leq \mathrm{V}_{\max } \quad \forall \mathrm{D}=1: \mathrm{NH}$

$\mathrm{QS}_{\min } \leq \mathrm{QS}_{\mathrm{i}} \leq \mathrm{QS}_{\max }$

$S_{i, j}^{\min } \leq S_{i, j} \leq S_{i, j}^{\max }$

Equations (19-1) - (19-3) are equality constraints which correspond to the power balance equation and the voltage drop equation across line 1, respectively. Equation (19-4) refers 
to the limitation of the bus voltage magnitude. Equation (19-5) corresponds to the limits on output of capacitors at the bus $\mathrm{i}^{\text {th }}$ and (19-6) describes the branches apparent power limits.

The optimization problem described as in (19) is solved using the LogarithmicBarrier interior point method (LBIPM). The LBIPM is an interior point solution method that is able to effectively solve the aforementioned constrained nonlinear optimization problem. It was chosen in this thesis because of its desirable convergence speed and characteristics. It is explained in the next section.

\subsection{The Cumulant Method for Optimizing Power Systems}

The solution strategy for the problem is detailed in this section. The goal of this solution method is to verify the probabilistic behaviour of the problem variables which can be observed by their PDF. Therefore, the first step is to formulate the optimization problem. In order to solve the problem, the LBIPM method is used. After convergence, the cumulants are obtained using some characteristics of the LBIPM. These cumulants are the key parameters to describe the probabilistic distributions. Once obtained, they are used to re-construct the distribution curves by using the Gram Charlier expansion. 
In summary, the main steps in the cumulant-based optimal capacitor planning problem are:

1) Do the sensitivity analysis to find the best locations for capacitor siting

2) Solve the optimization problem assuming the mean value for the loads and wind generations using a LBIPM

3) Find a linear relationship between problem variables and system loads and wind generators using the Hessian of the Lagrangian function

4) Find the cumulants of the problem variables using the linear relationship obtained in step3

5) Reconstruct the PDFs of the problem variables using the Gram-Charlier expansion theory

The first step to solve the problem is to determine the candidate buses. This step is presented in the next subsection.

\subsubsection{Sensitivity Analysis to Determine the Candidate Buses (Step 1)}

The solution procedure for minimizing (19) can become computationally difficult and complicated if all variables corresponding to the capacitor, i.e., size, location and switching time of capacitors, need to be determined simultaneously. Consequently, one efficient way to reduce the complexity of the problem is to find the optimal locations (candidate buses) to be compensated which lead to the greatest loss reduction prior to the optimization problem. 
For locating the candidate buses, a sensitivity analysis is used to reduce the search space for the optimization procedure. The sensitivity analysis chooses the buses with maximum effect on the real power losses in the system with respect to the nodal reactive power. Such technique has been widely adapted in capacitor allocation problems. For instance, a novel approach for sensitivity calculations in the radial distribution system was proposed in [24]. In this thesis, we borrow the idea for formulating the sensitivity index from [24] and adapt it to the new power balance equations and the voltage relations described in section 3.1 .

Consider the model of a branch in radial distribution systems given in Figure 5.

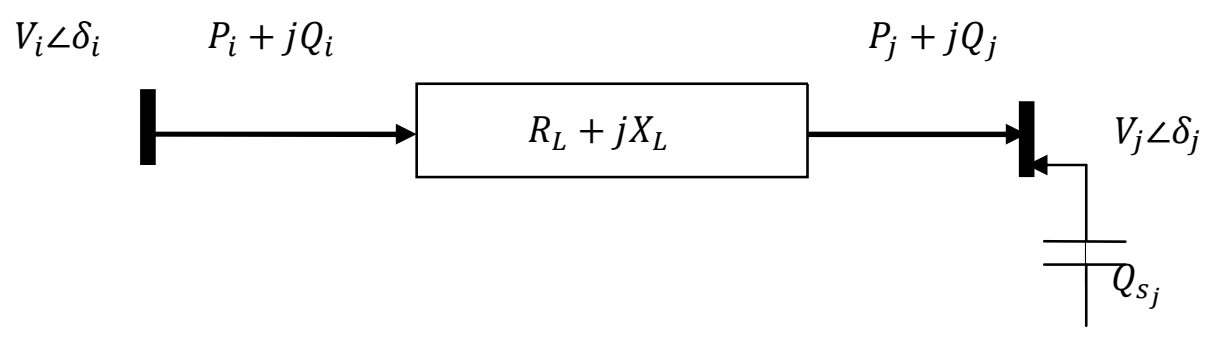

Figure 5 A branch model representation in distribution systems

Accordingly, the total real power loss is given by:

$\mathrm{TPL}=\sum_{\mathrm{l}=1}^{\mathrm{nl}} \mathrm{R}_{\mathrm{l}} \cdot\left(\mathrm{P}_{\mathrm{j}}^{2}+\mathrm{Q}_{\mathrm{j}}^{2}\right) \cdot \mathrm{V}_{\mathrm{j}}^{-2}$ 
where $P_{j}+Q_{j}$ is the complex power reaching bus $j$. For finding the sensitivity of the real power losses in the system with respect to reactive power injection, one can get the derivative of the real power loss with respect to reactive power injected at the bus by using the following relationship:

$\left(\frac{\partial \mathrm{TPL}}{\partial \mathrm{Q}_{\mathrm{s}}}\right)=\left(\frac{\partial \mathrm{TPL}}{\partial \mathrm{P}_{\mathrm{j}}}\right) \cdot\left(\frac{\partial \mathrm{P}_{\mathrm{j}}}{\partial \mathrm{Q}_{\mathrm{s}}}\right)+\left(\frac{\partial \mathrm{TPL}}{\partial \mathrm{Q}_{\mathrm{j}}}\right) \cdot\left(\frac{\partial \mathrm{Q}_{\mathrm{j}}}{\partial \mathrm{Q}_{\mathrm{s}}}\right)+\left(\frac{\partial \mathrm{TPL}}{\partial \mathrm{V}_{\mathrm{j}}}\right) \cdot\left(\frac{\partial \mathrm{V}_{\mathrm{j}}}{\partial \mathrm{Q}_{\mathrm{s}}}\right)$

Expanding equation (21) yields:

$\frac{\partial T P L}{\partial Q_{s}}=\sum_{l=1}^{n l}\left(\frac{2 \cdot R_{1} \cdot P_{j}}{V_{j}^{2}}\right)\left(\frac{\partial P_{j}}{\partial Q_{s}}\right)+\left(\frac{2 \cdot R_{1} \cdot Q_{j}}{V_{j}^{2}}\right)\left(\frac{\partial Q_{j}}{\partial Q_{s}}\right)-\left(\frac{2 \cdot R_{l} \cdot\left(P_{j}^{2}+Q_{j}^{2}\right)}{V_{j}{ }^{3}}\right) \cdot\left(\frac{\partial \mathrm{V}_{j}}{\partial Q_{s}}\right)$.

Equation (22) can be written in vector format as follows:

$\frac{\partial \mathrm{TPL}}{\partial \mathrm{Q}_{\mathrm{s}}}=[\mathrm{A}]^{\mathrm{T}}\left[\mathrm{X}_{\mathrm{j}}\right]$

where the vector $[A]^{\mathrm{T}}$ is of size $1 \times 3$. (NB - 1) and includes the coefficient of (22). Once a load flow is solved and the value of the nodal power and voltage magnitude are obtained, the vector $[\mathrm{A}]$ can be calculated easily. The vector $\left[\mathrm{X}_{\mathrm{j}}\right]$ consists of partial derivative terms of $(22)$ of size 3 . $(\mathrm{NB}-1) \times 1$, and can be expanded as follows:

$\left[\mathrm{X}_{\mathrm{j}}\right]=\left[\left[\frac{\partial \mathrm{P}_{1}}{\partial \mathrm{Q}_{\mathrm{s}}} \frac{\partial \mathrm{P}_{2}}{\partial \mathrm{Q}_{\mathrm{s}}} \ldots \frac{\partial \mathrm{P}_{(\mathrm{NB}-1)}}{\partial \mathrm{Q}_{\mathrm{s}}}\right],\left[\frac{\partial \mathrm{Q}_{1}}{\partial \mathrm{Q}_{\mathrm{s}}} \frac{\partial \mathrm{Q}_{2}}{\partial \mathrm{Q}_{\mathrm{s}}} \ldots \frac{\partial \mathrm{Q}_{(\mathrm{NB}-1)}}{\partial \mathrm{Q}_{\mathrm{s}}}\right],\left[\frac{\partial \mathrm{V}_{1}}{\partial \mathrm{Q}_{\mathrm{s}}} \frac{\partial \mathrm{V}_{2}}{\partial \mathrm{Q}_{\mathrm{s}}} \ldots \frac{\partial \mathrm{V}_{(\mathrm{NB}-1)}}{\partial \mathrm{Q}_{\mathrm{s}}}\right]\right]^{\mathrm{T}}$

The next step is to calculate the vector $\left[\mathrm{X}_{\mathrm{j}}\right]$. As the expansion of the vector $\left[\mathrm{X}_{\mathrm{j}}\right]$ is given in (24), the vector $\left[X_{j}\right]$ contains the partial derivative of the active and reactive power flow 
as well as the voltage relation with respect to $Q_{S}$. Referring to Figure 5, to calculate these partial derivatives, the power balance equations and voltage relationship for this branch model are written as

$P_{i}=R_{l} \cdot\left(P_{j}^{2}+Q_{j}^{2}\right) \cdot V_{j}^{-2}+P_{j}+P D_{j}$

$Q_{i}=X_{l} \cdot\left(P_{j}^{2}+Q_{j}^{2}\right) \cdot V_{j}^{-2}+Q_{j}-Q_{s}+Q_{j}$

$V_{i}^{2}=V_{j}^{2}+2 \cdot\left(P_{j} \cdot R_{l}+Q_{j} \cdot X_{l}\right)+\frac{\left(R_{1}^{2}+X_{l}^{2}\right) \cdot\left(P_{j}^{2}+Q_{j}^{2}\right)}{V_{j}^{2}}$

By taking the derivative of (24)-(26) with respect to $Q_{s}$, we obtain:

$$
\begin{aligned}
& \left(\frac{2 \cdot \mathrm{R}_{\mathrm{l}} \cdot \mathrm{P}_{\mathrm{j}}}{\mathrm{V}_{\mathrm{j}}^{2}}+1\right) \cdot\left(\frac{\partial \mathrm{P}_{\mathrm{j}}}{\partial \mathrm{Q}_{\mathrm{s}}}\right)+\left(\frac{2 \cdot \mathrm{R}_{\mathrm{l}} \cdot \mathrm{Q}_{\mathrm{j}}}{\mathrm{V}_{\mathrm{j}}^{2}}\right) \cdot\left(\frac{\partial \mathrm{Q}_{\mathrm{j}}}{\partial \mathrm{Q}_{\mathrm{s}}}\right)-\left(\frac{2 \cdot \mathrm{R}_{\mathrm{l}} \cdot\left(\mathrm{P}_{\mathrm{j}}^{2}+\mathrm{Q}_{\mathrm{j}}^{2}\right)}{\mathrm{V}_{\mathrm{j}}^{3}}\right) \cdot\left(\frac{\partial \mathrm{V}_{\mathrm{j}}}{\partial \mathrm{Q}_{\mathrm{s}}}\right)-\left(\frac{\partial \mathrm{P}_{\mathrm{i}}}{\partial \mathrm{Q}_{\mathrm{s}}}\right)=0 \\
& \left(\frac{2 \cdot \mathrm{X}_{\mathrm{l}} \cdot \mathrm{P}_{\mathrm{j}}}{\mathrm{V}_{\mathrm{j}}^{2}}\right) \cdot\left(\frac{\partial \mathrm{P}_{\mathrm{j}}}{\partial \mathrm{Q}_{\mathrm{s}}}\right)+\left(\frac{2 \cdot \mathrm{X}_{\mathrm{l}} \cdot \mathrm{Q}_{\mathrm{j}}}{\mathrm{V}_{\mathrm{j}}^{2}}+1\right) \cdot\left(\frac{\partial \mathrm{Q}_{\mathrm{j}}}{\partial \mathrm{Q}_{\mathrm{s}}}\right)-\left(\frac{2 \cdot \mathrm{X}_{\mathrm{l}} \cdot\left(\mathrm{P}_{\mathrm{j}}^{2}+\mathrm{Q}_{\mathrm{j}}^{2}\right)}{\mathrm{V}_{\mathrm{j}}^{3}}\right)\left(\frac{\partial \mathrm{V}_{\mathrm{j}}}{\partial \mathrm{Q}_{\mathrm{s}}}\right)-\left(\frac{\partial \mathrm{Q}_{\mathrm{i}}}{\partial \mathrm{Q}_{\mathrm{s}}}\right)=1, \\
& \left(\mathrm{~V}_{\mathrm{j}}-\frac{\left(\mathrm{R}_{\mathrm{l}}^{2}+\mathrm{X}_{\mathrm{l}}^{2}\right) \cdot\left(\mathrm{P}_{\mathrm{j}}^{2}+\mathrm{Q}_{\mathrm{j}}^{2}\right)}{\mathrm{V}_{\mathrm{j}}^{3}}\right) \cdot\left(\frac{\partial \mathrm{V}_{\mathrm{j}}}{\partial \mathrm{Q}_{\mathrm{s}}}\right)+\left(\mathrm{R}_{\mathrm{l}}+\frac{\left(\mathrm{R}_{1}^{2}+\mathrm{X}_{1}^{2}\right) \cdot \mathrm{P}_{\mathrm{j}}}{\mathrm{V}_{\mathrm{j}}^{2}}\right) \cdot\left(\frac{\partial \mathrm{P}_{\mathrm{j}}}{\partial \mathrm{Q}_{\mathrm{s}}}\right)+\left(\mathrm{X}_{\mathrm{l}}+\frac{\left(\mathrm{R}_{1}^{2}+\mathrm{X}_{1}^{2}\right) \cdot \mathrm{Q}_{\mathrm{j}}}{\mathrm{V}_{\mathrm{j}}^{2}}\right) \cdot\left(\frac{\partial \mathrm{Q}_{\mathrm{j}}}{\partial \mathrm{Q}_{\mathrm{s}}}\right)- \\
& \mathrm{V}_{\mathrm{i}} \cdot\left(\frac{\partial \mathrm{V}_{\mathrm{i}}}{\partial \mathrm{Q}_{\mathrm{s}}}\right)=0,
\end{aligned}
$$

where

$$
\begin{aligned}
& \left(\frac{\partial \mathrm{P}_{\mathrm{i}}}{\partial \mathrm{Q}_{\mathrm{s}}}\right)=\sum_{\mathrm{j}}\left(\frac{\partial \mathrm{P}_{\mathrm{j}}}{\partial \mathrm{Q}_{\mathrm{s}}}\right), \\
& \left(\frac{\partial \mathrm{Q}_{\mathrm{i}}}{\partial \mathrm{Q}_{\mathrm{s}}}\right)=\sum_{\mathrm{j}}\left(\frac{\partial \mathrm{Q}_{\mathrm{j}}}{\partial \mathrm{Q}_{\mathrm{s}}}\right) .
\end{aligned}
$$


Writing equations (25)-(27) for all the lines in the systems, i.e., 3. (NB - 1) lines, the following system in a compact format is achieved:

$[\mathrm{B}]_{3 .(\mathrm{NB}-1) \times 3 .(\mathrm{NB}-1)} \cdot\left[\mathrm{X}_{\mathrm{j}}\right]_{3 .(\mathrm{NB}-1) \times 1}=\left[\mathrm{C}_{\mathrm{j}}\right]_{3 .(\mathrm{NB}-1) \times 1^{\prime}}$

where $\left[C_{j}\right]$ is a vector of constant value at the right hand side of the equations (27)-(29). By solving (32) for $\left[\mathrm{X}_{\mathrm{j}}\right]$ and substituting that in (23), $\frac{\partial T \mathrm{TL}}{\partial \mathrm{Q}_{\mathrm{s}}}$ of the system can be determined. The buses with the highest real power loss sensitivity with respect to the reactive power injected into the system are ranked in descending order and can be chosen in the selection procedure. In summary the algorithm of the selection procedure can be adapted to the capacitor planning problem using the following steps:

Step 1- Set $\mathrm{i}=1, \mathrm{NQS}=1$ (number of capacitor) and find TC (i) from solving the deterministic capacitor planning problem

Step 2- Set $\mathrm{i}=\mathrm{i}+1$ and find the active power loss sensitivity for reactive power injection using equation (32) and (23)

Step 3- Rank the candidate buses with the highest sensitivity found in Step 2 Step 5 - Connect a capacitor in the first ranked bus Step 6- Solve deterministic capacitor planning problem Step 7- if $\mathrm{TC}(\mathrm{i})<\mathrm{TC}(\mathrm{i}-1)$ and $\min (\mathrm{V})<\mathrm{V}_{\min }$, set $\mathrm{NQS}=\mathrm{NQS}+1$ and go to Step 2; otherwise exit the loop

By performing the above steps, the best candidate buses for capacitor sitting are selected. 


\subsubsection{The LBIPM Solution (Step 2)}

The Logarithmic Barrier Interior Point Method (LBIPM) is one of the applications of the interior-point methods that have been widely used to efficiently solve large power system constrained optimization problems for many years. However, the application of the LBIPM is not only restricted to the use in nonlinear programming problems, but it can be also efficiently applied to Quadratic programming as well as to linear programming. The method is explained briefly as follows [25]:

Consider the following NLP problem model:

minimize $f(x)$

subject to:

$$
\begin{aligned}
& \mathrm{g}(\mathrm{x})=\mathrm{D} \\
& \hat{\mathrm{x}}^{\min } \leq \hat{\mathrm{I}} \mathrm{x} \leq \hat{\mathrm{x}}^{\text {max }}
\end{aligned}
$$

where, for the cost function minimization problem in capacitor planning, this system can be defined as:

- $\quad x$ consisting of the system variables $\mathrm{x}=\left[\begin{array}{lll}\mathrm{V} & \mathrm{Q} & \mathrm{QS}\end{array}\right]^{\mathrm{T}}$.

- $g(x)$ comprises the equality constraints separated into two parts: the voltage relation $\left(\mathrm{FV}(\mathrm{X})=[0]_{(\mathrm{nb}-1) \times 1}\right)$ and the power balance equation $(\mathrm{FS}(\mathrm{X})=$ $\left.[D]_{2 \times(n b-1) \times 1}\right) \cdot[D]$ is the a vector of generation and loading (see equations (19-1) and (19-2)). 
To apply the LBIPM to the above system, firstly all inequality constraints in the NLP problem should be converted to the equalities by adding slack variables as follows:

minimize $f(x)$

subject to:

$$
\begin{aligned}
& \mathrm{g}(\mathrm{x})-\mathrm{D}=0 \\
& -\mathrm{s}_{1}-\mathrm{s}_{2}-\hat{\mathrm{x}}^{\mathrm{min}}+\hat{\mathrm{x}}^{\mathrm{max}}=0 \\
& -\hat{\mathrm{I} x}-\mathrm{s}_{2}+\hat{\mathrm{x}}^{\mathrm{max}}=0 \\
& \mathrm{~s}_{1}, \mathrm{~s}_{2} \geq 0
\end{aligned}
$$

By incorporating the slack variables $s_{i} \geq 0$ into the problem using logarithmic barrier terms, we get:

$\operatorname{minimize} f(x)-\mu \sum_{j=1}^{3 .(N B-1)}\left(\operatorname{lns}_{1_{j}}+\operatorname{lns}_{2_{j}}\right)$

subject to:

$$
\begin{aligned}
& g(x)-D=0 \\
& -s_{1}-s_{2}-\hat{x}^{\min }+\hat{x}^{\max }=0 \\
& -\hat{I} x-s_{2}+\hat{x}^{\max }=0
\end{aligned}
$$

where $\mu_{\mathrm{j}}>0$ is a barrier parameter which tends to zero as iterations progress. Using the method of Lagrange multipliers, the next step is to write the Lagrangian function of the above systems: 
$\mathrm{L}(\mathrm{u})=\mathrm{f}(\mathrm{x})-\mu \sum_{\mathrm{j}=1}^{3 .(\mathrm{NB}-1)}\left(\operatorname{lns}_{1_{\mathrm{j}}}+\operatorname{lns}_{2_{\mathrm{j}}}\right)-\lambda^{\mathrm{T}} \sum_{\mathrm{j}=1}^{3 .(\mathrm{NB}-1)}(\mathrm{g}(\mathrm{x})-\mathrm{D})-$

$\mathrm{z}_{1}^{\mathrm{T}}\left(-\mathrm{s}_{1}-\mathrm{s}_{2}-\hat{\mathrm{x}}^{\mathrm{min}}+\hat{\mathrm{x}}^{\mathrm{max}}\right)-\mathrm{z}_{2}^{\mathrm{T}}\left(-\hat{\mathrm{I} x}-\mathrm{s}_{2}+\hat{\mathrm{x}}^{\mathrm{max}}\right)$

where $\lambda$ is the Lagrange multiplier, and $\mathrm{u}$ is a vector of primal and dual variables in the optimization problem.

Using the system variables, (35) becomes:

$L(u)=f(X)-\lambda^{T}(g(X)-D)$

where $u=[X \lambda]^{\mathrm{T}}$ is the vector of primal and dual variables.

\subsubsection{Gradient, Hessian and Newton Step}

In optimization theory, the Karush-Kuhn-Tucker conditions (also known as the Kuhn-Tucker or KKT conditions) are necessary for a solution in nonlinear programming to be optimal $[26,27]$. Accordingly, an optimal solution of (36) must satisfy the gradient of the Lagrangian function which is known as the first order Karush-Kuhn-Tucker (KKT) conditions:

$$
\begin{aligned}
& \nabla_{\mathrm{x}} \mathrm{L}(\mathrm{u})=\nabla \mathrm{f}(\mathrm{x})-\mathrm{J}_{\mathrm{g}}(\mathrm{x})^{\mathrm{T}} \lambda+\hat{\mathrm{I}}^{\mathrm{T}} \mathrm{z}_{2}=0 \\
& \nabla_{\lambda} \mathrm{L}(\mathrm{u})=-\mathrm{g}(\mathrm{x})+\mathrm{D}=0 \\
& \nabla_{\mathrm{s} 1} \mathrm{~L}(\mathrm{u})=-\mu \mathrm{s}_{1}^{-1}+\mathrm{z}_{1}=0
\end{aligned}
$$


$\nabla_{\mathrm{s} 2} \mathrm{~L}(\mathrm{u})=-\mu \mathrm{s}_{2}^{-1}+\mathrm{z}_{1}+\mathrm{z}_{2}=0$,

$\nabla_{\mathrm{z} 1} \mathrm{~L}(\mathrm{u})=-\mathrm{s}_{1}-\mathrm{s}_{2}-\hat{\mathrm{x}}^{\mathrm{min}}+\hat{\mathrm{x}}^{\max }=0$,

$\nabla_{\mathrm{z} 2} \mathrm{~L}(\mathrm{u})=-\hat{\mathrm{I} x}-\mathrm{s}_{2}+\widehat{\mathrm{x}}^{\mathrm{max}}=0$,

where $\nabla f(x)$ is the gradient of the $\mathrm{f}(\mathrm{x})$, and $\mathrm{J}_{\mathrm{g}}$ is the Jacobian of the $\mathrm{g}(\mathrm{x})$. To solve the nonlinear system of (38) one can apply a Newton-Raphson-based solver which gives the following relationship:

$\mathrm{H}(\mathrm{u}) \Delta \mathrm{u}=-\nabla \mathrm{L}(\mathrm{u})$,

where $\mathrm{H}(\mathrm{u})$ and $\mathrm{\nabla L}(\mathrm{u})$ are the Hessian and the gradient of the Lagrangian, respectively and $\Delta \mathrm{u}$ stands for the Newton step. By expanding (39) the following symmetric system is obtained [25]:

$$
\left[\begin{array}{cccccc}
\mu \mathrm{s}_{1}^{-2} & 0 & \mathrm{I} & 0 & 0 & 0 \\
0 & \mu \mathrm{s}_{1}^{-2} & \mathrm{I} & \mathrm{I} & 0 & 0 \\
\mathrm{I} & \mathrm{I} & 0 & 0 & 0 & 0 \\
0 & \mathrm{I} & 0 & 0 & \hat{\mathrm{I}} & 0 \\
0 & 0 & 0 & \hat{\mathrm{I}}^{\mathrm{T}} & \nabla_{\mathrm{x}}^{2} \mathrm{~L}_{\mathrm{u}} & -\mathrm{Jg}_{\mathrm{g}}^{\mathrm{T}} \\
0 & 0 & 0 & 0 & -\mathrm{J}_{\mathrm{g}} & 0
\end{array}\right] \times\left[\begin{array}{c}
\Delta \mathrm{s}_{1} \\
\Delta \mathrm{s}_{2} \\
\Delta \mathrm{z}_{1} \\
\Delta \mathrm{z}_{2} \\
\Delta \mathrm{x} \\
\Delta \lambda
\end{array}\right]=\left[\begin{array}{c}
\mu \mathrm{s}_{1}^{-1}-\mathrm{z}_{1} \\
\mu \mathrm{s}_{2}^{-1}-\mathrm{z}_{1}-\mathrm{z}_{2} \\
-\mathrm{s}_{1}-\mathrm{s}_{2}-\hat{\mathrm{x}}^{\mathrm{min}}+\hat{\mathrm{x}}^{\max } \\
-\hat{\mathrm{I} x}-\mathrm{s}_{2}+\hat{\mathrm{x}}^{\mathrm{max}} \\
\nabla \mathrm{f}(\mathrm{x})-\mathrm{J}_{\mathrm{g}}(\mathrm{x})^{\mathrm{T}} \lambda+\hat{\mathrm{I}}^{\mathrm{T}} \mathrm{z}_{2} \\
\mathrm{~g}(\mathrm{x})-\mathrm{D}
\end{array}\right] \text {, }
$$

where $\nabla_{\mathrm{X}}^{2} \mathrm{~L}_{\mathrm{u}}$ is the second derivative of the Lagrangian with respect to $\mathrm{x}$. One idea to obtain the Newton step from the large system above is to solve for the $\Delta \mathrm{x}$ and $\Delta \lambda$ first from the reduced system represented below:

$\left[\begin{array}{cc}\mathrm{M} & -\mathrm{J}_{\mathrm{g}}^{\mathrm{T}} \\ -\mathrm{J}_{\mathrm{g}} & 0\end{array}\right] \times\left[\begin{array}{c}\Delta \mathrm{x} \\ \Delta \lambda\end{array}\right]=\left[\begin{array}{c}-\mathrm{N} \\ \mathrm{g}(\mathrm{x})-\mathrm{D}\end{array}\right]$ 
where

$\mathrm{M}=\nabla_{\mathrm{x}}^{2} \mathrm{~L}_{\mathrm{u}}+\mu \hat{\mathrm{I}}^{\mathrm{T}}\left(\mathrm{s}_{1}^{-2}+\mathrm{s}_{2}^{-2}\right) \hat{\mathrm{I}}$,

$\mathrm{N}=\nabla f(\mathrm{x})-\mathrm{J}_{\mathrm{g}}(\mathrm{x})^{\mathrm{T}} \lambda+\hat{\mathrm{I}}^{\mathrm{T}} \mathrm{z}_{2}$.

Once the primal and dual variables of the system are obtained, $\Delta \mathrm{s}_{1}, \Delta \mathrm{s}_{2}, \Delta \mathrm{z}_{1}, \Delta \mathrm{z}_{2}$ can be computed. Comparing equation (39) with equation (41), one can conclude that the Hessian of the Lagrangian in this system is the matrix terms of (41), i.e.

$\mathrm{H}=\left[\begin{array}{cc}\mathrm{M} & -\mathrm{J}_{\mathrm{g}}^{\mathrm{T}} \\ -\mathrm{J}_{\mathrm{g}} & 0\end{array}\right]$

\subsubsection{The Cumulant Method (Steps 3 and 4)}

The cumulant method is adapted to the probabilistic capacitor planning problem to obtain the statistic parameters of unknown variables, which are formulated making use of the statistic parameters of known variables, such as the system loading and WG power output. This relationship is linear, as it will be explained in this subsection.

Consider a linear combination of $\mathrm{n}$ independent random variable $\mathrm{x}$ used to create a new random variable $\mathrm{Y}$ as follows [28]:

$Y=c_{1} x_{1}+c_{2} x_{2}+c_{3} x_{3}+\ldots+c_{n} x_{n}$ 
where $c_{i}$ is the $\mathrm{i}^{\text {th }}$ coefficient in the linear combination. From the probabilistic definitions discussed in chapter 2 , the moment generation function of random variable $Y, \Phi_{Y}(\mathrm{~s})$, can be written as:

$\Phi_{\mathrm{Y}}(\mathrm{s})=\mathrm{E}\left[\mathrm{e}^{\mathrm{sY}}\right]=\mathrm{E}\left[\mathrm{e}^{\mathrm{s}\left(\mathrm{c}_{1} \mathrm{x}_{1}+\mathrm{c}_{2} \mathrm{x}_{2}+\ldots+\mathrm{c}_{\mathrm{n}} \mathrm{x}_{\mathrm{n}}\right.}\right]=\mathrm{E}\left[\mathrm{e}^{\mathrm{s}\left(\mathrm{c}_{1} \mathrm{x}_{1}\right)} \mathrm{e}^{\mathrm{s}\left(\mathrm{c}_{2} \mathrm{x}_{2}\right)} \ldots \mathrm{e}^{\mathrm{s}\left(\mathrm{c}_{\mathrm{n}} \mathrm{x}_{\mathrm{n}}\right)}\right]$

Assuming that $\mathrm{x}_{1}, \mathrm{x}_{2}, \mathrm{x}_{3}, \ldots ., \mathrm{x}_{\mathrm{n}}$ are independent, the above relationship can be written as

$\Phi_{Y}(s)=E\left[e^{s\left(c_{1} x_{1}\right)}\right] E\left[e^{s\left(c_{2} x_{2}\right)}\right] \ldots E\left[e^{s\left(c_{n} x_{n}\right)}\right]=\Phi_{x 1}\left(c_{1} s\right) \Phi_{x 2}\left(c_{2} s\right) \ldots \Phi_{x n}\left(c_{n} s\right)$.

For simplification purposes, the multiplication of the moment generating function of $\mathrm{x}_{\mathrm{i}}$ in the left-hand side of equation (47) can be converted into the summation of them. To achieve that, the natural logarithm (ln) function should be used. By taking the natural logarithm from the above relationship, we get:

$$
\begin{aligned}
& \ln \left(\Phi_{\mathrm{Y}}(\mathrm{s})\right)=\ln \left(\Phi_{\mathrm{x} 1}\left(\mathrm{c}_{1} \mathrm{~s}\right) \Phi_{\mathrm{x} 2}\left(\mathrm{c}_{2} \mathrm{~s}\right) \ldots \Phi_{\mathrm{xn}}\left(\mathrm{c}_{\mathrm{n}} \mathrm{s}\right)\right)= \\
& \ln \left(\Phi_{\mathrm{x} 1}\left(\mathrm{c}_{1} \mathrm{~s}\right)\right)+\ln \left(\Phi_{\mathrm{x} 2}\left(\mathrm{c}_{2} \mathrm{~s}\right)\right)+\ldots+\ln \left(\Phi_{\mathrm{xn}}\left(\mathrm{c}_{\mathrm{n}} \mathrm{s}\right)\right) .
\end{aligned}
$$

From chapter 2 , the cumulant generating function, $\Psi_{\mathrm{X}}(\mathrm{s})$, can be written in terms of the moment generating function $\Phi_{\mathrm{X}}(\mathrm{s})$ as follows:

$\Psi_{\mathrm{X}}(\mathrm{s})=\ln \left(\Phi_{\mathrm{x}}(\mathrm{s})\right)$

Consequently, writing (48) in the terms of cumulant generating function gives: 
$\Psi_{\mathrm{Z}}(\mathrm{s})=\Psi_{\mathrm{x} 1}\left(\mathrm{c}_{1} \mathrm{~s}\right)+\Psi_{\mathrm{x} 2}\left(\mathrm{c}_{2} \mathrm{~s}\right)+\ldots+\Psi_{\mathrm{xn}}\left(\mathrm{c}_{\mathrm{n}} \mathrm{s}\right)$.

To compute different orders of cumulant, different order derivatives of the cumulant generating function should be taken while setting $s=0$. For example, for computing zero, first and second order cumulants, the zero, first and second order derivatives of the cumulant generating function are taken as:

$\Psi_{\mathrm{Y}}(\mathrm{s})=\Psi_{\mathrm{x} 1}(\mathrm{~s})\left(\mathrm{c}_{1} \mathrm{~s}\right)+\Psi_{\mathrm{x} 2}(\mathrm{~s})\left(\mathrm{c}_{2} \mathrm{~s}\right)+\ldots+\Psi_{\mathrm{xn}}(\mathrm{s})\left(\mathrm{c}_{\mathrm{n}} \mathrm{s}\right)$,

$\Psi^{\prime}{ }_{Y}(\mathrm{~s})=\mathrm{c}_{1} \Psi^{\prime}{ }_{\mathrm{x} 1}(\mathrm{~s})\left(\mathrm{c}_{1} \mathrm{~s}\right)+\mathrm{c}_{2} \Psi^{\prime}{ }_{\mathrm{X} 2}(\mathrm{~s})\left(\mathrm{c}_{2} \mathrm{~s}\right)+\ldots+\mathrm{c}_{\mathrm{n}} \Psi^{\prime}{ }_{\mathrm{Xn}}(\mathrm{s})\left(\mathrm{c}_{\mathrm{n}} \mathrm{s}\right)$

$\Psi^{\prime \prime}{ }_{Y}(\mathrm{~s})=\mathrm{c}_{1}{ }^{2} \Psi^{\prime \prime}{ }_{\mathrm{X} 1}(\mathrm{~s})\left(\mathrm{c}_{1} \mathrm{~s}\right)+\mathrm{c}_{2}{ }^{2} \Psi^{\prime \prime}{ }_{\mathrm{X} 2}(\mathrm{~s})\left(\mathrm{c}_{2} \mathrm{~s}\right)+\ldots+\mathrm{c}_{\mathrm{n}}{ }^{2} \Psi^{\prime \prime}{ }_{\mathrm{Xn}}(\mathrm{s})\left(\mathrm{c}_{\mathrm{n}} \mathrm{s}\right)$.

Setting $\mathrm{s}=0$ yields:

$\Psi{ }^{\prime \prime}(\mathrm{s})=\mathrm{c}_{1}{ }^{2} \Psi^{\prime \prime}{ }_{\mathrm{x} 1}(0)+\mathrm{c}_{2}{ }^{2} \Psi{ }_{\mathrm{X} 2}^{\prime \prime}(\mathrm{s})(0)+\ldots+\mathrm{c}_{\mathrm{n}}{ }^{2} \Psi^{\prime \prime}{ }_{\mathrm{xn}}(\mathrm{s})(0)$.

Cumulants of third and higher order can be computed following the same procedure. A general equation for the $\mathrm{n}^{\text {th }}$ order cumulant of $\mathrm{Y}$ is the following:

$\mathrm{k}_{\mathrm{n}}=\Psi_{\mathrm{Y} 1}^{(\mathrm{n})}(0)=\mathrm{c}_{1}^{\mathrm{n}} \Psi_{\mathrm{x} 1}^{(\mathrm{n})}(0)+\mathrm{c}_{2}^{\mathrm{n}} \Psi_{\mathrm{x} 2}^{(\mathrm{n})}(0)+\ldots+\mathrm{c}_{\mathrm{n}}^{\mathrm{n}} \Psi_{\mathrm{xn}}^{(\mathrm{n})}(0)$.

In (53), it can be observed that the $\mathrm{n}^{\text {th }}$ order cumulant of $\mathrm{Y}$ can be obtained if the value of the $\mathrm{n}^{\text {th }}$ order cumulant of random variables $\mathrm{x}_{\mathrm{i}}$ and the corresponding coefficients $\mathrm{c}_{\mathrm{i}}$ are known. In conclusion, if a random variable $\mathrm{Y}$ denotes an unknown variable of the problem, and $\mathrm{x}_{\mathrm{i}}$ denotes the known variable with known probabilistic information given 
as the different order of cumulants of $\mathrm{x}_{\mathrm{i}}$, the different order cumulants of the unknown random variables can be easily obtained from the same order cumulant of the $\mathrm{x}_{\mathrm{i}}$.

Using the aforementioned reasoning, (39) can be rearranged by replacing $\nabla \mathrm{L}(\mathrm{u})$ with $\mathrm{F}(\mathrm{u})$, giving

$\Delta \mathrm{u}=-\mathrm{H}(\mathrm{u})^{-1} \mathrm{~F}(\mathrm{u})$

where $\mathrm{F}(\mathrm{u})$ consists power flow (FS) and voltage drop (FV) equations and N, (42).

With a vector of change in bus generation and loading, the vector of changes in the unknown variables can be linearly mapped with the vector of changes in bus generation and loading, i.e., $\Delta \mathrm{D}$, using the inverse of Hessian:

$\Delta \mathrm{u}=-\mathrm{H}(\mathrm{u})^{-1} \cdot \mathrm{F}(\mathrm{u})=-\mathrm{H}(\mathrm{u})^{-1} \cdot\left[\begin{array}{l}{[0]} \\ \Delta \mathrm{D}\end{array}\right]$.

While the vector $\mathrm{F}(\mathrm{u})$ includes power flow and voltage drop equations, the corresponding equation in each row of the power flow equations is replaced by the cumulants of the random loads. Accordingly, the cumulants of the output variables are obtained by using the following relation:

$\mathrm{k}_{\mathrm{u}, \mathrm{n}}=\left(-\mathrm{H}^{-1}\right)^{\mathrm{n}} \times \mathrm{k}_{\mathrm{D}, \mathrm{n}}$,

where $\mathrm{k}_{\mathrm{u}, \mathrm{n}}$ is a vector of $\mathrm{n}^{\text {th }}$-order cumulants for the unknown variables and $\mathrm{k}_{\mathrm{D}, \mathrm{n}}$ is a vector of $\mathrm{n}^{\text {th }}$-order cumulants for the random bus generation and loading. Consequently, the Hessian contains of the constant multipliers given by: 
$-H^{-1}=\left[\begin{array}{ccccc}c_{1,1} & c_{1,2} & c_{1,3} & \cdots & c_{1, n} \\ c_{2,1} & c_{2,2} & c_{2,3} & \cdots & c_{2, n} \\ \vdots & \vdots & \vdots & \ddots & \vdots \\ c_{n, 1} & c_{n, 2} & c_{n, 3} & \ldots & c_{n, n}\end{array}\right]$

Accordingly, the $\mathrm{n}^{\text {th }}$-order cumulant for the $\mathrm{i}^{\text {th }}$ in $\mathrm{u}$ is computed using the following equation [19]:

$\mathrm{k}_{\mathrm{u}_{\mathrm{i}, \mathrm{n}}}=\mathrm{c}_{\mathrm{i}, 1}^{\mathrm{n}} \mathrm{k}_{\mathrm{D}_{1, \mathrm{n}}}+\mathrm{c}_{\mathrm{i}, 2}^{\mathrm{n}} \mathrm{k}_{\mathrm{D}_{2, \mathrm{n}}}+\cdots+\mathrm{c}_{\mathrm{i}, 1}^{\mathrm{n}} \mathrm{k}_{\mathrm{D}_{\mathrm{n}, \mathrm{n}}}$

where $u_{i}$ is the $i^{\text {th }}$ element in $u$ and $k_{D_{j, n}}$ is the $n^{\text {th }}$ cumulant for the $j^{\text {th }}$ component variable. Once the cumulants of the output variables are computed, their PDFs are reconstructed using Gram-Charlier/Edgeworth Expansion theory.

\subsubsection{Gram-Charlier Expansion Theory (Step 5)}

According to the Gram-Charlier Expansion, the PDFs of the many distributions can be formed as a series comprised of a standard normal distribution and its derivatives. The proposed solution method makes use of this characteristic to reconstruct the PDFs of the problem variables after their cumulants are defined in terms of the known cumulants (of the known variables).

Consider a random variable $\mathrm{x}$ with the cumulants of $\mathrm{k}_{\mathrm{n}}$. The PDF of $\mathrm{x}$ can be written in terms of the known PDF of $\varphi$. This known PDF is usually chosen as the standard normal distribution, i.e., with $\mu=0$ and $\sigma=1$. Thus the PDF of $\mathrm{x}$ is written as: 
$\mathrm{f}(\mathrm{x})=\varphi(\mathrm{x})+\frac{\mathrm{c}_{1}}{1 !} \varphi^{(1)}(\mathrm{x})+\frac{\mathrm{c}_{2}}{2 !} \varphi^{(2)}(\mathrm{x})+\frac{\mathrm{c}_{3}}{3 !} \varphi^{(3)}(\mathrm{x})+\cdots$

where $\varphi^{(n)}$ represents the $n^{\text {th }}$ derivative of the standard normal distribution and $c_{i}$ is the is the $\mathrm{i}^{\text {th }}$ Edgeworth series coefficient. The Edgeworth form of the series uses the cumulants of $x$ to compute the series coefficient. Rearranging the above summation in terms of $\varphi$, a new parameter called Tchebycheff-Hermite or Hermite polynomial is introduced:

$\mathrm{f}(\mathrm{x})=\mathrm{c}_{0} \mathrm{He}_{0} \varphi(\mathrm{x})+\mathrm{c}_{1} \mathrm{He}_{1} \varphi(\mathrm{x})+\mathrm{c}_{2} \mathrm{He}_{2} \varphi(\mathrm{x})+\mathrm{c}_{3} \mathrm{He}_{3} \varphi(\mathrm{x})+\cdots$

where $\mathrm{He}_{\mathrm{i}}$ is the $\mathrm{i}^{\text {th }}$ Hermite polynomial. The above series form is called A series [19]. In the next sections the Hermite Polynomials and the computation of the Edgeworth series coefficient are discussed.

\subsubsection{Hermite Polynomials}

In the previous section, it was shown that the Gram-Charlier Expansion series allows to the PDF of random variable $\mathrm{x}$ to be constructed in a series form called A series. The series introduces two variables that can be defined in terms of the standard distribution functions and the cumulants of the random variable $\mathrm{x}$. In this subsection one of these two variables, called the Hermite polynomial, is introduced.

Comparing the equation (58) and (59), it is showed that $\mathrm{i}^{\text {th }}$ Hermite polynomials are defined in terms of the $\mathrm{i}^{\text {th }}$ order derivative of the standard normal distribution as follows $[29,30]:$ 
$\mathrm{He}_{\mathrm{i}}(\mathrm{x})=(-1)^{\mathrm{i}} \cdot \mathrm{e}^{\frac{\mathrm{x}^{2}}{2}} \cdot \frac{\mathrm{d}^{\mathrm{i}}}{d \mathrm{dx}^{\mathrm{i}}} \varphi(\mathrm{x})=(-1)^{\mathrm{i}} \mathrm{e}^{\frac{\mathrm{x}^{2}}{2}} \cdot \frac{\mathrm{d}^{\mathrm{i}}}{\mathrm{dx}^{\mathrm{i}}} \mathrm{e}^{\frac{-\mathrm{x}^{2}}{2}}$

Accordingly, the first five Hermite polynomials are:

$\mathrm{He}_{0}(\mathrm{x})=1$,

$\mathrm{He}_{1}(\mathrm{x})=\mathrm{x}$,

$\mathrm{He}_{2}(\mathrm{x})=\mathrm{x}^{2}-1$

$\mathrm{He}_{3}(\mathrm{x})=\mathrm{x}^{3}-3 \mathrm{x}$

$\mathrm{He}_{4}(\mathrm{x})=\mathrm{x}^{4}-6 \mathrm{x}^{2}+3$

$\mathrm{He}_{5}(\mathrm{x})=\mathrm{x}^{5}-10 \mathrm{x}^{3}+15 \mathrm{x}$

\subsubsection{Edgeworth A-Series Coefficients}

Recalling equation (58), the probability density function of $\mathrm{x}$ can be rewritten in an exponential form as follow when the cumulant of the $f(x)$ is given.

$\mathrm{f}(\mathrm{x})=\left[\mathrm{e}^{\sum_{\mathrm{i}=3}^{\infty} \mathrm{K}_{\mathrm{i}} \frac{(-\mathrm{D})^{\mathrm{i}}}{\mathrm{i} !}}\right] \varphi(\mathrm{x})$

where $\mathrm{k}_{\mathrm{i}}$ is the $\mathrm{i}^{\mathrm{th}}$ cumulant of the $\mathrm{f}(\mathrm{x})$ and $\mathrm{D}$ is the differential operator with respect to $\mathrm{x}$. Expanding (62) gives [29]:

$f(x)=\left[1+\frac{\left(-\frac{k_{3}}{3 !} D^{3}+\frac{k_{4}}{4 !} D^{4}-\frac{k_{5}}{5 !} D^{5}+\cdots\right)}{1 !}+\frac{\left(-\frac{k_{3}}{3 !} D^{3}+\frac{k_{4}}{4 !} D^{4}-\frac{k_{5}}{5 !} D^{5}+\cdots\right)^{2}}{2 !}+\frac{\left(-\frac{k_{3}}{3 !} D^{3}+\frac{k_{4}}{4 !} D^{4}-\frac{k_{5}}{5 !} D^{5}+\cdots\right)^{3}}{3 !}+\right.$
$\cdots] \varphi(x)$. 
By rearranging (63) the following is obtained:

$f(x)=\left[1-\frac{k_{3}}{3 !} D^{3}+\frac{k_{4}}{4 !} D^{4}-\frac{k_{5}}{5 !} D^{5}+\left(\frac{k_{6}}{6 !}+\frac{k_{3}^{2}}{2 ! 3 !^{2}}\right) D^{6}+\cdots\right] \varphi(x)$

The differential operator in (64) can be substituted with the Hermite polynomials obtained in the previous section by the following relationship:

$\mathrm{He}_{\mathrm{i}}(\mathrm{x}) \cdot \varphi(\mathrm{x})=(-\mathrm{D})^{\mathrm{n}} \varphi(\mathrm{x})$

Substituting (65) in (64) yields:

$f(x)=1+\frac{k_{3}}{3 !} H_{3} \alpha(x)+\frac{k_{4}}{4 !} H e_{4} \alpha(x)+\frac{k_{5}}{5 !} H_{5} \alpha(x)+\frac{\left(k_{6}+10 k_{3}{ }^{2}\right)}{6 !} H_{6} \alpha(x)+\cdots$

Recalling equation (59), the values of the Edgeworth series coefficients can be obtained.

Table 1 presents the first six values of these coefficients. 
Table 1 Edgeworth Coefficients

\begin{tabular}{|c|c|}
\hline Coefficient $\left(c_{n}\right)$ & value \\
\hline 0 & 1 \\
\hline 1 & 0 \\
\hline 2 & 0 \\
\hline 3 & $\frac{1}{6} k_{3}$ \\
\hline 4 & $\frac{1}{24} k_{4}$ \\
\hline 5 & $\frac{1}{120} k_{5}$ \\
\hline 6 & $\frac{1}{720}\left(k_{6}+10 k_{3}^{2}\right)$ \\
\hline
\end{tabular}




\section{CHAPTER 4 Results And Discussions}

The solution method described in the preceding chapter is applied to a 7-bus and 33-bus RDS with one and two wind generators connected to them respectively. In order to assess the accuracy of the solution method, comparison studies have been carried out with Monte Carlo simulations (MCS) consisting of 2500 samples. The absolute percentage errors of the probabilistic information of the system variables are presented.

This section presents and discusses the results from the solution method.

\subsection{7-Bus System}

The methodology described in Chapter 3 is tested on the 7-bus test system with one wind generator shown in Figure 6. The system load and line data are given in the Appendix A.

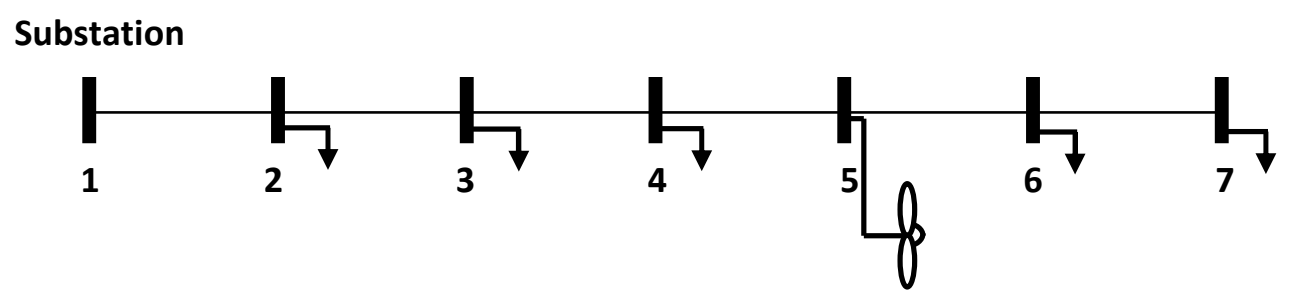

Figure 6 Single line diagram of the 7-bus distribution test system 


\subsubsection{Comparison of the results of the Cumulant method with those of MCS}

In this section the results of the cumulant method are compared with those of MCS using 2500 samples. The loads are modeled using Gaussian distribution with the standard deviation equal to the $10 \%$ of the nominal bus loading value.

Table 2 gives the statistical parameters assumed for the Weibull distribution representing the wind generator. The data of the system including the mean values of the loads are given in the Appendix A.

Table 2 Parameters of the Weibull PDF for the wind generator

\begin{tabular}{c|c|c|c}
\hline Bus No. & $\begin{array}{c}\text { Mean } \\
\text { Generation(kW) }\end{array}$ & Shape Factor & $\begin{array}{c}\text { Standard Deviation } \\
{[\%]}\end{array}$ \\
\hline 5 & 400 & 2 & $\begin{array}{c}55 \% \text { of the } \\
\text { Mean }\end{array}$ \\
\hline
\end{tabular}

In the present case, three different load levels, namely light, medium and heavy loads, have been considered with the corresponding time duration given in table 3 , which also presents the system cost details. That makes the structure of the Hessian matrix consist of three submatrices such that the inverse of it contains the coefficients for the linear relation between system variables and the input random variables (loads and WGs) in the corresponding load level. Similarly, the cumulant vector of the loads and WGs consists of three subvectors. Equation (67) shows these segments clearly. 
In the inverse of the Hessian matrix and vectors below, the subscripts of the coefficients (C) and Cumulant (k) can be L, M, and H, standing for Low, Medium and High, respectively.

$$
\left[\begin{array}{l}
\mathrm{k}_{\mathrm{u}_{\mathrm{L}, \mathrm{n}}} \\
\mathrm{k}_{\mathrm{u}_{\mathrm{M}, \mathrm{n}}} \\
\mathrm{k}_{\mathrm{u}_{\mathrm{H}, \mathrm{n}}}
\end{array}\right]=\left[\begin{array}{c:c:c}
\mathrm{C}_{\mathrm{L}} & \mathrm{C}_{\mathrm{M}} & \mathrm{C}_{\mathrm{H}} \\
\hdashline \mathrm{C}_{\mathrm{M}} & \mathrm{C}_{\mathrm{M}} & \mathrm{C}_{\mathrm{H}} \\
\hdashline \mathrm{C}_{\mathrm{H}} & \mathrm{C}_{\mathrm{H}} & \mathrm{C}_{\mathrm{H}}
\end{array}\right]^{-\mathrm{n}} \times\left[\begin{array}{c}
{[0]} \\
\mathrm{k}_{\mathrm{d}_{\mathrm{L}, \mathrm{n}}}+\mathrm{k}_{\mathrm{WG}_{\mathrm{L}, \mathrm{n}}} \\
\mathrm{k}_{\mathrm{d}_{\mathrm{M}, \mathrm{n}}}+\mathrm{k}_{\mathrm{WG}_{\mathrm{M}, \mathrm{n}}} \\
\mathrm{k}_{\mathrm{d}_{\mathrm{H}, \mathrm{n}}}+\mathrm{k}_{\mathrm{WG}, \mathrm{n}}
\end{array}\right]
$$

Consequently, $\mathrm{k}_{\mathrm{u}_{\mathrm{L}, \mathrm{n}}}, \mathrm{k}_{\mathrm{u}_{\mathrm{M}, \mathrm{n}}}$ and $\mathrm{k}_{\mathrm{u}_{\mathrm{H}, \mathrm{n}}}$ are the Cumulants of the system variables in the light, medium and heavy load level and $\left(\mathrm{k}_{\mathrm{d}_{\mathrm{L}, \mathrm{n}}}+\mathrm{k}_{\mathrm{WG}_{\mathrm{L}, \mathrm{n}}}\right),\left(\mathrm{k}_{\mathrm{d}_{\mathrm{M}, \mathrm{n}}}+\mathrm{k}_{\mathrm{WG}_{\mathrm{M}, \mathrm{n}}}\right)$ and $\left(\mathrm{k}_{\mathrm{d}_{\mathrm{H}, \mathrm{n}}}+\right.$ $\mathrm{k}_{\mathrm{WG}_{\mathrm{H}, \mathrm{n}}}$ ) are the Cumulants of the system loads and WGs in the prescribed load levels.

\section{Table 3 Load Duration Data}

\begin{tabular}{|c|c|c|c|c|c|}
\hline & Low & Load Lev & High & $\begin{array}{c}\text { Variable } \\
\text { Capacitor } \\
\text { Cost } \\
\text { KS } \\
\text { (\$/kVAr) }\end{array}$ & $\begin{array}{c}\text { Cost of } \\
\text { Energy } \\
K L \\
(\$ / k W h)\end{array}$ \\
\hline Amount(p.u.) & 0.5 & 0.7 & 1.5 & \multirow{2}{*}{90} & \multirow{2}{*}{0.06} \\
\hline Duration(Hrs) & 1000 & 1000 & 6760 & & \\
\hline
\end{tabular}

The sensitivity index calculation corresponding to the procedure detailed in section 3.3.1 is carried out to find the best locations for siting the capacitor banks. These locations are known as the candidate buses. It is assumed that a capacitor switch is connected to all buses except the first bus. The bus bars are sorted in descending order of 
their active power loss sensitivity, which was calculated with respect to the reactive power injection in the corresponding bus. Once the bus with the highest sensitivity is determined, the capacitor switch is closed and a new sensitivity calculation is performed. It can be seen from the step procedure given in section 3.3.1 that a candidate bus can be selected more than once to allow more than one capacitor can to be connected to a bus.

Figure 7 shows the active power loss sensitivity value of each bus at the third time interval, before capacitor installation. According to this figure, the best candidate bus for capacitor sitting is bus 7 . The sensitivity step procedure is carried out again until all conditions are satisfied.

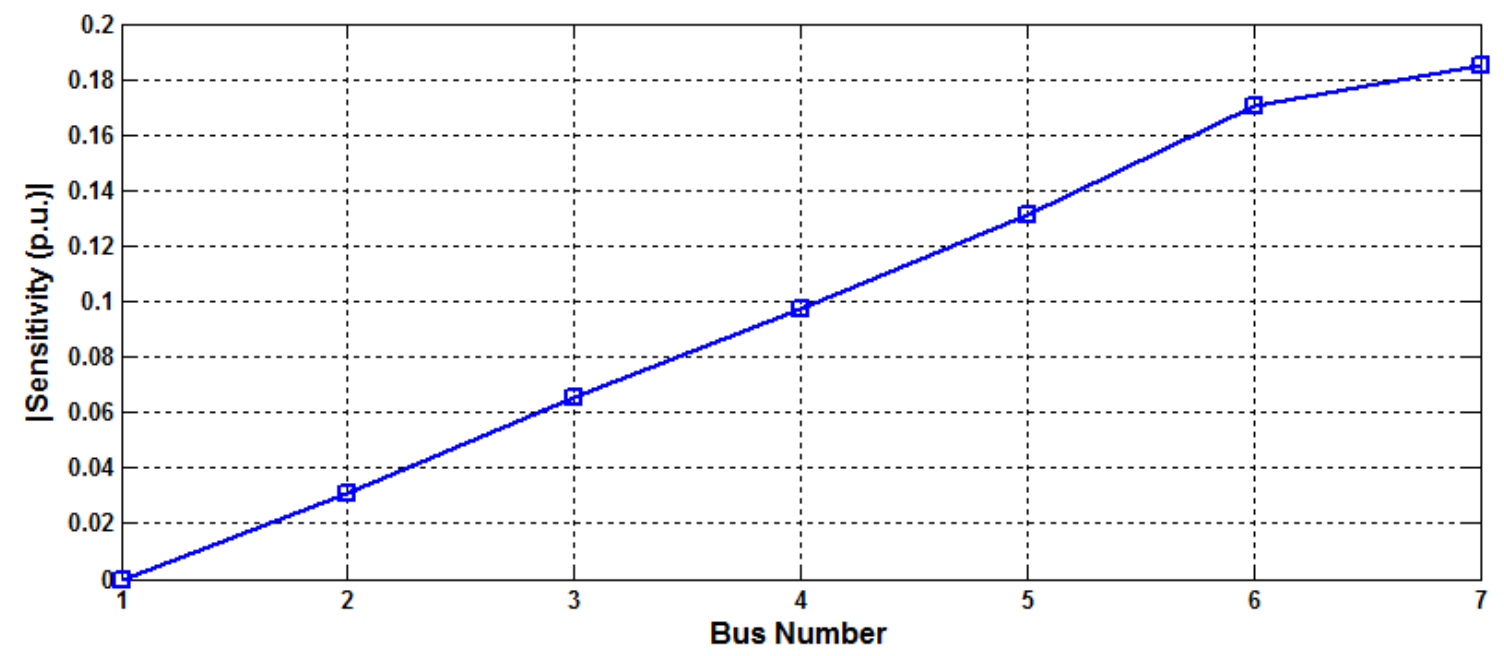

Figure 7 Sensitivity Index Solutions

Table 4 presents in detail the probabilistic optimal solutions for the real power loss and the cost of energy loss at each time duration, with and without capacitors as per 
cumulant method and MCS solutions. The table also gives the size of capacitors at each candidate bus. A significant decrease in real power loss and consequently in the annual cost of energy loss after capacitor installation can be seen from the table. In addition, the results of cumulant method are in close agreement with those of MCS.

Table 4 Optimal solutions and comparison of the two methods

\begin{tabular}{|c|c|c|c|c|c|}
\hline \multirow{2}{*}{ Method } & \multirow{2}{*}{ Time Duration } & \multicolumn{2}{|c|}{ Capacitors } & \multirow{2}{*}{$\begin{array}{l}\text { Real Power } \\
\text { Loss } \\
\text { (kW) }\end{array}$} & \multirow[b]{2}{*}{$\begin{array}{l}\text { Annual Cost of } \\
\text { Energy Losses } \\
\text { (\$) }\end{array}$} \\
\hline & & Bus No. & $\begin{array}{c}\text { Size } \\
\text { (kVAr) }\end{array}$ & & \\
\hline \multirow{3}{*}{$\begin{array}{l}\text { Base Case } \\
\text { Cumulant }\end{array}$} & 1 & \multirow{3}{*}{\multicolumn{2}{|c|}{0}} & 23.757 & \multirow{3}{*}{$4,123,100$} \\
\hline & 2 & & & 52.359 & \\
\hline & 3 & & & 327.59 & \\
\hline \multirow{3}{*}{ Base Case } & 1 & \multirow{3}{*}{\multicolumn{2}{|c|}{0}} & 22.847 & \multirow{3}{*}{$4,101,800$} \\
\hline & 2 & & & 51.588 & \\
\hline & 3 & & & 326.09 & \\
\hline \multirow{3}{*}{$\begin{array}{l}\text { Cumulant } \\
\text { using OPF }\end{array}$} & 1 & \multirow{3}{*}{7} & \multirow{3}{*}{1738.7} & 9.9915 & \multirow{3}{*}{$2,137,500$} \\
\hline & 2 & & & 25.068 & \\
\hline & 3 & & & 170.48 & \\
\hline \multirow{3}{*}{$\begin{array}{c}\text { MCS using } \\
\text { OPF }\end{array}$} & 1 & \multirow{3}{*}{7} & \multirow{3}{*}{1738.6} & 10.785 & \multirow{3}{*}{$2,139,000$} \\
\hline & 2 & & & 25.615 & \\
\hline & 3 & & & 170.40 & \\
\hline
\end{tabular}


Table 5 presents the probabilistic optimal solutions for the total cost. From this table it can be seen that the mean value of the total cost yields a cost of 2.2940 million dollars using the cumulant method and 2.2964 million dollars using the MCS. It can be seen that the mean values of the optimal solutions of both methods closely match each other with a percentage error of $0.10 \%$.

The percentage error of the Standard deviation is 57.23\%. This large percentage error is due to the power loss formulation, which adds the errors of the power and voltage values at all buses. Consequently, the existing variance errors at all buses are combined, yielding a total large percentage error. Moreover, there is a two stage procedure to obtain the cumulants of the total costs from the known cumulants of loads and wind generation. Firstly, the cumulants of the system power flow and nodal voltage should be obtained using the method as explained earlier, and secondly the total cost equation should be linearized so that the cumulant of the objective function can be calculated from the cumulant of the system variables. It can be concluded that the cumulant of the total cost is indirectly related to the cumulant of the known variables. This results in a further increased error as well.

Note that the total cost of employing capacitors clearly offset the annual energy loss for the uncompensated cases. The savings will be more pronounced after the first year. 


\section{Table 5 Total Cost Values}

\begin{tabular}{|c|c|c|c|c|c|}
\hline \multicolumn{2}{|c|}{ Cumulant } & \multicolumn{2}{|c|}{ MCS } & \multirow{2}{*}{$\begin{array}{l}\text { Error } \\
\text { of } \\
\text { Mean } \\
{[\%]}\end{array}$} & \multirow{2}{*}{$\begin{array}{c}\text { Error of } \\
\text { Standard } \\
\text { Deviation } \\
\text { [\%] }\end{array}$} \\
\hline $\begin{array}{l}\text { Mean value of } \\
\text { Total Cost } \\
\text { (millions of \$) }\end{array}$ & $\begin{array}{c}\text { Standard Deviation } \\
\text { of Total Cost } \\
\text { (millions of } \$ \text { ) }\end{array}$ & $\begin{array}{l}\text { Mean value of } \\
\text { Total Cost } \\
\text { (millions of \$) }\end{array}$ & $\begin{array}{c}\text { Standard Deviation } \\
\text { of Total Cost } \\
\text { (millions of } \$ \text { ) }\end{array}$ & & \\
\hline 2.2940 & 0.188 & 2.2964 & 0.441 & 0.10 & 57.23 \\
\hline
\end{tabular}

Figure 8 shows the voltage improvement before and after the capacitor installation at the third time interval. From this figure it can be seen that the minimum voltage before installing any capacitor, i.e., at the base case, is 0.86 p.u. which is improved to 0.927 p.u. after capacitor installation.

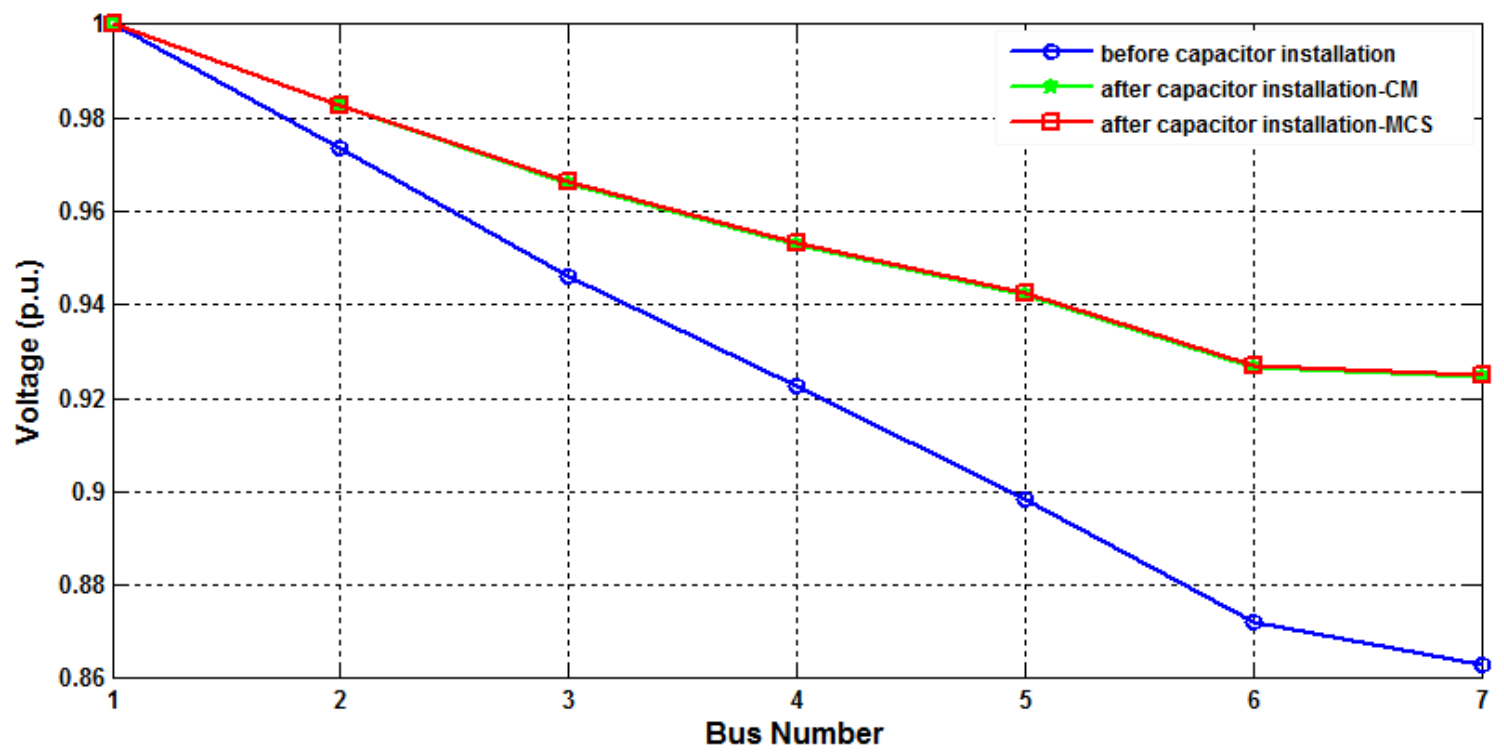

Figure 8 Voltage improvement before and after capacitor installation 
The probabilistic optimal results for the system variables, voltage magnitude, active and reactive power flow solutions, and capacitor size in all time durations are detailed in table 6 and table 7. These results are divided into two portions. The first portion includes the results for the mean value and the discussion about the percentage error between both cumulant and MCS. The second portion of the results presents the standard deviation values and the discussion about the percent error between both cumulant and MCS. The mean values for the loads and WGs were taken at the nominal value from the 7-bus system. The results of both mean and standard deviation values are discussed as follows:

1) Mean Values: Table 6 contains the results related to the mean values for all system variables in per unit as well as a comparison between the cumulant method and MCS presented as an absolute percentage error in all TDs. The results for the percentage error of the voltage mean value is very small, with the maximum of $0.06 \%$ which occurs at TD3 at buses 5 and 6 . The percentage errors of the mean value for the other system variables are not as small, but well below $10 \%$.

2) Variance Value: Table 7 contains the results of the standard deviation values for all system variables in per unit as well as a percent error comparison between the cumulant method and MCS in all TDs. From the table it can be seen that the percentage error of the standard deviation of all variables are below $10 \%$.The maximum percentage error for standard deviation of voltage, active and reactive 
power and capacitor size are $2.25 \%$ at TD1, 3.01\% at TD3, 9.45\% at TD3 and $1.46 \%$ at TD2, respectively. 
Chapter 4 Results and Discussions

Table 6 Mean values of the system variables

\begin{tabular}{|c|c|c|c|c|c|c|c|c|c|c|}
\hline & \multirow{2}{*}{$\begin{array}{l}\text { Bus } \\
\text { No. }\end{array}$} & \multicolumn{3}{|c|}{$\begin{array}{l}\text { Cumulant Method } \\
\text { Mean value }\end{array}$} & \multicolumn{3}{|c|}{$\begin{array}{l}\text { MCS-2500 samples } \\
\text { Mean value }\end{array}$} & \multicolumn{3}{|c|}{ Error (\%) } \\
\hline & & TD1 & TD2 & TD3 & TD1 & TD2 & TD3 & TD1 & TD2 & TD3 \\
\hline \multirow{7}{*}{$\begin{array}{l}\text { Voltage } \\
\text { (PU) }\end{array}$} & 1 & 1.000 & 1.000 & 1.000 & 1.000 & 1.000 & 1.000 & 0.000 & 0.000 & 0.000 \\
\hline & 2 & 0.996 & 0.993 & 0.983 & 0.996 & 0.993 & 0.983 & 0.011 & 0.012 & 0.013 \\
\hline & 3 & 0.992 & 0.987 & 0.966 & 0.992 & 0.988 & 0.966 & 0.025 & 0.025 & 0.027 \\
\hline & 4 & 0.990 & 0.983 & 0.953 & 0.990 & 0.983 & 0.953 & 0.038 & 0.039 & 0.041 \\
\hline & 5 & 0.988 & 0.980 & 0.942 & 0.989 & 0.980 & 0.943 & 0.055 & 0.056 & 0.060 \\
\hline & 6 & 0.983 & 0.973 & 0.927 & 0.984 & 0.974 & 0.927 & 0.055 & 0.056 & 0.060 \\
\hline & 7 & 0.983 & 0.972 & 0.925 & 0.983 & 0.973 & 0.925 & 0.055 & 0.056 & 0.059 \\
\hline \multirow{7}{*}{$\begin{array}{c}\text { Active } \\
\text { Power } \\
\text { (PU) }\end{array}$} & 1 & 0.000 & 0.000 & 0.000 & 0.000 & 0.000 & 0.000 & 0.000 & 0.000 & 0.000 \\
\hline & 2 & 0.633 & 1.055 & 2.804 & 0.608 & 1.029 & 2.779 & 4.097 & 2.432 & 0.906 \\
\hline & 3 & 0.508 & 0.877 & 2.400 & 0.483 & 0.853 & 2.376 & 5.121 & 2.894 & 1.013 \\
\hline & 4 & 0.397 & 0.720 & 2.044 & 0.372 & 0.695 & 2.020 & 6.743 & 3.594 & 1.207 \\
\hline & 5 & 0.280 & 0.555 & 1.675 & 0.255 & 0.530 & 1.650 & 9.951 & 4.757 & 1.482 \\
\hline & 6 & 0.677 & 0.948 & 2.039 & 0.677 & 0.949 & 2.040 & 0.045 & 0.046 & 0.049 \\
\hline & 7 & 0.325 & 0.455 & 0.975 & 0.326 & 0.456 & 0.977 & 0.167 & 0.167 & 0.167 \\
\hline \multirow{7}{*}{$\begin{array}{c}\text { Reactive } \\
\text { Power } \\
\text { (PU) }\end{array}$} & 1 & 0.000 & 0.000 & 0.000 & 0.000 & 0.000 & 0.000 & 0.000 & 0.000 & 0.000 \\
\hline & 2 & 0.283 & 0.399 & 0.974 & 0.283 & 0.398 & 0.972 & 0.105 & 0.130 & 0.138 \\
\hline & 3 & 0.183 & 0.257 & 0.644 & 0.182 & 0.256 & 0.643 & 0.329 & 0.315 & 0.253 \\
\hline & 4 & 0.079 & 0.110 & 0.311 & 0.079 & 0.109 & 0.311 & 0.489 & 0.338 & 0.114 \\
\hline & 5 & -0.064 & -0.093 & -0.139 & -0.065 & -0.093 & -0.139 & 1.010 & 0.620 & 0.275 \\
\hline & 6 & -0.067 & -0.098 & -0.163 & -0.068 & -0.098 & -0.164 & 0.993 & 0.618 & 0.334 \\
\hline & 7 & -0.339 & -0.479 & -0.984 & -0.339 & -0.478 & -0.983 & 0.007 & 0.076 & 0.152 \\
\hline $\begin{array}{l}\text { Capacitor } \\
\text { Size(PU) }\end{array}$ & 7 & 0.590 & 0.831 & 1.739 & 0.591 & 0.831 & 1.739 & 0.079 & 0.039 & 0.001 \\
\hline
\end{tabular}


Chapter 4 Results and Discussions

Table 7 Standard deviation values of the system variables

\begin{tabular}{|c|c|c|c|c|c|c|c|c|c|c|}
\hline & \multirow{2}{*}{$\begin{array}{l}\text { Bus } \\
\text { No. }\end{array}$} & \multicolumn{3}{|c|}{$\begin{array}{l}\text { Cumulant Method } \\
\text { Mean value }\end{array}$} & \multicolumn{3}{|c|}{$\begin{array}{l}\text { MCS-2500 samples } \\
\text { Mean value }\end{array}$} & \multicolumn{3}{|c|}{ Error (\%) } \\
\hline & & TD1 & TD2 & TD3 & TD1 & TD2 & TD3 & TD1 & TD2 & TD3 \\
\hline \multirow{7}{*}{$\begin{array}{l}\text { Voltage } \\
\text { (PU) }\end{array}$} & 1 & 0.000 & 0.000 & 0.000 & 0.000 & 0.000 & 0.000 & 0.000 & 0.000 & 0.000 \\
\hline & 2 & 0.001 & 0.001 & 0.001 & 0.001 & 0.001 & 0.001 & 1.644 & 1.596 & 0.239 \\
\hline & 3 & 0.002 & 0.002 & 0.003 & 0.002 & 0.002 & 0.003 & 1.832 & 1.842 & 0.624 \\
\hline & 4 & 0.004 & 0.004 & 0.005 & 0.004 & 0.004 & 0.005 & 1.841 & 1.839 & 0.550 \\
\hline & 5 & 0.005 & 0.005 & 0.007 & 0.005 & 0.005 & 0.007 & 1.948 & 1.964 & 0.676 \\
\hline & 6 & 0.005 & 0.005 & 0.007 & 0.005 & 0.006 & 0.007 & 2.157 & 2.145 & 0.481 \\
\hline & 7 & 0.005 & 0.006 & 0.008 & 0.005 & 0.006 & 0.008 & 2.255 & 2.227 & 0.356 \\
\hline \multirow{7}{*}{$\begin{array}{c}\text { Active } \\
\text { Power } \\
\text { (PU) }\end{array}$} & 1 & 0.000 & 0.000 & 0.000 & 0.000 & 0.000 & 0.000 & 0.000 & 0.000 & 0.000 \\
\hline & 2 & 0.232 & 0.241 & 0.297 & 0.237 & 0.246 & 0.305 & 2.152 & 2.312 & 2.409 \\
\hline & 3 & 0.230 & 0.238 & 0.287 & 0.236 & 0.244 & 0.296 & 2.418 & 2.656 & 3.020 \\
\hline & 4 & 0.229 & 0.235 & 0.278 & 0.235 & 0.242 & 0.286 & 2.394 & 2.592 & 2.863 \\
\hline & 5 & 0.228 & 0.233 & 0.269 & 0.234 & 0.239 & 0.277 & 2.465 & 2.652 & 2.913 \\
\hline & 6 & 0.048 & 0.067 & 0.144 & 0.048 & 0.067 & 0.144 & 0.154 & 0.152 & 0.124 \\
\hline & 7 & 0.033 & 0.046 & 0.098 & 0.033 & 0.046 & 0.098 & 0.286 & 0.286 & 0.286 \\
\hline \multirow{7}{*}{$\begin{array}{c}\text { Reactive } \\
\text { Power } \\
\text { (PU) }\end{array}$} & 1 & 0.000 & 0.000 & 0.000 & 0.000 & 0.000 & 0.000 & 0.000 & 0.000 & 0.000 \\
\hline & 2 & 0.015 & 0.021 & 0.047 & 0.015 & 0.021 & 0.046 & 0.552 & 0.883 & 3.233 \\
\hline & 3 & 0.012 & 0.017 & 0.038 & 0.012 & 0.017 & 0.037 & 1.124 & 0.951 & 0.183 \\
\hline & 4 & 0.010 & 0.014 & 0.030 & 0.010 & 0.014 & 0.031 & 0.613 & 0.865 & 3.143 \\
\hline & 5 & 0.008 & 0.012 & 0.026 & 0.008 & 0.012 & 0.028 & 1.171 & 1.267 & 8.697 \\
\hline & 6 & 0.008 & 0.012 & 0.027 & 0.008 & 0.012 & 0.030 & 1.209 & 1.413 & 9.451 \\
\hline & 7 & 0.024 & 0.034 & 0.072 & 0.024 & 0.034 & 0.074 & 1.549 & 1.466 & 2.690 \\
\hline $\begin{array}{l}\text { Capacitor } \\
\text { Size(PU) }\end{array}$ & 7 & 0.035 & 0.049 & 0.105 & 0.034 & 0.048 & 0.103 & 1.329 & 1.464 & 1.073 \\
\hline
\end{tabular}




\subsection{3-Bus System}

The methodology described in Chapter 3 is tested on the 33-bus, 32-branch test system described in [31]. The system, however, is modified to accommodate two wind generators with a mean capacity equal to $500 \mathrm{~kW}$ each. The single line diagram of the system is depicted on Figure 9. The system load and line data are given in the Appendix A.

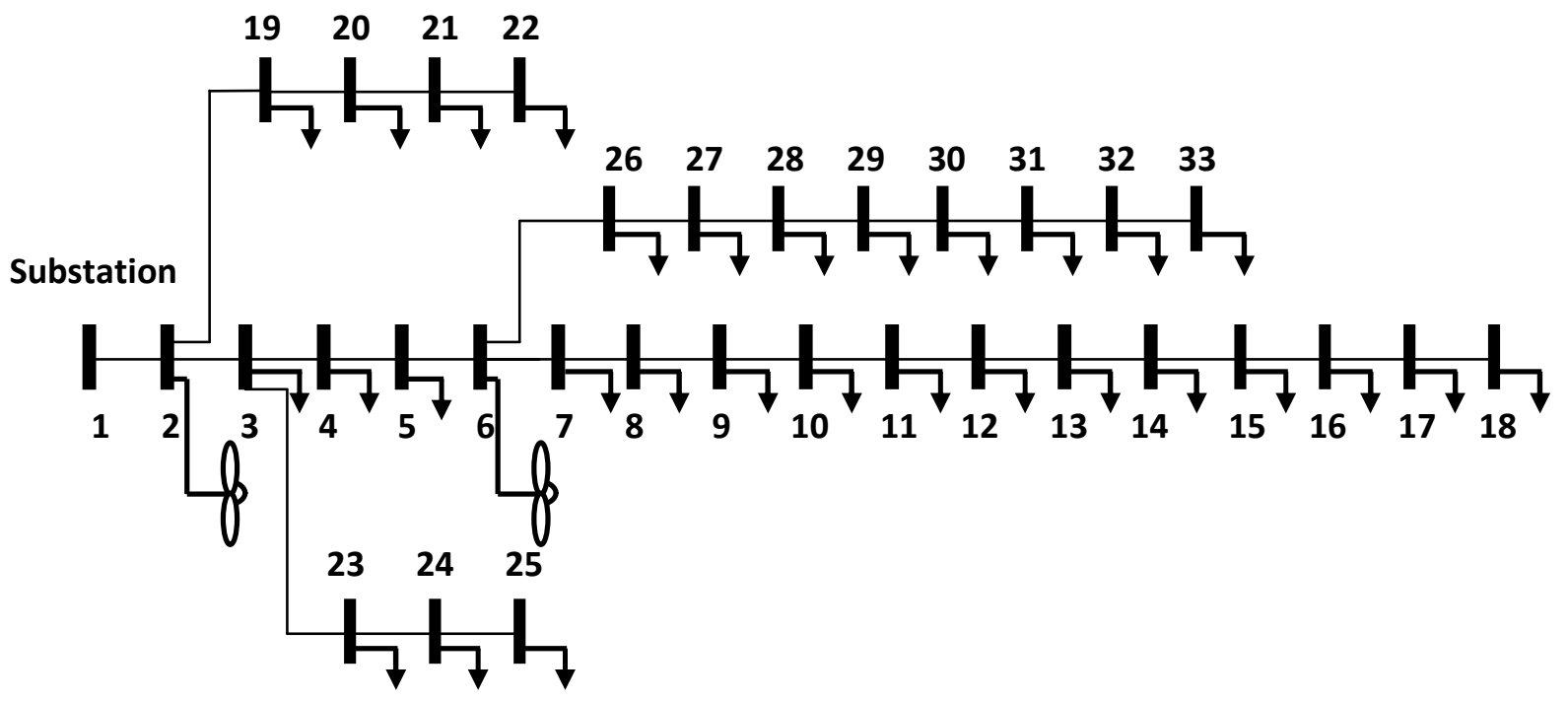

Figure 9 Single line diagram of the 33-bus distribution test system

\subsubsection{Comparison of the results of the cumulant method with those of MCS}

The cumulant solution method is tested on a 33-bus system with two wind generators connected to it. The standard deviations of the loads are equal to $10 \%$ of the nominal bus loading value. The load duration data of the system is same as table 3 . 
Table 8 includes the statistical parameters of the Weibull distribution used to represent the wind generators. Note both wind generators are assumed to be identical.

\section{Table 8 Parameters of the Weibull PDF for the wind generator}

\begin{tabular}{c|c|c|c}
\hline Bus No. & $\begin{array}{c}\text { Mean } \\
\text { Generation }(\mathrm{kW})\end{array}$ & Shape Factor & $\begin{array}{c}\text { Standard Deviation } \\
{[\%]}\end{array}$ \\
\hline 2 and 6 & 500 & 2 & $\begin{array}{c}55 \% \text { of the } \\
\text { Mean }\end{array}$ \\
\hline
\end{tabular}

Figure 10 shows the active power loss sensitivity value of each bus before capacitor allocation at the third time interval. According to this figure, the best candidate bus for capacitor sitting is bus 33. The sensitivity step procedure is carried out again until all conditions are satisfied.

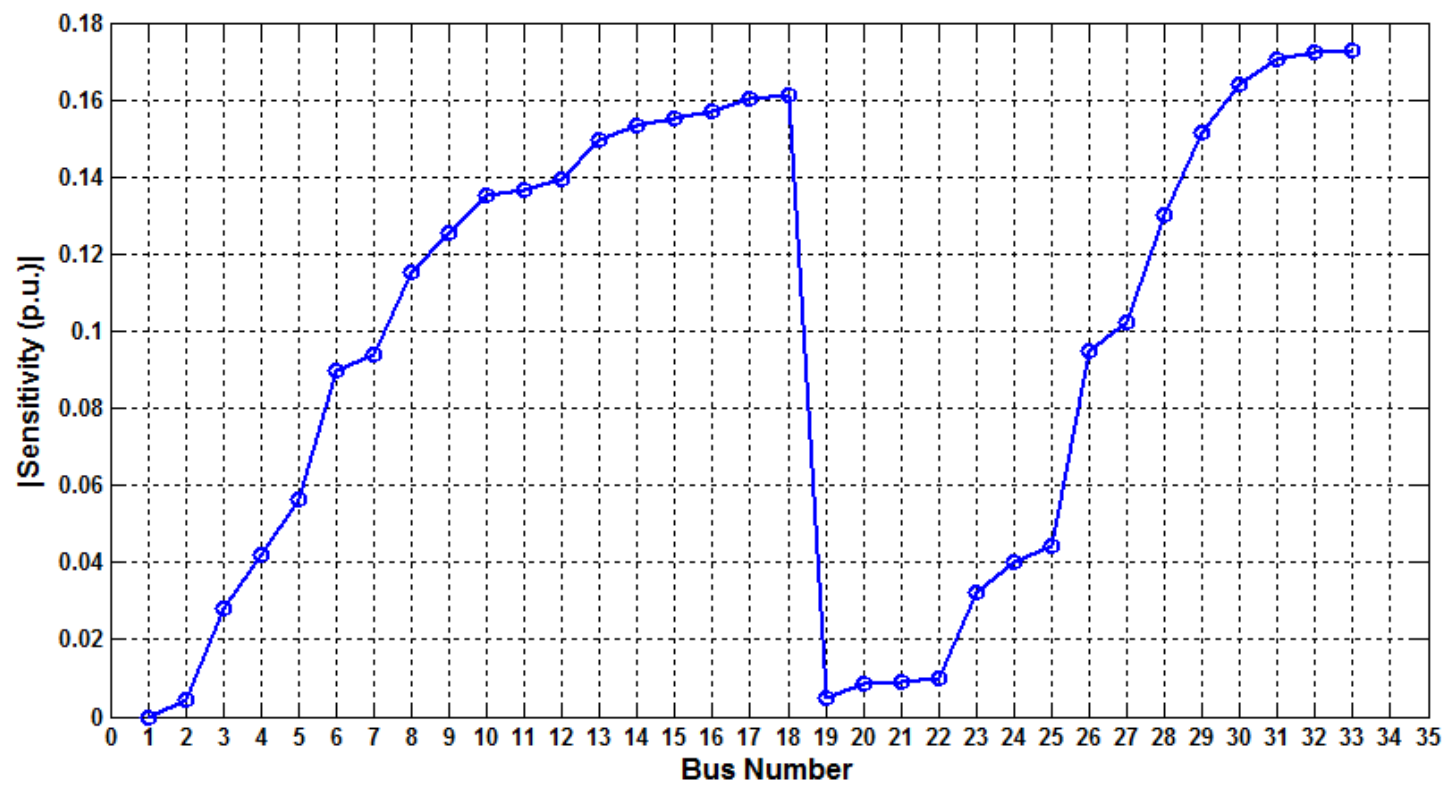

Figure 10 Sensitivity Index Solutions 
The results obtained using the Cumulant method have been compared with those of MCS consisting of 2500 samples. Table 9 presents the probabilistic optimal solutions for the real power loss and the cost of energy loss at each time duration, with and without capacitors as per cumulant method and MCS solutions.

The table also gives the size of capacitors at each candidate bus. A significant decrease in real power loss and consequently in the annual cost of energy loss after capacitor installation can be seen from the table. In addition, the results of the cumulant method are in close agreement with those of MCS. 
Table 9 Optimal solutions and comparison of the two methods

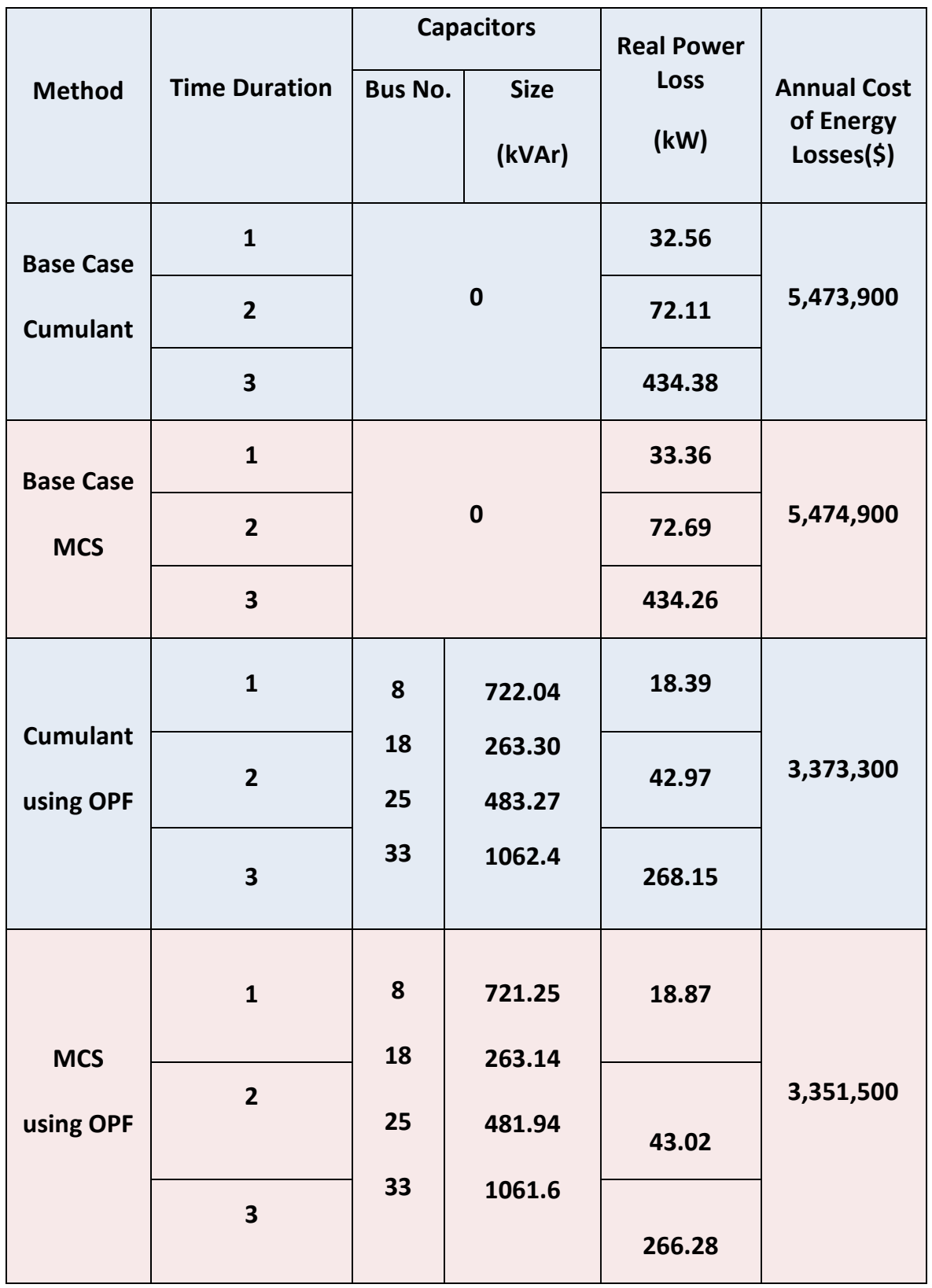


Table 10 represents the probabilistic optimal solutions for the total cost. From this table the mean value of the total cost is 3.6011 million dollars using the cumulant method and 3.5803 million dollars using the MCS. The corresponding percentage error is only $0.57 \%$. The percentage error of Standard deviation, however, is $55.02 \%$. This large error can is due to the same reason to that of the 7-bus system.

\section{Table 10 Total Cost Values}

\begin{tabular}{|c|c|c|c|c|c|}
\hline \multicolumn{2}{|c|}{ Cumulant } & \multicolumn{2}{|c|}{ MCS } & \multirow{2}{*}{$\begin{array}{l}\text { Error } \\
\text { of } \\
\text { Mean } \\
{[\%]}\end{array}$} & \multirow{2}{*}{$\begin{array}{c}\text { Error of } \\
\text { Standard } \\
\text { Deviation } \\
\text { [\%] }\end{array}$} \\
\hline $\begin{array}{l}\text { Mean value of } \\
\text { Total Cost } \\
\text { (millions of \$) }\end{array}$ & $\begin{array}{l}\text { Standard Deviation } \\
\text { of Total Cost } \\
\text { (millions of \$) }\end{array}$ & $\begin{array}{l}\text { Mean value of } \\
\text { Total Cost } \\
\text { (millions of \$) }\end{array}$ & $\begin{array}{l}\text { Standard Deviation } \\
\text { of Total Cost } \\
\text { (millions of \$) }\end{array}$ & & \\
\hline 3.6011 & 0.173 & 3.5803 & 0.386 & 0.57 & 55.02 \\
\hline
\end{tabular}

Figure 11 shows the voltage improvement before and after capacitor planning at TD3. The figure shows that the minimum of voltage before installing any capacitor, i.e. base case, is 0.86 p.u., which is improved to 0.91 p.u. after capacitor planning. 


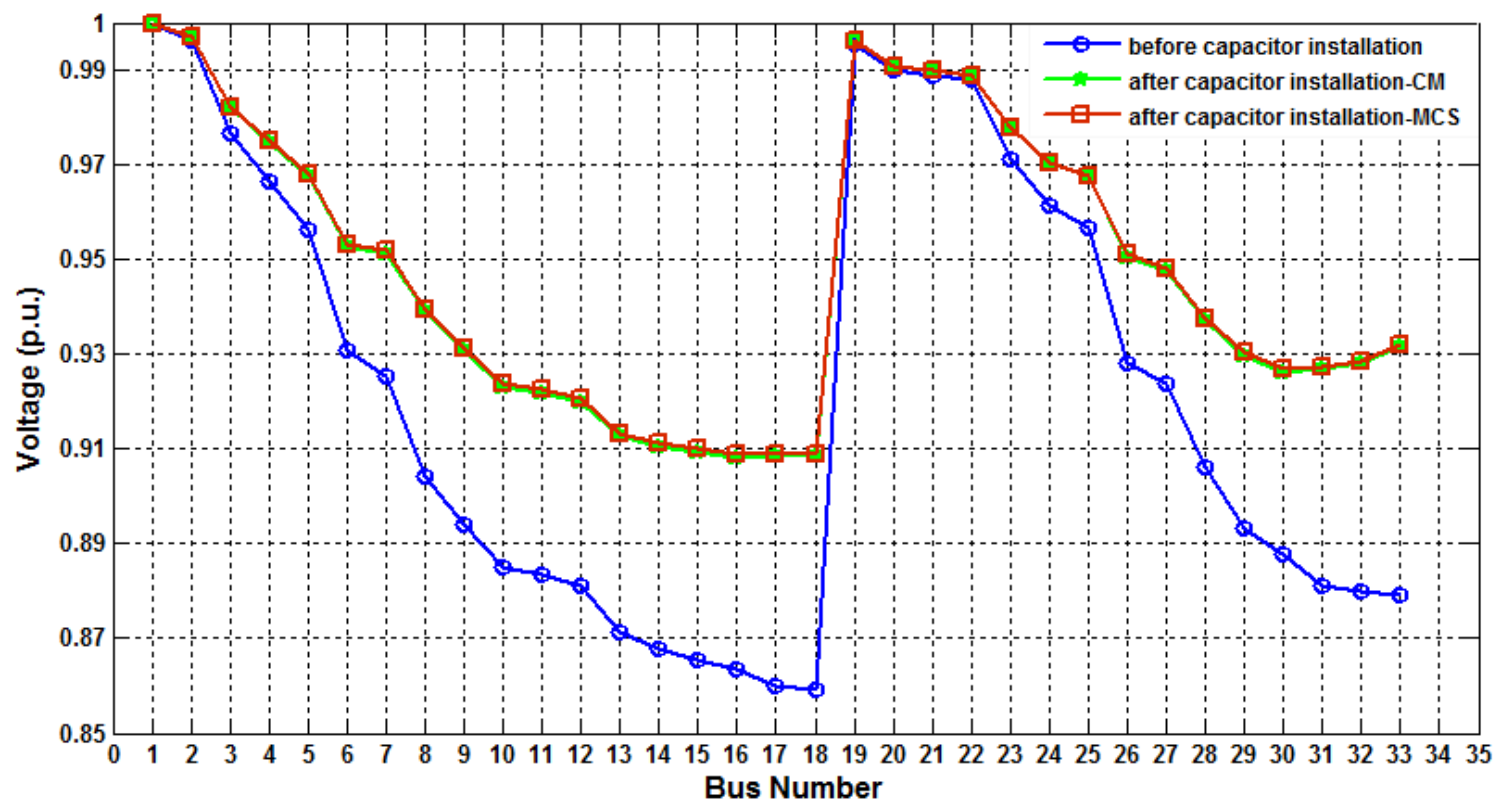

Figure 11 Voltage improvement before and after capacitor installation

Figure 12 and 13 show the reconstructed PDF and CDF of the objective function using Gram-Charlier/Edgeworth Series, respectively. 


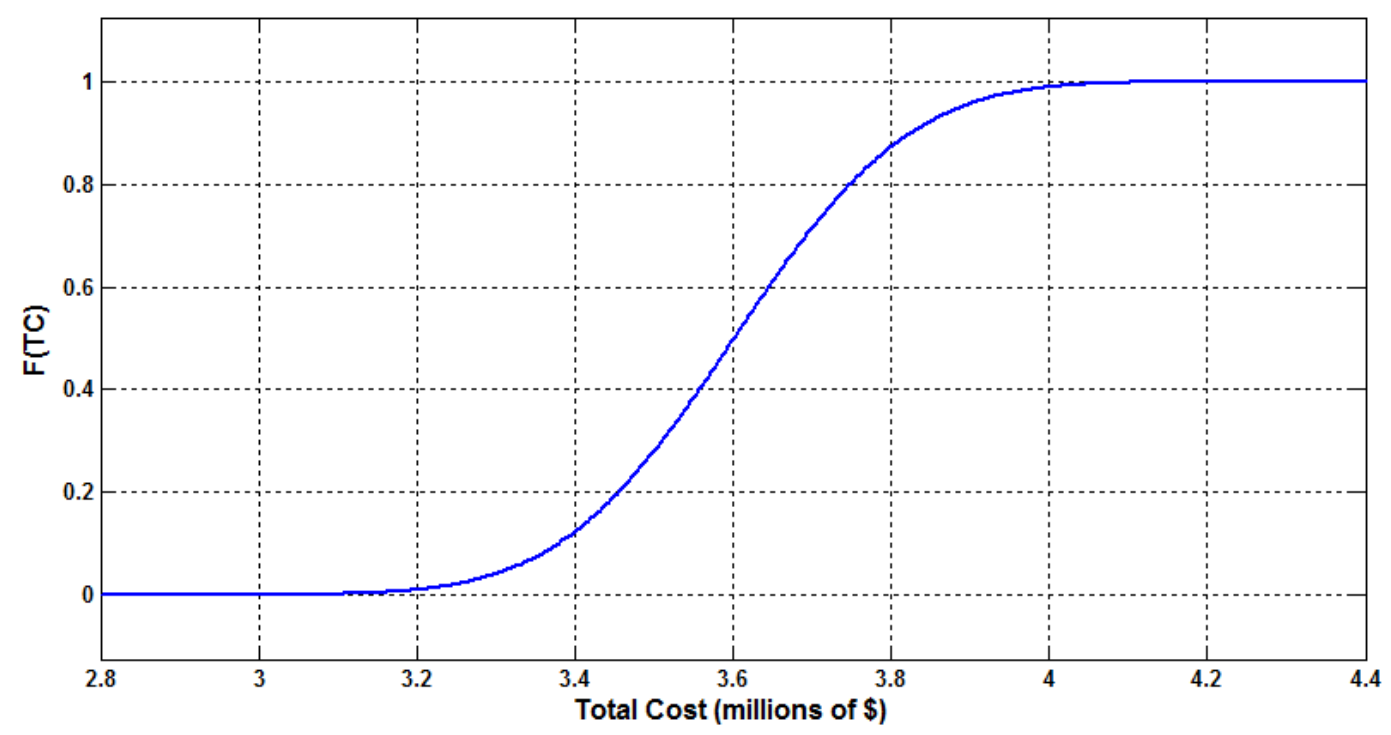

Figure 12 Reconstructed PDF of Total Cost

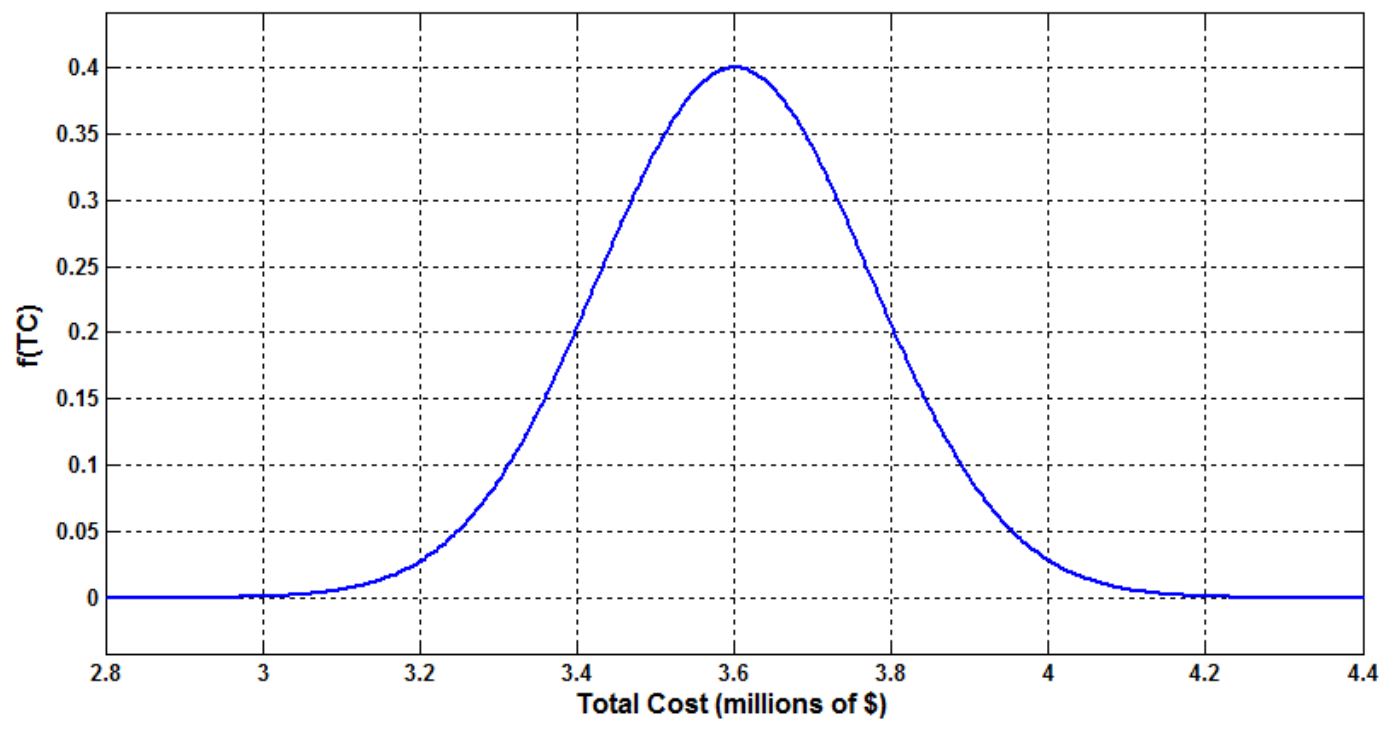

Figure 13 Reconstructed CDF of Total Cost 
The probabilistic optimal results for the system variables, voltage magnitude, active and reactive power flow solutions and the capacitor size in all time durations are detailed in table 23 and table 24 in Appendix B. However, in table 11 and table 12 the maximum corresponding error are given. From table 11 can be seen that the percentage errors of the mean value for the other system variables are all below $9 \%$.

The results presented in table 12 and 24 show that the percentage error of the standard deviation of all variables are below $10 \%$ except the percentage error of the standard deviation of the reactive power at bus 2 . It should be noted that one of the wind generators is connected at this bus without any reactive loads. Consequently, the reactive power injected to this bus has a small variation, which causes a larger error in absolute percentage error in comparison with other buses.

The maximum percentage error for standard deviation of voltage, active and reactive power and capacitor size are $5.37 \%, 13.87 \%, 7.96 \%$ and $4.67 \%$, respectively, which occur at the first time interval for active power and third time interval for other variables. 
Table 11 maximum error of mean values of the system variables

\begin{tabular}{|c|c|c|c|c|c|c|c|c|c|c|}
\hline & \multirow{2}{*}{$\begin{array}{l}\text { Bus } \\
\text { No. }\end{array}$} & \multicolumn{3}{|c|}{$\begin{array}{l}\text { Cumulant Method } \\
\text { Mean value }\end{array}$} & \multicolumn{3}{|c|}{$\begin{array}{l}\text { MCS-2500 samples } \\
\text { Mean value }\end{array}$} & \multicolumn{3}{|c|}{ Error (\%) } \\
\hline & & TD1 & TD2 & TD3 & TD1 & TD2 & TD3 & TD1 & TD2 & TD3 \\
\hline $\begin{array}{l}\text { Voltage } \\
\text { (PU) }\end{array}$ & $\begin{array}{c}16,17, \\
18\end{array}$ & 0.976 & 0.964 & 0.908 & 0.977 & 0.964 & 0.909 & 0.05 & 0.052 & 0.062 \\
\hline $\begin{array}{c}\text { Active } \\
\text { Power(PU) }\end{array}$ & 2 & 0.776 & 1.502 & 4.528 & 0.713 & 1.439 & 4.462 & 8.827 & 4.421 & 1.49 \\
\hline $\begin{array}{c}\text { Reactive } \\
\text { Power(PU) }\end{array}$ & 14 & -0.001 & -0.002 & -0.006 & -0.001 & -0.002 & -0.006 & 4.415 & 4.05 & 3.06 \\
\hline $\begin{array}{l}\text { Capacitor } \\
\text { Size(PU) }\end{array}$ & 25 & 0.209 & 0.294 & 0.483 & 0.209 & 0.294 & 0.482 & 0.14 & 0.164 & 0.276 \\
\hline
\end{tabular}

Table 12 maximum error of standard deviation values of the system variables

\begin{tabular}{|c|c|c|c|c|c|c|c|c|c|c|}
\hline & \multirow{2}{*}{$\begin{array}{l}\text { Bus } \\
\text { No. }\end{array}$} & \multicolumn{3}{|c|}{$\begin{array}{l}\text { Cumulant Method } \\
\text { SD value }\end{array}$} & \multicolumn{3}{|c|}{$\begin{array}{l}\text { MCS-2500 samples } \\
\text { SD value }\end{array}$} & \multicolumn{3}{|c|}{ Error (\%) } \\
\hline & & TD1 & TD2 & TD3 & TD1 & TD2 & TD3 & TD1 & TD2 & TD3 \\
\hline $\begin{array}{l}\text { Voltage } \\
\text { (PU) }\end{array}$ & 18 & 0.0039 & 0.0041 & 0.0051 & 0.0038 & 0.0039 & 0.0048 & 2.6264 & 2.8657 & 5.3733 \\
\hline $\begin{array}{c}\text { Active } \\
\text { Power(PU) }\end{array}$ & 31 & 0.0132 & 0.0185 & 0.0398 & 0.0129 & 0.0181 & 0.0389 & 2.2412 & 2.2385 & 2.2184 \\
\hline $\begin{array}{c}\text { Reactive } \\
\text { Power(PU) }\end{array}$ & 2 & 0.0071 & 0.0101 & 0.0242 & 0.0069 & 0.0097 & 0.0212 & 2.6173 & 4.0918 & 13.877 \\
\hline $\begin{array}{l}\text { Capacitor } \\
\text { Size(PU) }\end{array}$ & 8 & 0.0079 & 0.0111 & 0.0243 & 0.0078 & 0.0111 & 0.0255 & 0.3101 & 0.1816 & 4.6717 \\
\hline
\end{tabular}


The PDFs of all system variables are reconstructed from their cumulants using Gram Charlier/ Edgeworth series. Figures 14, 15 and 16 show the reconstructed PDFs of the voltage, nodal real power and capacitor size at bus 8 in the first time interval and compare it with those of MCS. In order to illustrate the PDF of capacitor size, bus 8 is selected randomly from other candidate buses. From these figures it can be seen that the PDFs have a non-Gaussian behaviour. That can be seen more clearly in Figure 15, which illustrates the nodal real power at this bus.

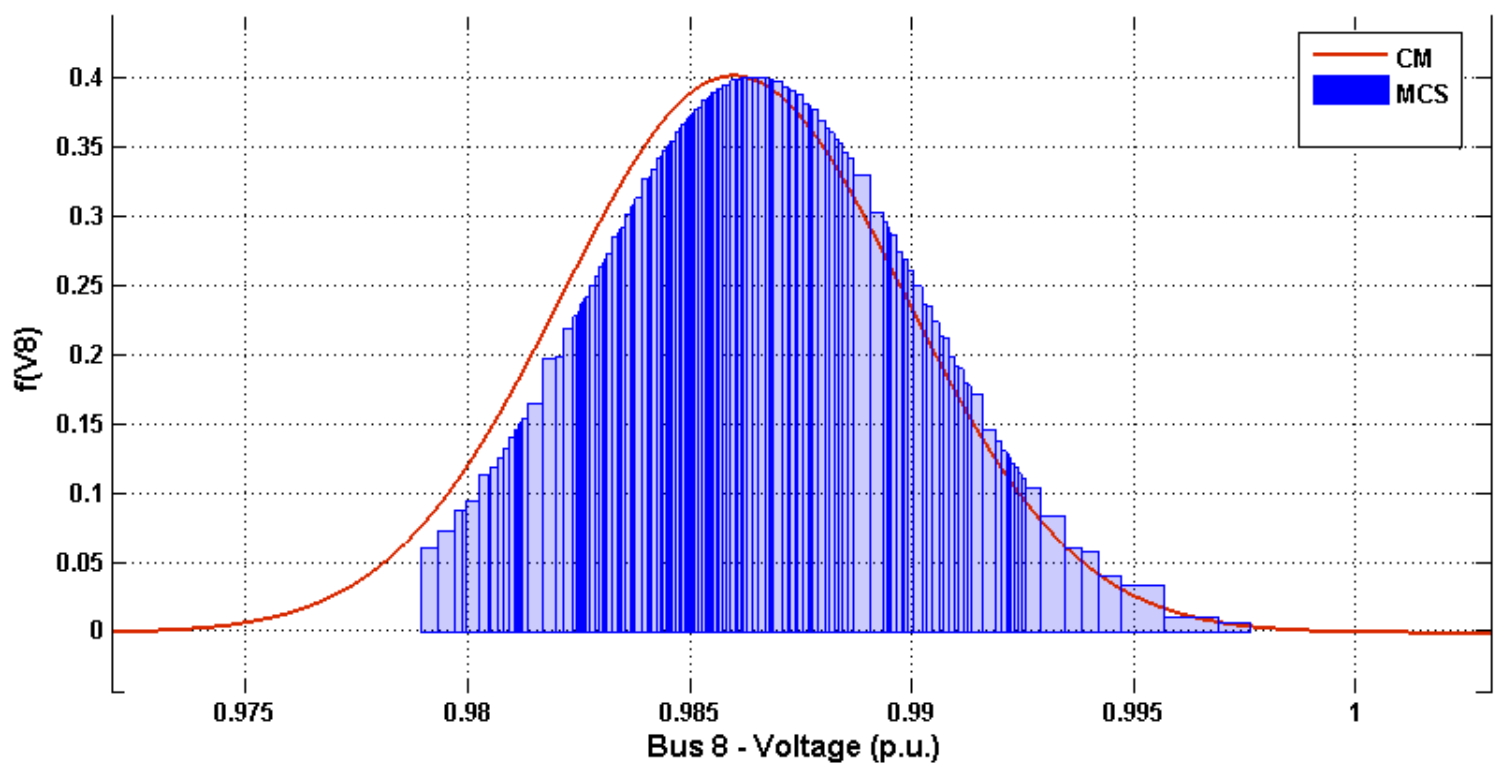

Figure 14 PDF of Voltage at Bus 8 reconstructed by Gram-Charlier/Edgeworth 


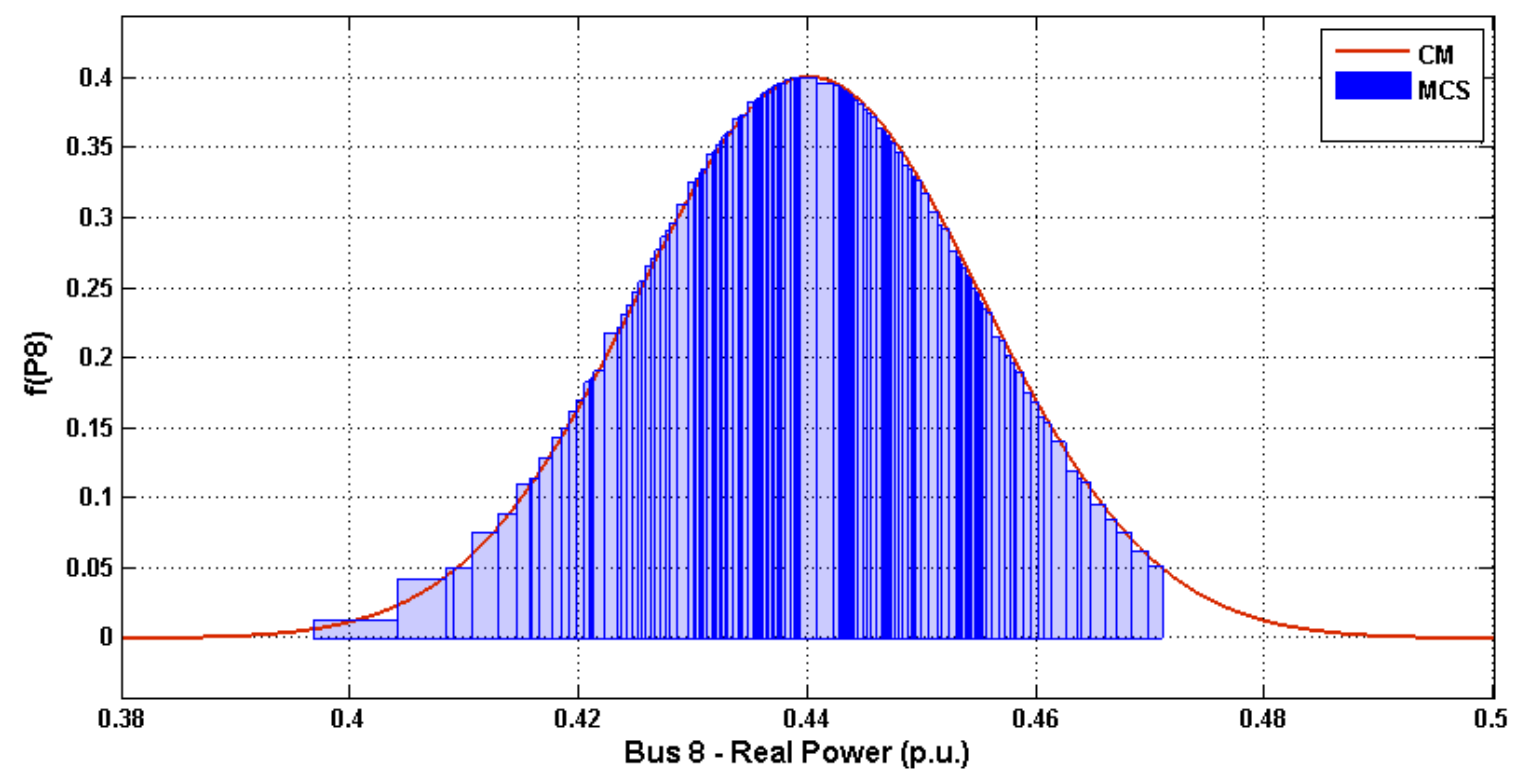

Figure 15 PDF of real Power at Bus 8 reconstructed by Gram-Charlier/Edgeworth

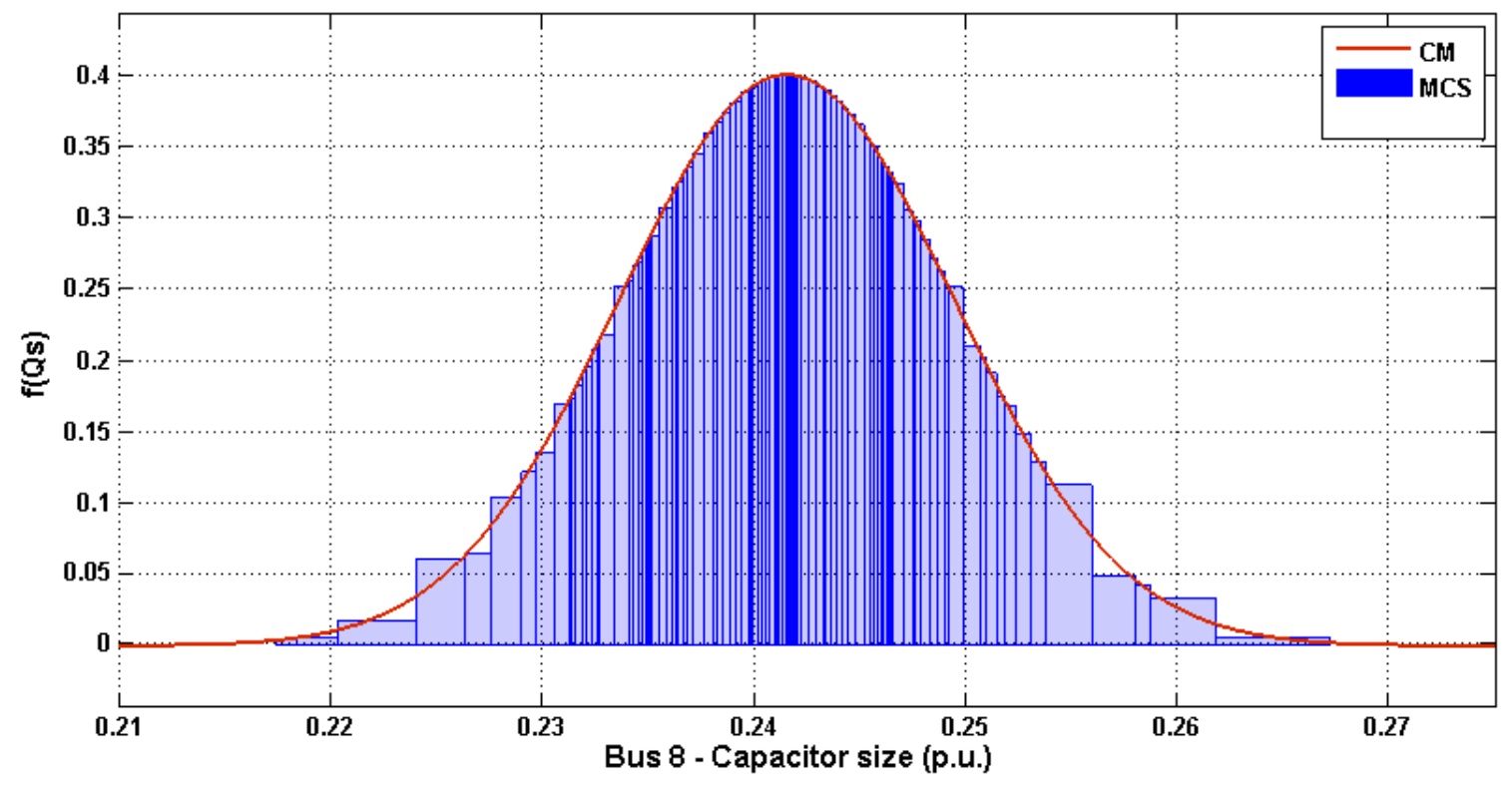

Figure 16 PDF of capacitor size at Bus 8 reconstructed by Gram-Charlier/Edgeworth 
To explain the non-Guassian behaviour of the system random variables at this bus, one may note that one of the WGs is connected at bus 6 and since the WGs were modeled as Weibull distributions, the probabilistic behaviour of the systems variables in the buses nearby have a tendency to behave more like a Weibull distribution. The small difference between PDFs of cumulant and MCS in Figure 14 is due to the small error between the standard deviation values obtained from both methods.

These results clearly imply that the cumulant method provides results acceptably close to those obtained from MCS. Therefore, the method has been validated. The cumulant method brings the advantage of computational speed and analytical soundness, as opposed to the exhaustive nature of MCS.

Next chapter presents the main conclusions of this research work. 


\section{CHAPTER 5 Conclusions}

This thesis studied a new probabilistic formulation for the optimal capacitor planning problem in distribution systems with high penetration of wind generators. The probabilistic components of the systems are loads and wind generators which were modeled as Gaussian and Weibull distributions, respectively. The different orders of their cumulants were obtained from their PDFs. To find the best locations to site the capacitor banks, a selection procedure was formulated to identify the buses with highest active power loss sensitivity with respect to the reactive power injection. By selecting the candidate buses beforehand, this task greatly reduces the complexity and variable size of the optimization problem. Once the best locations are determined, the power system is formulated as an optimization problem and solved by using the LBIPM. This solution delivers the Hessian matrix, which is inverted to provide a linear mapping from the cumulants of the system loadings and WGs to those of the unknown system variables (voltage, reactive and active powers).

The method was implemented and tested on a 7-bus and on a 33-bus system. Once the cumulants of all unknown system variables are obtained, their PDFs as well as the objective function were reconstructed using the Gram Charlier/ Edgeworth series. 
In order to illustrate the efficiency and accuracy of the cumulant method, the results obtained using the cumulant method were compared with those of MCS with 2500 samples. The errors were found to be acceptable. The proposed probabilistic algorithm has much less computational burden and complexity, making it very practical and advantageous. Moreover, the PDFs provided by the proposed solution offer great insight to power system planners when finding the most cost effective solutions for capacitor allocation in distribution systems. 


\section{Appendix A}

\section{TEST SYSTEMS DATA}

\section{7-Bus System Data}

Table 13 Voltage data: 7-bus RDS

\begin{tabular}{|c|c|c|}
\hline $\begin{array}{c}\text { Slack Bus Voltage } \\
\text { (p.u.) }\end{array}$ & $\begin{array}{c}\text { Maximum Voltage Limit } \\
\text { (p.u.) }\end{array}$ & $\begin{array}{c}\text { Minimum Voltage Limit } \\
\text { (p.u.) }\end{array}$ \\
\hline 1.00 & 1.10 & 0.9 \\
\hline
\end{tabular}

Table 14 Feeder data: 7-bus RDS

\begin{tabular}{|c|c|c|c|}
\hline $\begin{array}{c}\text { PG } \\
(\mathrm{MW})\end{array}$ & $\begin{array}{c}\text { QG } \\
\text { (Mvar) }\end{array}$ & $\begin{array}{c}\text { QGMAX } \\
\text { (Mvar) }\end{array}$ & $\begin{array}{c}\text { QGMIN } \\
\text { (Mvar) }\end{array}$ \\
\hline 1.00 & 1.10 & 1000 & -1000 \\
\hline
\end{tabular}

Table 15 Shunt capacitor limits: 7-bus RDS

\begin{tabular}{|c|c|c|}
\hline $\begin{array}{c}\text { QSMAX } \\
\text { (Mvar) }\end{array}$ & $\begin{array}{c}\text { QSMIN } \\
\text { (Mvar) }\end{array}$ & $\begin{array}{c}\text { QSSTP } \\
\text { (Mvar) }\end{array}$ \\
\hline 2 & 0 & 1.00 \\
\hline
\end{tabular}


Table 16 Mean values and standard deviation of the loads

\begin{tabular}{|c|c|c|c|}
\hline \multirow{2}{*}{ Bus Number } & \multicolumn{2}{|c|}{ Mean } & \multirow{2}{*}{$\begin{array}{c}\text { Standard } \\
\text { Deviation [\%] }\end{array}$} \\
\cline { 2 - 3 } & $\begin{array}{c}\text { Real Power } \\
(\mathrm{kW})\end{array}$ & $\begin{array}{c}\text { Reactive } \\
\text { Power (kW) }\end{array}$ & \\
\hline 1 & 0 & 0 & 10 \\
\hline 2 & 0.2465 & 0.197 & 10 \\
\hline 3 & 0.2209 & 0.206 & 10 \\
\hline 4 & 0.232 & 0.286 & 10 \\
\hline 5 & 0 & 0 & 10 \\
\hline 6 & 0.701 & 0.542 & 10 \\
\hline 7 & 0.65 & 0.503 & 10 \\
\hline
\end{tabular}

Table 17 Line data 7-bus RDS

\begin{tabular}{|c|c|c|c|c|c|}
\hline From Bus & To Bus & $R(\Omega)$ & $X(\Omega)$ & $\begin{array}{c}\text { Rating } \\
(\text { MVA })\end{array}$ & $\begin{array}{c}\text { System } \\
\text { Voltage } \\
(\mathrm{kV})\end{array}$ \\
\hline 1 & 2 & 0.7314 & 0.7158 & 100 & 12.66 \\
\hline 2 & 3 & 0.8411 & 0.8231 & 100 & 12.66 \\
\hline 3 & 4 & 0.8411 & 0.8231 & 100 & 12.66 \\
\hline 4 & 5 & 1.0605 & 1.0379 & 100 & 12.66 \\
\hline 5 & 6 & 1.197 & 0.808 & 100 & 12.66 \\
\hline 6 & 7 & 0.8542 & 0.5766 & 100 & 12.66 \\
\hline
\end{tabular}




\section{3-Bus System Data}

Table 18 Voltage data: 33-bus RDS

\begin{tabular}{|c|c|c|}
\hline $\begin{array}{c}\text { Slack Bus Voltage } \\
\text { (p.u.) }\end{array}$ & $\begin{array}{c}\text { Maximum Voltage Limit } \\
\text { (p.u.) }\end{array}$ & $\begin{array}{c}\text { Maximum Voltage Limit } \\
\text { (p.u.) }\end{array}$ \\
\hline 1.00 & 1.10 & 0.9 \\
\hline
\end{tabular}

Table 19 Feeder data: 33-bus RDS

\begin{tabular}{|c|c|c|c|}
\hline $\begin{array}{c}\text { PG } \\
(\mathrm{MW})\end{array}$ & $\begin{array}{c}\text { QG } \\
\text { (Mvar) }\end{array}$ & $\begin{array}{c}\text { QGMAX } \\
\text { (Mvar) }\end{array}$ & $\begin{array}{c}\text { QGMIN } \\
\text { (Mvar) }\end{array}$ \\
\hline 1.00 & 1.10 & 1000 & -1000 \\
\hline
\end{tabular}

Table 20 Shunt capacitor limits: 33-bus RDS

\begin{tabular}{|c|c|c|}
\hline $\begin{array}{c}\text { QSMAX } \\
\text { (Mvar) }\end{array}$ & $\begin{array}{c}\text { QSMIN } \\
\text { (Mvar) }\end{array}$ & $\begin{array}{c}\text { QSSTP } \\
\text { (Mvar) }\end{array}$ \\
\hline 100 & 0 & 1.00 \\
\hline
\end{tabular}


Table 21 Mean values and standard deviation of the loads

\begin{tabular}{|c|c|c|c|}
\hline \multirow[b]{2}{*}{ Bus Number } & \multicolumn{2}{|c|}{ Mean } & \multirow[b]{2}{*}{$\begin{array}{c}\text { Standard } \\
\text { Deviation [\%] }\end{array}$} \\
\hline & $\begin{array}{c}\text { Real Power } \\
\text { (kW) }\end{array}$ & $\begin{array}{c}\text { Reactive } \\
\text { Power (kW) }\end{array}$ & \\
\hline 1 & 0 & 0 & 10 \\
\hline 2 & 0 & 0 & 10 \\
\hline 3 & 0.09 & 0.04 & 10 \\
\hline 4 & 0.12 & 0.08 & 10 \\
\hline 5 & 0.06 & 0.03 & 10 \\
\hline 6 & 0 & 0 & 10 \\
\hline 7 & 0.2 & 0.1 & 10 \\
\hline 8 & 0.2 & 0.1 & 10 \\
\hline 9 & 0.06 & 0.02 & 10 \\
\hline 10 & 0.06 & 0.02 & 10 \\
\hline 11 & 0.045 & 0.03 & 10 \\
\hline 12 & 0.06 & 0.035 & 10 \\
\hline 13 & 0.06 & 0.035 & 10 \\
\hline 14 & 0.12 & 0.08 & 10 \\
\hline 15 & 0.06 & 0.01 & 10 \\
\hline 16 & 0.06 & 0.02 & 10 \\
\hline 17 & 0.06 & 0.02 & 10 \\
\hline 18 & 0.09 & 0.04 & 10 \\
\hline 19 & 0.09 & 0.04 & 10 \\
\hline 20 & 0.09 & 0.04 & 10 \\
\hline 21 & 0.09 & 0.04 & 10 \\
\hline 22 & 0.09 & 0.04 & 10 \\
\hline 23 & 0.09 & 0.05 & 10 \\
\hline 24 & 0.4 & 0.2 & 10 \\
\hline
\end{tabular}


Appendices

\begin{tabular}{|c|c|c|c|}
\hline 25 & 0.4 & 0.2 & 10 \\
\hline 26 & 0.06 & 0.025 & 10 \\
\hline 27 & 0.06 & 0.025 & 10 \\
\hline 28 & 0.06 & 0.02 & 10 \\
\hline 29 & 0.12 & 0.07 & 10 \\
\hline 30 & 0.2 & 0.6 & 10 \\
\hline 31 & 0.15 & 0.07 & 10 \\
\hline 32 & 0.21 & 0.1 & 10 \\
\hline 33 & 0.06 & 0.04 & 10 \\
\hline
\end{tabular}

Table 22 Line data 33-bus RDS

\begin{tabular}{|c|c|c|c|c|c|}
\hline From Bus & To Bus & $\mathbf{R}(\mathbf{\Omega})$ & $\mathbf{X}(\Omega)$ & $\begin{array}{l}\text { Rating } \\
\text { (MVA) }\end{array}$ & $\begin{array}{c}\text { System } \\
\text { Voltage } \\
\text { (kV) }\end{array}$ \\
\hline 1 & 2 & 0.0922 & 0.047 & 100 & 12.66 \\
\hline 2 & 3 & 0.493 & 0.2511 & 100 & 12.66 \\
\hline 3 & 4 & 0.3662 & 0.1864 & 100 & 12.66 \\
\hline 4 & 5 & 0.3811 & 0.1941 & 100 & 12.66 \\
\hline 5 & 6 & 0.819 & 0.707 & 100 & 12.66 \\
\hline 6 & 7 & 0.1872 & 0.6188 & 100 & 12.66 \\
\hline 7 & 8 & 1.7114 & 1.2351 & 100 & 12.66 \\
\hline 8 & 9 & 1.03 & 0.74 & 100 & 12.66 \\
\hline 9 & 10 & 1.044 & 0.74 & 100 & 12.66 \\
\hline 10 & 11 & 0.1966 & 0.065 & 100 & 12.66 \\
\hline 11 & 12 & 0.3744 & 0.1238 & 100 & 12.66 \\
\hline 12 & 13 & 1.468 & 1.155 & 100 & 12.66 \\
\hline 13 & 14 & 0.5416 & 0.7129 & 100 & 12.66 \\
\hline 14 & 15 & 0.591 & 0.526 & 100 & 12.66 \\
\hline 15 & 16 & 0.7463 & 0.545 & 100 & 12.66 \\
\hline 16 & 17 & 1.289 & 1.721 & 100 & 12.66 \\
\hline 17 & 18 & 0.732 & 0.574 & 100 & 12.66 \\
\hline 2 & 19 & 0.164 & 0.1565 & 100 & 12.66 \\
\hline 19 & 20 & 1.5042 & 1.3554 & 100 & 12.66 \\
\hline
\end{tabular}


Appendices

\begin{tabular}{|c|c|c|c|c|c|}
\hline 20 & 21 & 0.4095 & 0.4784 & 100 & 12.66 \\
\hline 21 & 22 & 0.7089 & 0.9373 & 100 & 12.66 \\
\hline 3 & 23 & 0.4512 & 0.3083 & 100 & 12.66 \\
\hline 23 & 24 & 0.898 & 0.7091 & 100 & 12.66 \\
\hline 24 & 25 & 0.896 & 0.7011 & 100 & 12.66 \\
\hline 6 & 26 & 0.203 & 0.1034 & 100 & 12.66 \\
\hline 26 & 27 & 0.2842 & 0.1447 & 100 & 12.66 \\
\hline 27 & 28 & 1.059 & 0.9337 & 100 & 12.66 \\
\hline 28 & 29 & 0.8042 & 0.7006 & 100 & 12.66 \\
\hline 29 & 30 & 0.5075 & 0.2585 & 100 & 12.66 \\
\hline 30 & 31 & 0.9744 & 0.963 & 100 & 12.66 \\
\hline 31 & 32 & 0.3105 & 0.3619 & 100 & 12.66 \\
\hline 32 & 33 & 0.341 & 0.5302 & 100 & 12.66 \\
\hline
\end{tabular}




\section{APPENDIX B}

\section{RESULT COMPARISON OF THE 33-BUS SYSTEM}

Table 23 Mean values of the system variables

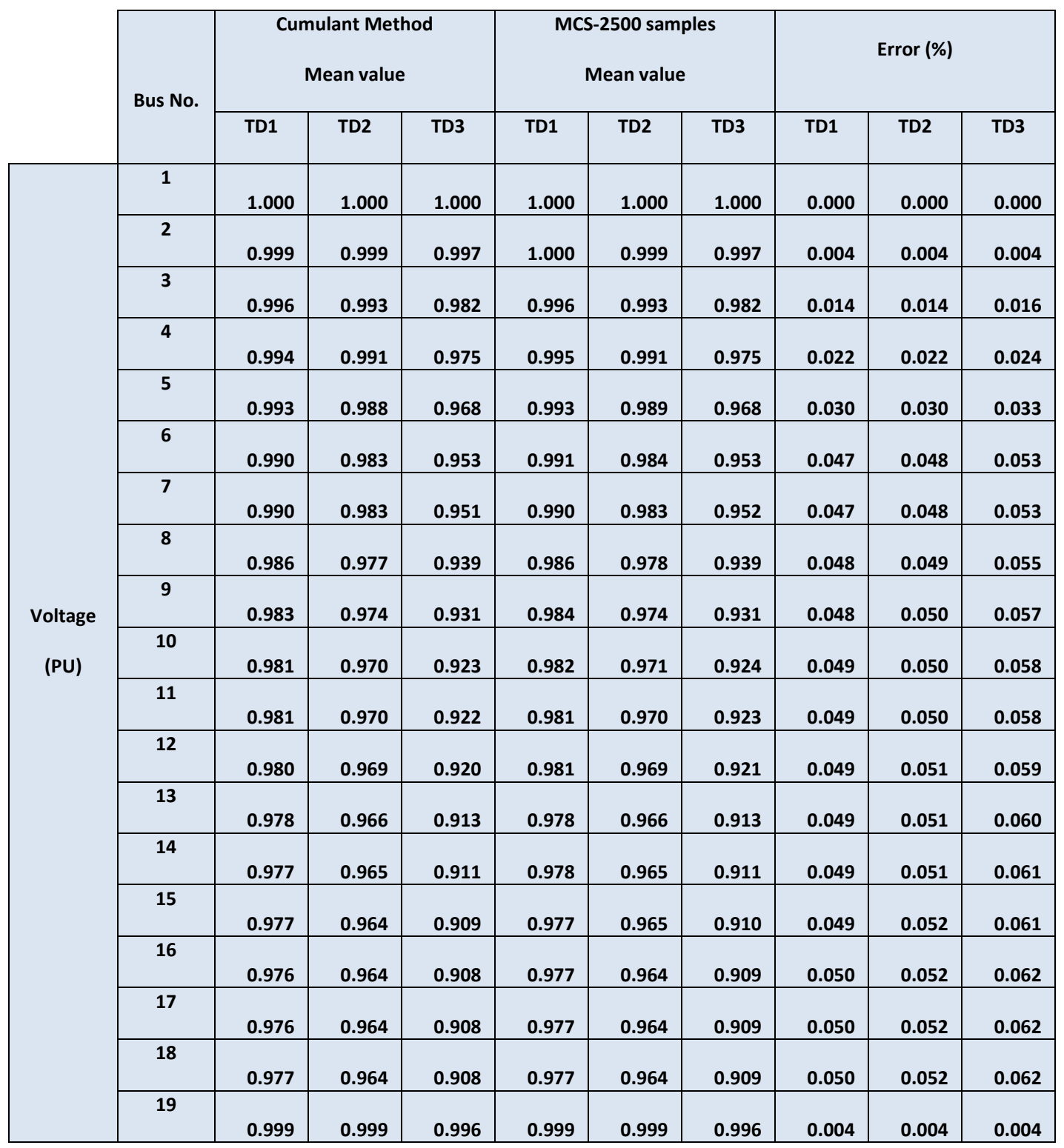


Appendices

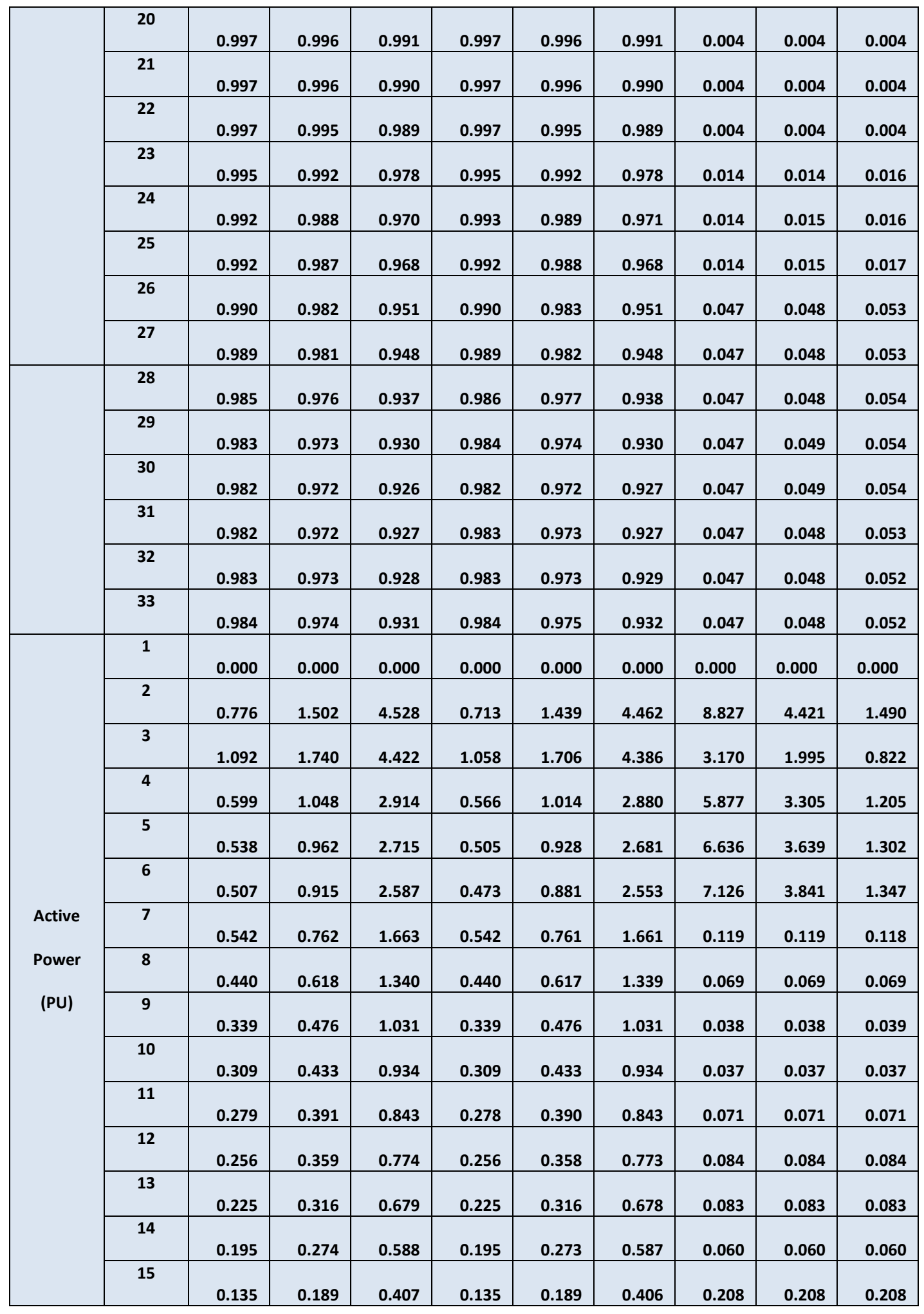


Appendices

\begin{tabular}{|c|c|c|c|c|c|c|c|c|c|c|}
\hline & 16 & 0.105 & 0.147 & 0.316 & 0.105 & 0.147 & 0.315 & 0.268 & 0.268 & 0.267 \\
\hline & 17 & 0.075 & 0.105 & 0.225 & 0.075 & 0.105 & 0.225 & 0.206 & 0.205 & 0.205 \\
\hline & 18 & 0.045 & 0.063 & 0.135 & 0.045 & 0.063 & 0.135 & 0.349 & 0.349 & 0.349 \\
\hline & 19 & 0.180 & 0.252 & 0.542 & 0.180 & 0.252 & 0.542 & 0.098 & 0.098 & 0.097 \\
\hline & 20 & 0.135 & 0.189 & 0.405 & 0.135 & 0.189 & 0.405 & 0.074 & 0.074 & 0.074 \\
\hline & 21 & 0.090 & 0.126 & 0.270 & 0.090 & 0.126 & 0.270 & 0.177 & 0.177 & 0.176 \\
\hline & 22 & 0.045 & 0.063 & 0.135 & 0.045 & 0.063 & 0.135 & 0.314 & 0.314 & 0.314 \\
\hline & 23 & 0.446 & 0.625 & 1.346 & 0.446 & 0.625 & 1.345 & 0.057 & 0.056 & 0.054 \\
\hline & 24 & 0.400 & 0.561 & 1.202 & 0.400 & 0.560 & 1.202 & 0.068 & 0.068 & 0.067 \\
\hline & 25 & 0.200 & 0.280 & 0.600 & 0.200 & 0.280 & 0.599 & 0.092 & 0.092 & 0.092 \\
\hline & 26 & 0.464 & 0.652 & 1.418 & 0.464 & 0.652 & 1.419 & 0.058 & 0.059 & 0.064 \\
\hline & 27 & 0.433 & 0.609 & 1.324 & 0.434 & 0.609 & 1.325 & 0.066 & 0.067 & 0.072 \\
\hline & 28 & 0.402 & 0.564 & 1.222 & 0.403 & 0.565 & 1.223 & 0.085 & 0.086 & 0.090 \\
\hline & 29 & 0.371 & 0.521 & 1.125 & 0.372 & 0.522 & 1.126 & 0.111 & 0.111 & 0.114 \\
\hline & 30 & 0.311 & 0.436 & 0.941 & 0.311 & 0.437 & 0.942 & 0.079 & 0.079 & 0.082 \\
\hline & 31 & 0.210 & 0.295 & 0.634 & 0.211 & 0.295 & 0.635 & 0.159 & 0.159 & 0.160 \\
\hline & 32 & 0.135 & 0.190 & 0.407 & 0.135 & 0.190 & 0.408 & 0.059 & 0.059 & 0.059 \\
\hline & 33 & 0.030 & 0.042 & 0.090 & 0.030 & 0.042 & 0.090 & 0.123 & 0.123 & 0.123 \\
\hline \multirow{11}{*}{$\begin{array}{l}\text { Reactive } \\
\text { Power } \\
\text { (PU) }\end{array}$} & 1 & 0.000 & 0.000 & 0.000 & 0.000 & 0.000 & 0.000 & 0.000 & 0.000 & 0.000 \\
\hline & 2 & 0.228 & 0.320 & 0.984 & 0.228 & 0.320 & 0.983 & 0.022 & 0.045 & 0.035 \\
\hline & 3 & 0.146 & 0.203 & 0.709 & 0.145 & 0.202 & 0.708 & 0.120 & 0.123 & 0.049 \\
\hline & 4 & 0.108 & 0.150 & 0.434 & 0.107 & 0.150 & 0.433 & 0.174 & 0.196 & 0.140 \\
\hline & 5 & 0.067 & 0.093 & 0.304 & 0.067 & 0.093 & 0.304 & 0.216 & 0.196 & 0.066 \\
\hline & 6 & 0.051 & 0.068 & 0.226 & 0.051 & 0.068 & 0.227 & 0.681 & 0.398 & 0.095 \\
\hline & 7 & -0.069 & -0.102 & -0.183 & -0.070 & -0.102 & -0.183 & 0.228 & 0.069 & 0.227 \\
\hline & 8 & -0.121 & -0.175 & -0.350 & -0.121 & -0.175 & -0.350 & 0.062 & 0.027 & 0.194 \\
\hline & 9 & 0.070 & 0.098 & 0.216 & 0.070 & 0.098 & 0.216 & 0.070 & 0.070 & 0.073 \\
\hline & 10 & 0.059 & 0.083 & 0.181 & 0.059 & 0.083 & 0.181 & 0.046 & 0.047 & 0.051 \\
\hline & 11 & 0.049 & 0.069 & 0.151 & 0.049 & 0.069 & 0.151 & 0.062 & 0.063 & 0.067 \\
\hline
\end{tabular}


Appendices

\begin{tabular}{|c|c|c|c|c|c|c|c|c|c|c|}
\hline & 12 & 0.034 & 0.048 & 0.105 & 0.034 & 0.048 & 0.105 & 0.160 & 0.161 & 0.166 \\
\hline & 13 & 0.016 & 0.023 & 0.049 & 0.016 & 0.023 & 0.048 & 0.202 & 0.206 & 0.220 \\
\hline & 14 & -0.001 & -0.002 & -0.006 & -0.001 & -0.002 & -0.006 & 4.415 & 4.050 & 3.060 \\
\hline & 15 & -0.041 & -0.058 & -0.126 & -0.041 & -0.058 & -0.126 & 0.132 & 0.131 & 0.124 \\
\hline & 16 & -0.046 & -0.065 & -0.142 & -0.046 & -0.065 & -0.142 & 0.108 & 0.107 & 0.101 \\
\hline & 17 & -0.056 & -0.079 & -0.173 & -0.056 & -0.079 & -0.173 & 0.085 & 0.084 & 0.079 \\
\hline & 18 & -0.066 & -0.093 & -0.203 & -0.066 & -0.093 & -0.203 & 0.095 & 0.094 & 0.090 \\
\hline & 19 & 0.080 & 0.112 & 0.242 & 0.080 & 0.113 & 0.242 & 0.143 & 0.143 & 0.144 \\
\hline & 20 & 0.060 & 0.084 & 0.180 & 0.060 & 0.084 & 0.181 & 0.129 & 0.129 & 0.129 \\
\hline & 21 & 0.040 & 0.056 & 0.120 & 0.040 & 0.056 & 0.120 & 0.301 & 0.301 & 0.301 \\
\hline & 22 & 0.020 & 0.028 & 0.060 & 0.020 & 0.028 & 0.060 & 0.392 & 0.392 & 0.392 \\
\hline & 23 & 0.017 & 0.023 & 0.200 & 0.017 & 0.023 & 0.201 & 0.109 & 0.224 & 0.212 \\
\hline & 24 & -0.009 & -0.014 & 0.119 & -0.009 & -0.014 & 0.119 & 0.834 & 0.183 & 0.209 \\
\hline & 25 & -0.109 & -0.154 & -0.183 & -0.109 & -0.154 & -0.183 & 0.006 & 0.042 & 0.237 \\
\hline & 26 & 0.119 & 0.167 & 0.396 & 0.119 & 0.167 & 0.396 & 0.155 & 0.117 & 0.045 \\
\hline & 27 & 0.107 & 0.149 & 0.357 & 0.106 & 0.149 & 0.357 & 0.165 & 0.122 & 0.043 \\
\hline & 28 & 0.093 & 0.130 & 0.309 & 0.093 & 0.130 & 0.309 & 0.188 & 0.141 & 0.057 \\
\hline & 29 & 0.082 & 0.114 & 0.272 & 0.082 & 0.114 & 0.272 & 0.195 & 0.144 & 0.057 \\
\hline & 30 & 0.047 & 0.065 & 0.165 & 0.047 & 0.065 & 0.166 & 0.094 & 0.005 & 0.112 \\
\hline & 31 & -0.253 & -0.356 & -0.741 & -0.253 & -0.356 & -0.740 & 0.056 & 0.071 & 0.097 \\
\hline & 32 & -0.289 & -0.406 & -0.849 & -0.289 & -0.406 & -0.848 & 0.027 & 0.041 & 0.062 \\
\hline & 33 & -0.339 & -0.476 & -1.002 & -0.339 & -0.476 & -1.002 & 0.059 & 0.071 & 0.088 \\
\hline \multirow[t]{4}{*}{ Capacitor } & 8 & 0.242 & 0.345 & 0.722 & 0.242 & 0.345 & 0.721 & 0.018 & 0.027 & 0.110 \\
\hline & 18 & 0.086 & 0.121 & 0.263 & 0.086 & 0.121 & 0.263 & 0.064 & 0.063 & 0.060 \\
\hline & 25 & 0.209 & 0.294 & 0.483 & 0.209 & 0.294 & 0.482 & 0.140 & 0.164 & 0.276 \\
\hline & 33 & 0.359 & 0.504 & 1.062 & 0.359 & 0.504 & 1.062 & 0.047 & 0.058 & 0.074 \\
\hline
\end{tabular}


Appendices

Table 24 Standard deviation values of the system variables

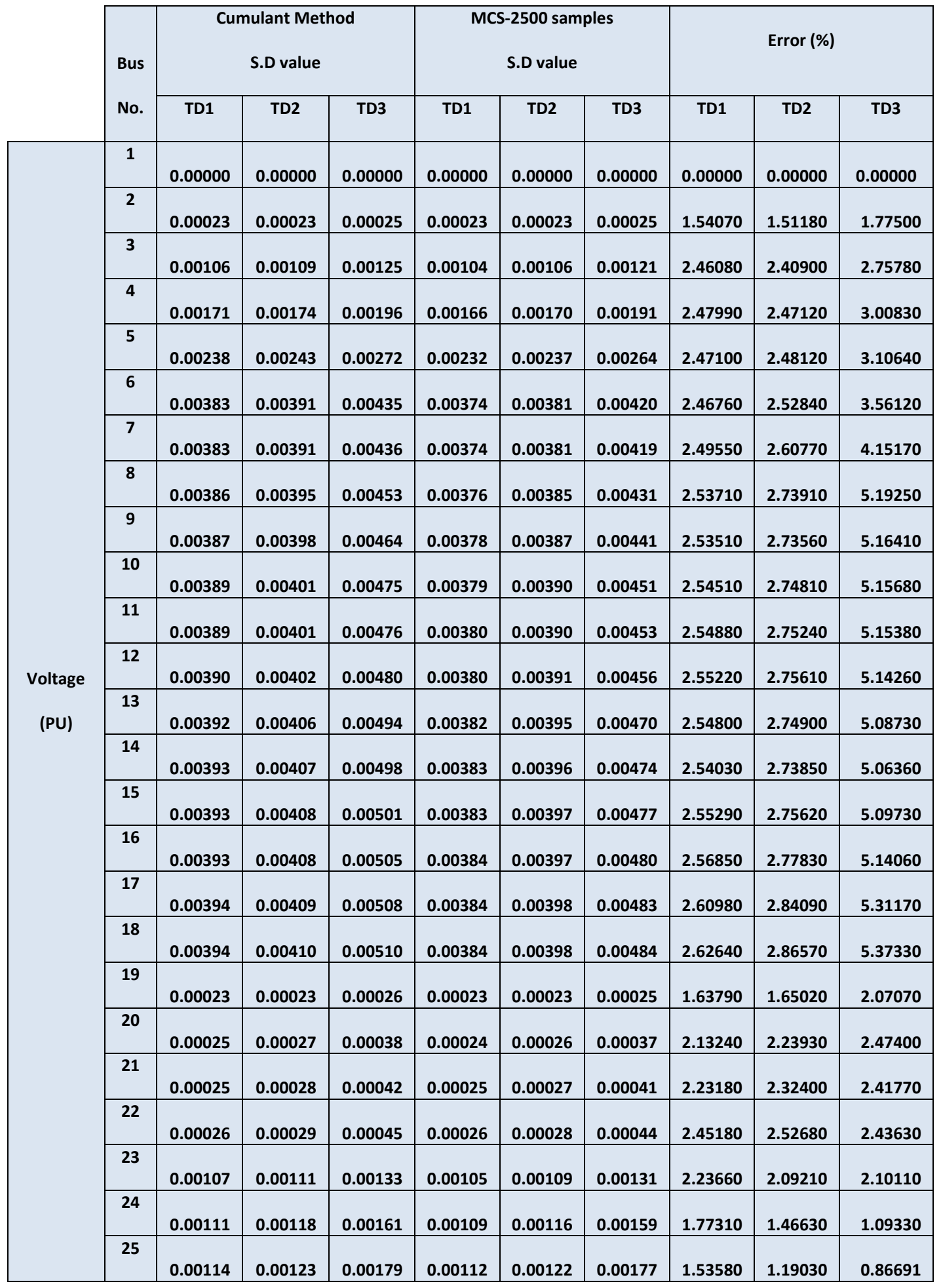


Appendices

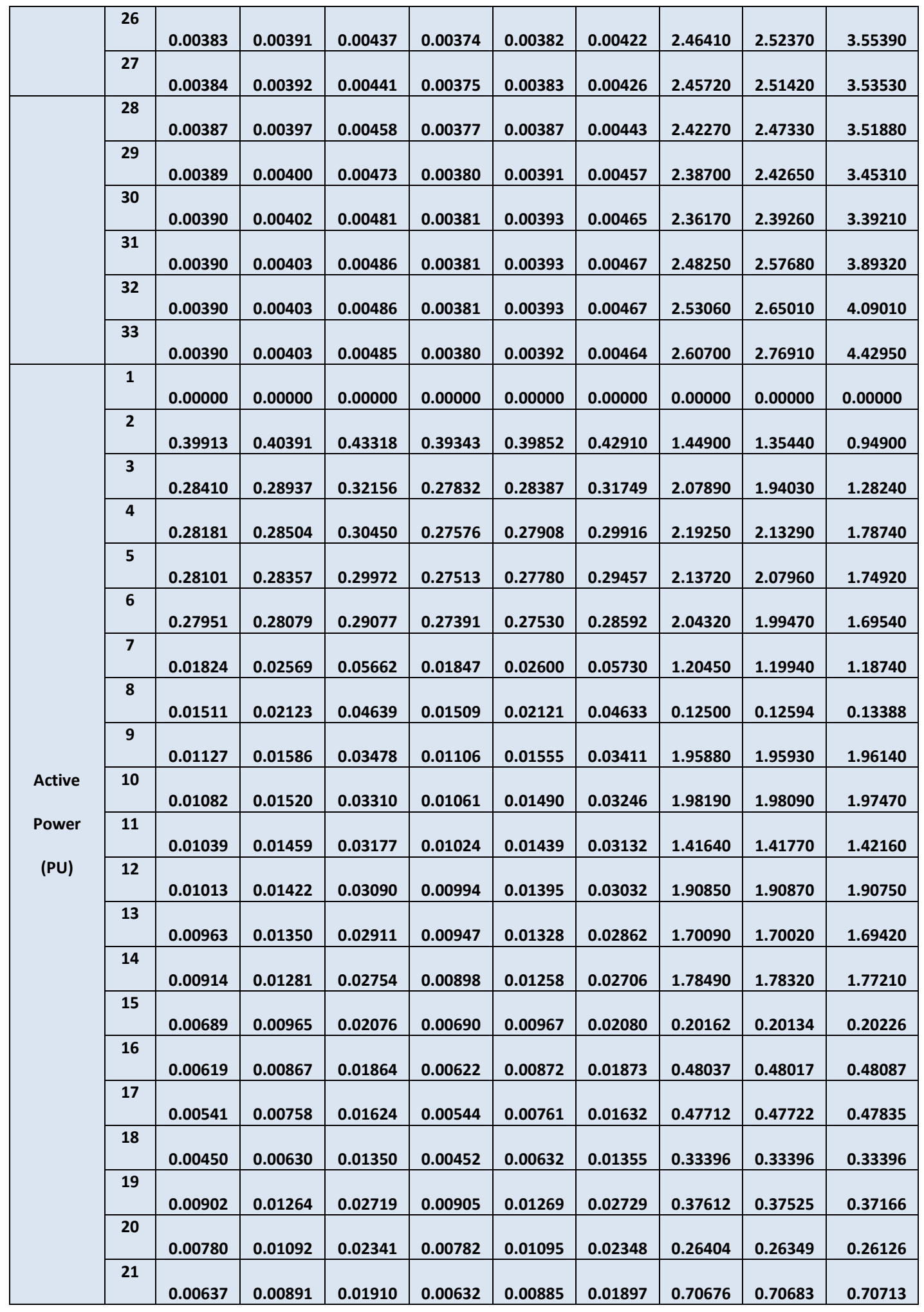


Appendices

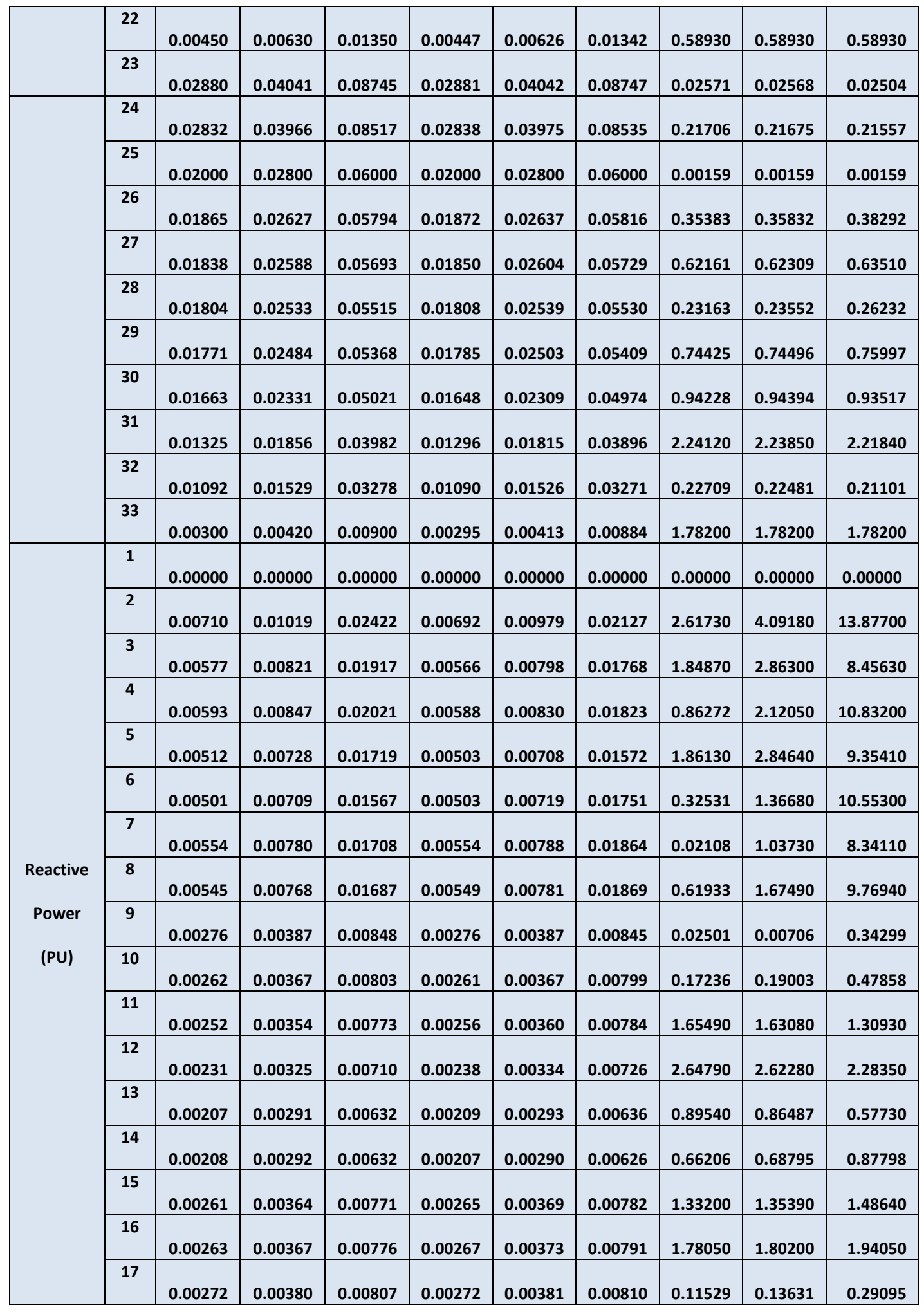


Appendices

\begin{tabular}{|c|c|c|c|c|c|c|c|c|c|c|}
\hline & 18 & 0.00287 & 0.00401 & 0.00853 & 0.00285 & 0.00399 & 0.00850 & 0.50109 & 0.47854 & 0.31770 \\
\hline & 19 & 0.00400 & 0.00561 & 0.01204 & 0.00399 & 0.00559 & 0.01200 & 0.32482 & 0.32842 & 0.34299 \\
\hline & 20 & 0.00346 & 0.00485 & 0.01040 & 0.00350 & 0.00490 & 0.01052 & 1.09200 & 1.09190 & 1.09170 \\
\hline & 21 & 0.00283 & 0.00396 & 0.00849 & 0.00284 & 0.00398 & 0.00852 & 0.38503 & 0.38471 & 0.38339 \\
\hline & 22 & 0.00200 & 0.00280 & 0.00600 & 0.00203 & 0.00284 & 0.00609 & 1.50750 & 1.50750 & 1.50750 \\
\hline & 23 & 0.00396 & 0.00560 & 0.01256 & 0.00403 & 0.00571 & 0.01294 & 1.84330 & 1.90490 & 2.93760 \\
\hline & 24 & 0.00370 & 0.00524 & 0.01186 & 0.00373 & 0.00529 & 0.01219 & 0.74990 & 0.95576 & 2.71470 \\
\hline & 25 & 0.00691 & 0.00969 & 0.02097 & 0.00698 & 0.00979 & 0.02129 & 0.94828 & 0.97037 & 1.53640 \\
\hline & 26 & 0.00928 & 0.01305 & 0.02861 & 0.00922 & 0.01296 & 0.02832 & 0.63009 & 0.70143 & 1.01530 \\
\hline & 27 & 0.00923 & 0.01297 & 0.02843 & 0.00912 & 0.01281 & 0.02799 & 1.23910 & 1.30780 & 1.60050 \\
\hline & 28 & 0.00918 & 0.01289 & 0.02815 & 0.00907 & 0.01273 & 0.02772 & 1.21740 & 1.29130 & 1.54590 \\
\hline & 29 & 0.00917 & 0.01287 & 0.02804 & 0.00908 & 0.01275 & 0.02770 & 0.92747 & 1.00270 & 1.22130 \\
\hline & 30 & 0.00931 & 0.01307 & 0.02840 & 0.00931 & 0.01306 & 0.02833 & 0.02883 & 0.05311 & 0.26575 \\
\hline & 31 & 0.02123 & 0.02973 & 0.06363 & 0.02109 & 0.02954 & 0.06344 & 0.68335 & 0.62796 & 0.30000 \\
\hline & 32 & 0.02148 & 0.03009 & 0.06457 & 0.02134 & 0.02992 & 0.06441 & 0.63312 & 0.57781 & 0.24650 \\
\hline & 33 & 0.02203 & 0.03090 & 0.06658 & 0.02199 & 0.03085 & 0.06669 & 0.20842 & 0.15612 & 0.16392 \\
\hline \multirow[t]{4}{*}{ Capacitor } & 8 & 0.00790 & 0.01111 & 0.02433 & 0.00788 & 0.01113 & 0.02552 & 0.31018 & 0.18169 & 4.67170 \\
\hline & 18 & 0.00350 & 0.00489 & 0.01043 & 0.00349 & 0.00489 & 0.01043 & 0.08274 & 0.07395 & 0.00278 \\
\hline & 25 & 0.01216 & 0.01703 & 0.03660 & 0.01222 & 0.01713 & 0.03688 & 0.54787 & 0.56426 & 0.76619 \\
\hline & 33 & 0.02212 & 0.03102 & 0.06685 & 0.02207 & 0.03097 & 0.06694 & 0.23159 & 0.18023 & 0.13348 \\
\hline
\end{tabular}




\section{REFERENCES}

[1] A. Schellenberg, W. Rosehart, and J. Aguado, "Cumulant based probabilistic optimal power flow (P-OPF)," in Proceedings of the 2004 International Conference on Probabilistic Methods Applied to Power Systems, Sept 2004, pp. 506-511.

[2] A. Papoulis and S. Pillai, "Probability, Random Variables, and Stochastic Processes," 4th ed. New York: McGraw-Hill, 2002.

[3] S. K. Khator and L. C. Leung, "Power Distribution Planning: A Review of Models and Issues," IEEE Trans. on Power Systems, vol. 12, no. 3, pp. 1184-1186, May 1997.

[4] A. Dukpa, B. Venkatesh, “ Fuzzy Stochastic Programming method: Capacitor planning in Distribution Systems with Wind Generators," IEEE Trans. on Power Systems, 2001,pp. 1 - 9.

[5] World wind energy association, World wind energy report 2010, April 2011. Available:

http://www.wwindea.org/home/images/stories/pdfs/worldwindenergyreport2010_s .pdf

(Accessed: July. 2011).

[6] H. Dura, "Optimum number, location, and size of shunt capacitors in radial distribution feeders: A dynamic programming approach," IEEE Trans. Power App. Syst., vol. PAS-87, no. 9, pp. 1769-1774, Sep. 1968. 
[7] J. J. Grainger and S. H. Lee, "Optimum size and location of shunt capacitors for reduction of losses on distribution feeders," IEEE Trans. Power App. Syst., vol. PAS-100, no. 3, pp. 1105-1118, Mar. 1981.

[8] J. J. Grainger and S. H. Lee, "Capacity release by shunt capacitor placement on distribution feeders: A new voltage-dependent model," IEEE Trans. Power App. Syst., vol. PAS-101, no. 5, pp. 1236-1244, May 1982.

[9] K. Iba, H. Suzuki, K. I. Suzuki, and K. Suzuki, "Practical reactive power allocation/operation planning using successive linear programming," IEEE Trans. Power Syst., vol. 3, no. 2, pp. 558-566, May 1988.

[10] M. H. Haque, "Capacitor placement in radial distribution systems for loss reduction," Proc. Inst. Elect. Eng., Gen., Transm., Distrib., vol.146, no. 5, pp. 501-505, Sep. 1999.

[11] Y. T. Hsiao and C. Y. Chien, "Optimization of capacitor allocation using an interactive trade-off method," Proc. Inst. Elect. Eng., Gen.,Transm., Distrib., vol. 148, no. 4, pp. 371-374, Jul. 2001.

[12] S. F. Mekhamer,M. E. El-Hawary, S. A. Soliman, M. A. Moustafa, and M. M. Mansour, "New heuristic strategies for reactive power compensation of radial distribution feeders," IEEE Trans. Power Del., vol. 17,no. 4, pp. 1128-1135, Oct. 2002.

[13] M. E. Baran and F. F.Wu, "Optimal capacitor placement on radial distribution systems," IEEE Trans. Power Del., vol. 4, no. 1, pp. 725-734, Jan. 1989.

[14] K. N. Miu, H. D. Chiang, and G. Darling, "Capacitor placement, replacement and control in large-scale distribution systems by a GA-based two-stage algorithm," IEEE Trans. Power Syst., vol. 12, no. 3, pp. 1160-1166, Aug. 1997. 
[15] M. Delfanti, G. P. Granelli, P. Marannino, and M. Montagna, "Optimal capacitor placement using deterministic and genetic algorithms," IEEE Trans. Power Syst., vol. 15, no. 3, pp. 1041-1046, Aug. 2000.3, pp. 1160-1166, Aug. 1997.

[16] B. A. Souza, H. N. Alves, and H. A. Ferreira, "Microgenetic algorithms and fuzzy logic applied to the optimal placement of capacitor banks in distribution networks," IEEE Trans. Power Syst., vol. 19, no. 2, pp. 942-947, May 2004.

[17] B. Venkatesh and R. Ranjan, "Fuzzy EP algorithm and dynamic data structure for optimal capacitor allocation in radial distribution systems," Proc. Inst. Elect. Eng., Gen., Transm., Distrib., vol. 153, no.1, pp. 80-88, Jan. 2006.

[18] A. M. L. da Silva, S. M. P. Ribeiro, V. L. Arienti, R. N. Allan and M. B. D. C. Filho, "Probabilistic load flow techniques applied to power system expansion planning," IEEE Transaction on Power Systems, vol. 5, no. 4, pp. 1047-1053, Nov. 1990.

[19] A. Schellenberg, W. Rosehart, and J. Aguado, "Cumulant-based probabilistic optimal power flow (P-OPF) with Gaussian and gamma distributions," IEEE Trans. on Power Systems, vol. 20, no. 2, pp. 773-781, May 2005

[20] R. Billinton, "Effects of load forecast uncertainty on bulk electric system reliability evaluation," IEEE Transactions on Power Systems, vol. 23, no. 2, pp. 418-425, May 2008.

[21] R. Billinton and R. N. Allan, "Reliability Evaluation of Power Systems", 2nd ed. New York: Plenum, 1996.

[22] I. Y. F. Lun and J. C. Lam, "A study of weibull parameters using long-term wind observations", Renewable Energy, 20: 145-153, 2000. 
[23] A. Dukpa, B. Venkatesh and L. Chang, An Accurate Voltage Solution Method of Radial Distribution System, Canadian Journal for Electrical and Computer Engineering, 34 (1/2): 69 - 74, Win/Spr 2009.

[24] D. K. Khatod, V. Pant, and J.D. Sharma, "A Novel Approach for Sensitivity Calculations in the Radial Distribution System," IEEE Transactions on Power Delivery, vol. 21, no. 4, pp. 2048-2057, October 2006.

[25] G. O. G. Torres and V. Quintana, "An interior-point method for nonlinear optimal power flow using voltage rectangular coordinates," IEEE Trans. Power Syst., vol. 13, no. 4, pp. 1211-1218, Nov. 1998.

[26] Kuhn, H. W.; Tucker, A. W. (1951). "Nonlinear programming". Proceedings of 2nd Berkeley Symposium. Berkeley: University of California Press. pp. 481-492.

[27] W. Karush (1939). "Minima of Functions of Several Variables with Inequalities as Side Constraints." M.Sc. Dissertation. Dept. of Mathematics, Univ. of Chicago, Chicago, Illinois.

[28] A. Schellenberg, W. Rosehart, and J. Aguado, "Cumulant based probabilistic optimal power flow (P-OPF)," in Proceedings of the 2004 International Conference on Probabilistic Methods Applied to Power Systems, Sept 2004, pp. $506-511$

[29] M. G. Kendall and A. Stuart, The Advanced Thoery of Statistics, 4th ed. New York: Macmillan, 1977.

[30] J. B. Calvert, "Hermite polynomials" http://www.du.edu/ jcalvert/math/hermite.htm, 2004.

(Accessed: July. 2011). 


\section{References}

[31] M. A. Kashem, V. Ganapathy, G. B. Jasmon, M. I. Buhari. "A Novel Method for Loss Minimization in Distribution Networks." International Conference on Electric Utility Deregulation and Restructuring and Power Technologies 2000. 